UNIVERSIDADE DE BRASÍLIA

FACULDADE DE TECNOLOGIA

PROGRAMA DE PÓS-GRADUAÇÃO EM ENGENHARIA ELÉTRICA

\title{
UM MECANISMO DE PROGNÓSTICO DE RISCO DE INSUSTENTABILIDADE DE SISTEMA ENTRE AGENTES DE DECISÃO
}

\author{
JEUEL BERNARDES ALVES
}

ORIENTADOR: LUÍS FERNANDO RAMOS MOLINARO

TESE DE DOUTORADO EM ENGENHARIA ELÉTRICA

\author{
PUBLICAÇÃO
}

BRASÍLIA/DF: JANEIRO - 2018 


\section{UNIVERSIDADE DE BRASÍLIA \\ FACULDADE DE TECNOLOGIA \\ DEPARTAMENTO DE ENGENHARIA ELÉTRICA}

\section{UM MECANISMO DE PROGNÓSTICO DE RISCO DE INSUSTENTABILIDADE DE SISTEMA ENTRE AGENTES DE DECISÃO}

\section{JEUEL BERNARDES ALVES}

TESE DE DOUTORADO SUBMETIDA AO DEPARTAMENTO DE ENGENHARIA ELÉTRICA DA FACULDADE DE TECNOLOGIA DA UNIVERSIDADE DE BRASILIA, COMO PARTE DOS REQUISITOS NECESSÁRIOS PARA A OBTENÇÃO DO GRAU DE DOUTOR.

APROVADA POR:
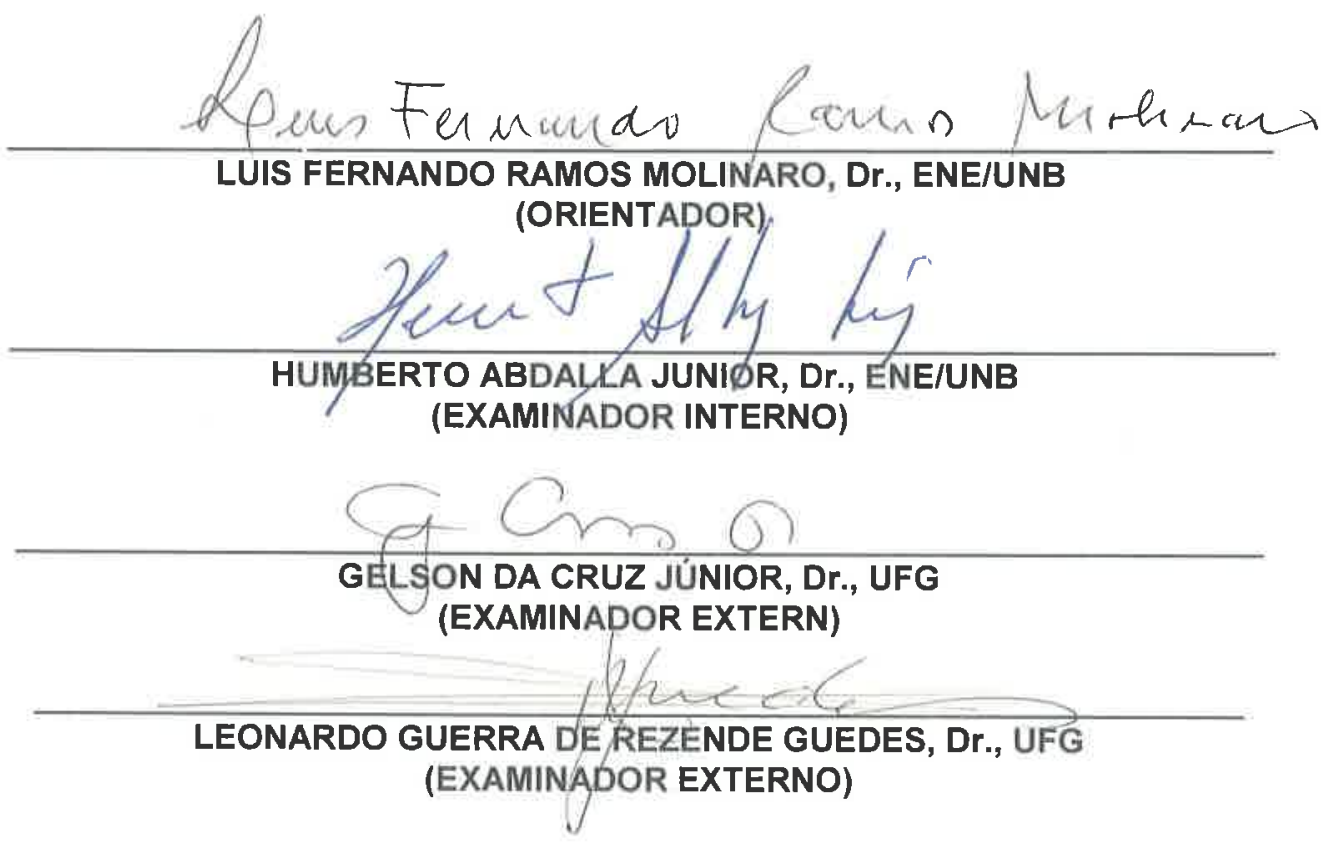

Brasília, 17 de janeiro de 2018. 


\section{FICHA CATALOGRÁFICA}

\begin{tabular}{|c|c|}
\hline \multicolumn{2}{|l|}{ ALVES, JEUEL BERNARDES } \\
\hline \multicolumn{2}{|c|}{$\begin{array}{l}\text { Um mecanismo de prognóstico de risco de insustentabilidade de sistema entre agentes de } \\
\text { decisão [Distrito Federal] } 2018 \text {. }\end{array}$} \\
\hline \multicolumn{2}{|c|}{ 114p., 210 x 297 mm (ENE/FT/UnB, Doutor, Engenharia Elétrica, 2018). Tese de } \\
\hline \multicolumn{2}{|c|}{ Doutorado - Universidade de Brasília. Faculdade de Tecnologia. Departamento de } \\
\hline \multicolumn{2}{|c|}{ Engenharia Elétrica. } \\
\hline \multicolumn{2}{|c|}{ Departamento de Engenharia Elétrica } \\
\hline 1. Sistema de apoio a decisão & 2. Seleção de portfolio de projetos \\
\hline 3. Tomada de decisão em grupo & 4. Decisão em cenários complexos \\
\hline \multicolumn{2}{|l|}{ 5. Minimização de risco } \\
\hline I. ENE/FT/UnB & II. Título (série) \\
\hline
\end{tabular}

\section{REFERÊNCIA BIBLIOGRÁFICA}

ALVES, J. B. (2018). Um mecanismo de prognóstico de risco de insustentabilidade de sistema entre agentes de decisão. Tese de Doutorado em Engenharia Elétrica, Publicação PPGEE.TD-125/2018, Departamento de Engenharia Elétrica, Universidade de Brasília, Brasília, DF, 114p.

\section{CESSÃO DE DIREITOS}

AUTOR: Jeuel Bernardes Alves.

TÍTULO: Um mecanismo de prognóstico de risco de insustentabilidade de sistema entre agentes de decisão.

GRAU: Doutor $\quad$ ANO: 2018

É concedida à Universidade de Brasília permissão para reproduzir cópias desta tese de doutorado e para emprestar ou vender tais cópias somente para propósitos acadêmicos e científicos. O autor reserva outros direitos de publicação e nenhuma parte dessa tese de doutorado pode ser reproduzida sem autorização por escrito do autor.

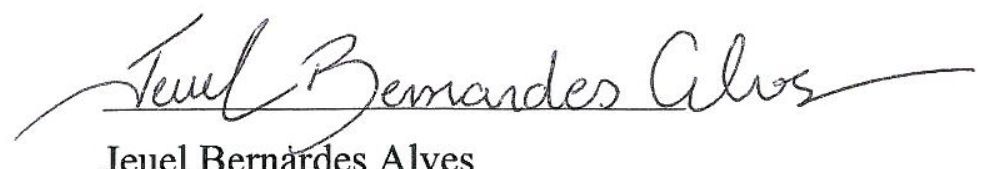

Jeuel Bernàrdes Alves

Rua 222 n $^{\circ} 467$, Goiânia.

74.603-160 Goiás - GO - Brasil. 


\section{AGRADECIMENTOS}

Às mulheres da minha vida, Blanca e Elisa.

Ao Orientador Professor Luís Fernando Ramos Molinaro.

Ao Professor Eliomar Araújo de Lima pela Co-orientação.

Ao Júlio Cesar de Oliveira Garcia por permitir pesquisar os dados da organização. Ao Leonardo Rodrigues de Oliveira Merelles no desenvolvimento do script R. Ao Núcleo de pesquisa NMl e Amigos.

Principalmente a DEUS por ter me sustentando até aqui, permitindo vivenciar novas experiências e aprendizados. 


\title{
RESUMO
}

\section{UM MECANISMO DE PROGNÓSTICO DE RISCO DE INSUSTENTABILIDADE DE SISTEMA ENTRE AGENTES DE DECISÃO.}

\author{
Autor: Jeuel Bernardes Alves \\ Orientador: Luís Fernando Ramos Molinaro \\ Programa de Pós-graduação em Engenharia Elétrica \\ Brasília, janeiro de 2018.
}

A investigação acerca do risco de insustentabilidade é inscrita na temática de sistemas de apoio à decisão e provocada pela questão científica: até que ponto a cooperação entre agentes de decisão minimiza o risco de insustentabilidade coletiva? Para averiguação da questão é proposto um mecanismo de prognóstico de risco de insustentabilidade coletiva entre os agentes de decisão sob conflito de interesses. Ao entender que a atuação individual do agente de decisão pode ser expressa sob a estrutura de projeto, de sorte a repercutir seus resultados sobre os demais e produzindo o desempenho coletivo na eficiência do portfolio no intuito de que estes impactos sejam medidos, é que é adotado o processo de investigação fundamentado na abordagem hipotético-dedutiva, uma vez que é admitido o desempenho de eficiência da teoria moderna de portfolios para validação dos ajustes nos projetos, bem como na identificação do limiar do risco de insustentabilidade coletiva. Foram obtidos dados históricos e documentais para estruturar o cenário de estudo em uma instituição de ensino superior e que na etapa de definição do planejamento orçamentário surgiram conflitos de interesses entre seus cursos. Para apoiar esse processo utilizou-se a simulação adaptativa para realizar cenários de ajustes nas variáveis de decisão dos projetos dos cursos com efeito no portfolio, bem como comparações entre os regimes de decisão cooperada e competitiva. O risco de eficiência do portfolio foi a medida utilizada tanto para indicar o regime de decisão, como para estruturar os ajustes dos projetos que permitiram minimizar o risco de insustentabilidade coletiva. Portanto, o mecanismo proposto permite congregar decisões entre agentes competitivos sob uma plataforma comum de prognóstico e fator risco de insustentabilidade coletiva, de forma a sugerir uma referência de comparação entre decisões cooperadas e competitivas, a partir de parâmetros de amplitude de ajuste de cada variável e tolerância ao risco ao longo do tempo. 


\section{ABSTRACT}

An investigation into the risk of unsustainability and training in the issue of decision support systems, and provoked by the scientific journal: to whoever points an agent between decision makers minimizes the risk of collective unsustainability? Therefore, a prognostic mechanism and risk factor of collective unsustainability among the decision agents under conflict of interests is proposed. What you are looking for is a project structure, so as to reflect its results on the others and produce the collective performance in the efficiency of the portfolio, without intention that these impacts are measured that are adopted by the process of investigation based on the hypothetical-deductive approach , since the efficient performance of the modern portfolio theory is accepted for validation of the adjustments in the projects, as well as in the identification of the threshold of the risk of instituting the collective. There are archives obtained historical and documentary data to structure the study scenario in an institution of higher education, that in the stage of definition of the budgetary planning arise conflict of interest between its courses. For the decision-making process of the decision group, use the adaptive simulation process to perform scenarios of adjustments in the decision variables of the course projects, as well as comparisons between the cooperative and competitive decision regimes. The portfolio's risk of efficiency for a measure used to indicate the decision regime, as a structure of project adjustments that allow to minimize the risk of collective unsustainability. On the other hand, the proposed mechanism allows the participation of competitive agents, under a common prognostic platform and risk factor of collective unsustainability, in order to suggest a reference of comparison between cooperative and competitive decisions, from the parameter amplitude of adjustment each variable and risk tolerance over time. 


\section{SUMÁRIO}

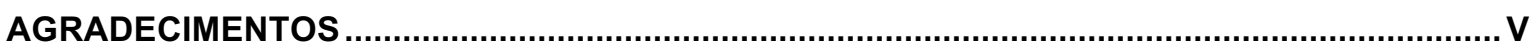

RESUMO

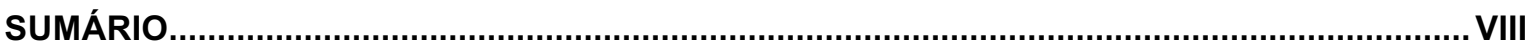

LISTA DE TABELAS

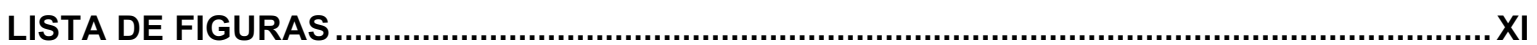

LISTA DE SIGLAS E ABREVIATURAS

1 - INTRODUÇÃO

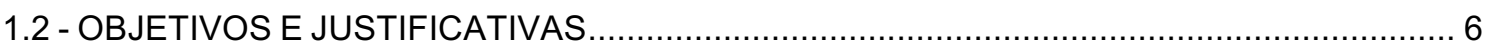

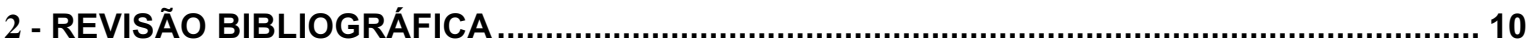

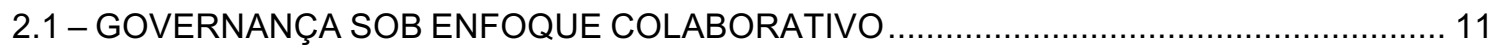

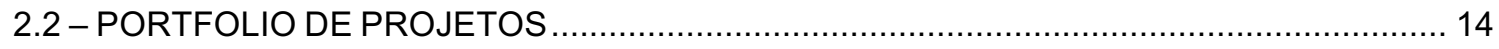

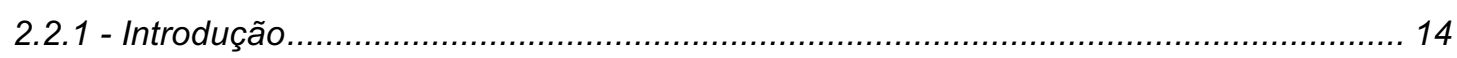

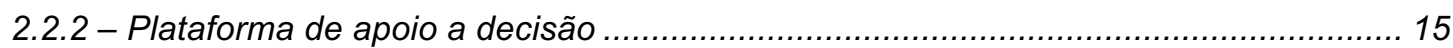

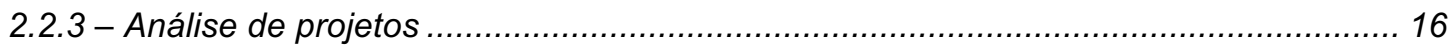

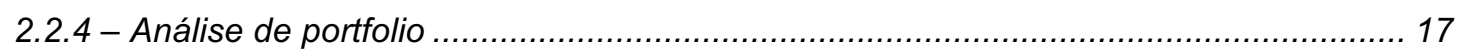

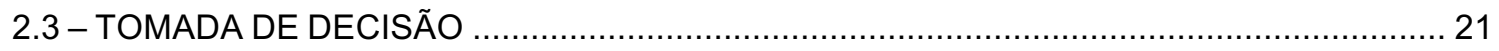

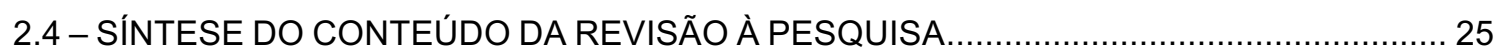

3 - METODOLOGIA

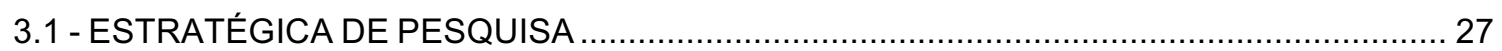

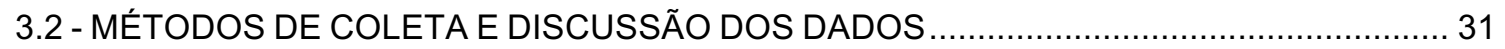

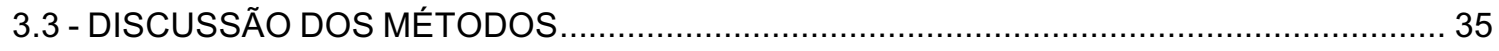

4 - MECANISMO DE PROGNÓSTICO E DE FATOR DE RISCO.................................................. 39

4.1 - INTRODUÇÃO

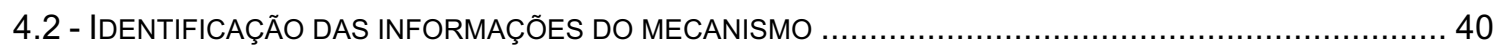

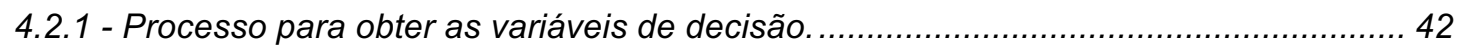

4.2.2 - Processo para obter as séries temporais dos projetos. ........................................... 45

4.2.3 - Relação das variáveis de decisão na minimização do risco. ...................................... 46

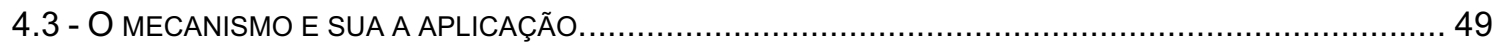

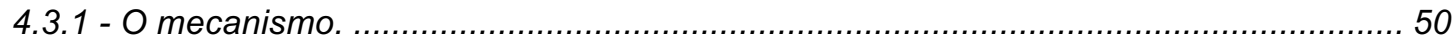

4.3.2 - As etapas de aplicação do mecanismo. ................................................................ 52 
5 - RESULTADOS E DISCUSSÃO

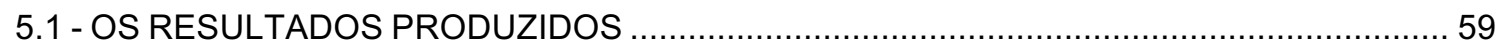

5.1.1 - Resultado de testes de ajustes no projeto sobre a eficiência do portfolio.................... 60

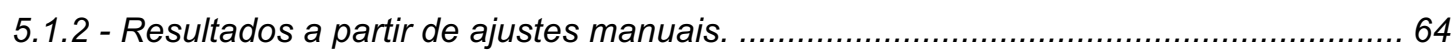

5.1.3 - Resultados a partir da automatização com ajustes adaptativos. ............................... 73

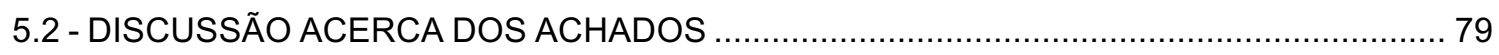

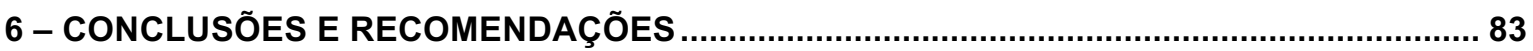

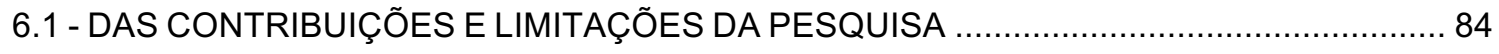

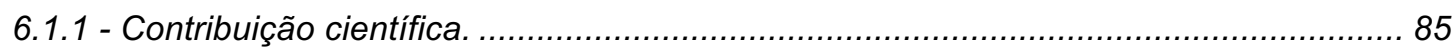

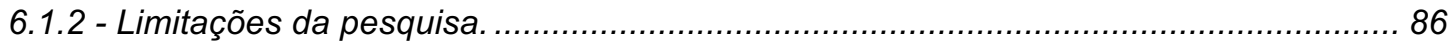

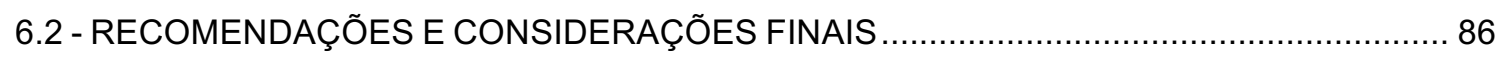

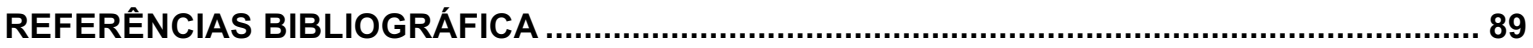

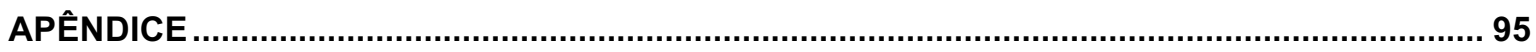




\section{LISTA DE TABELAS}

Tabela 4.1 - Variáveis do setor de ensino superior.

Tabela 4.2 - Variáveis da atividade produtiva do curso de ensino de uma IES .34

Tabela 5.3 - Teste de impacto de H0 na eficiência do portfolio. .60

Tabela 5.4 - Teste de impacto de H1 na eficiência do portfolio. .62

Tabela 5.5 - Resultados dos testes de hipóteses .63

Tabela 5.6 - Cenários gerados de forma manual. .65

Tabela 5.7 - Portfolios ótimo mensal por curso - cenário 0. .67

Tabela 5.8 - Portfolios ótimo mensal por curso - cenário 1. .68

Tabela 5.9 - Portfolio ótimo mensal por curso - cenário 4. .70

Tabela 5.10 - Cenários gerados de forma manual e automatizada. .74

Tabela 5.11 - Comparação entre critérios do regime de decisão competitiva. .76

Tabela 5.12 - Comparação entre critérios do regime de decisão cooperativa. .78

Tabela 5.13 - Relação de desempenho coletivo e individual por regime de decisão. .79 


\section{LISTA DE FIGURAS}

Figura 1.1 - Sem percepção do nível de risco de insustentabilidade. .....................................

Figura 1.2 - Com percepção do nível de risco de insustentabilidade.....................................

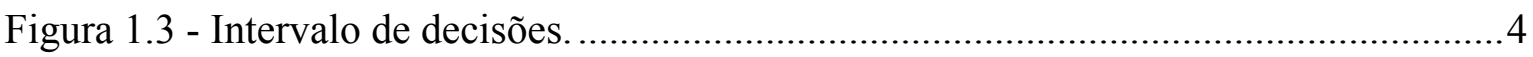

Figura 1.4 - Dilema de decisão individual do agente.........................................................

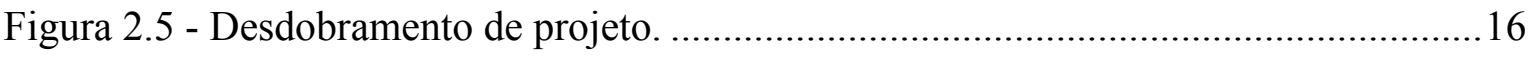

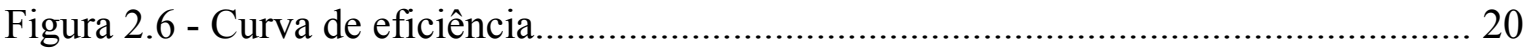

Figura 3.7 - Dinâmica do mecanismo de prognóstico de risco .............................................27

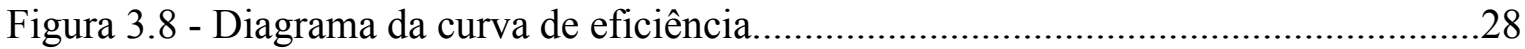

Figura 3.9 - Etapas para composição do portfolio de projetos. ............................................29

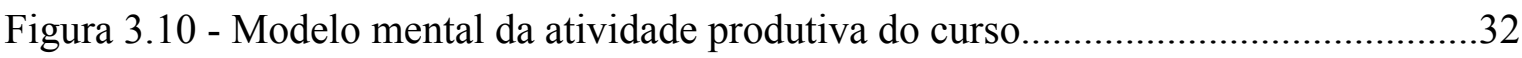

Figura 4.11 - Processo de ajuste do projeto à seleção de portfolio.......................................42

Figura 4.12 - As principais categorias de entradas de fluxo de caixa.................................43

Figura 4.13 - As principais categorias de saídas do fluxo de caixa....................................43

Figura 4.14 - Esquema conceitual da dinâmica operacional da atividade de ensino...........44

Figura 4.15 - Relação do ciclo operacional com o financeiro - adaptação pelo autor de

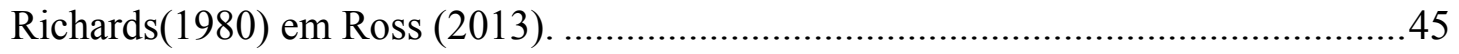

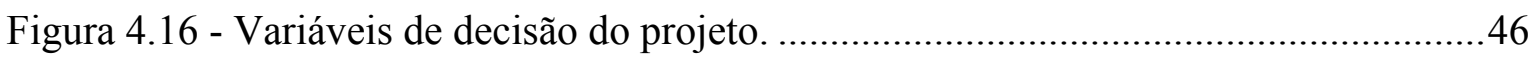

Figura 4.17 - Modelo conceitual da atividade de ensino do curso.......................................47

Figura 4.18- Modelo conceitual do processo de simulação..................................................51

Figura 4.19 - Entrada de dados para simulação dos ciclos operacionais e financeiro.........53

Figura 4.20 - Entrada da amplitude de ajustes de cada variável em cada projeto. ..............55

Figura 4.21 - Diagrama do processo experimental. ............................................................56

Figura 5.22 - Problema adaptativo na composição do portfolio de projetos. ........................72

Figura 5.23 - O ponto de comparação das curvas de decisões..............................................8

Figura 5.24 - Contribuição com a proposição do mecanismo de prognóstico.......................81

Figura A.3.25 - Desdobramento do planejamento da IES. ................................................98

Figura A.4.26 - Visão do ponto de minimização de risco de insustentabilidade.................99

Figura A.5.27 - Resultados de ações planejadas na IES................................................... 100

Figura A.6.28 - Diagrama da TMP tradicional e com o G.A.............................................. 101 


\section{LISTA DE SIGLAS E ABREVIATURAS}

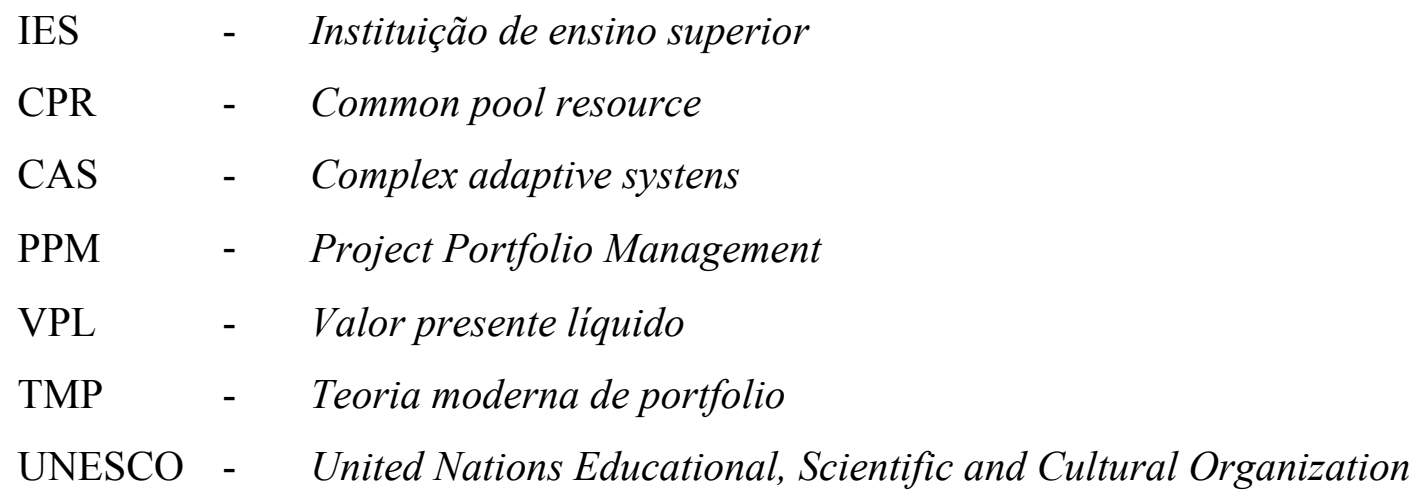




\section{1 - INTRODUÇÃO}

Os sistemas de apoio a tomada de decisão ainda apresentam desafios à sociedade do conhecimento. Por um lado, o crescimento exponencial das redes de telecomunicações no mundo, produzindo volumes de informações fragmentadas. Por outro lado, a sistemática redução do tempo de resposta do agente tomador de decisões, que acirra a expectativa de minimização do risco da decisão tomada.

Os ambientes macroeconômicos são compostos por redes socioeconômicas com intensas atividades, estabelecidas a todo instante por Organizações em torno do mundo. Em razão da interconexão entre as redes de atividades corporativas, os processos decisórios podem impactar um no resultado do outro, por fim impactando na sustentabilidade dos próprios agentes no sistema, o que por um ou vários motivos, acaba demandando maior rigor na análise de risco.

A sustentabilidade está associada à sobrevivência por tempo indeterminado dos agentes inscritos em um sistema (HARDIN, 1968; MCGINNIS,MICHAEL D.;OSTROM, 2014; E. OSTROM, 2009; ELINOR OSTROM, 1990), o que leva a compreender que uma Organização em seu contexto socioeconômico e ambiental é sustentável a partir de decisões governadas (MCGINNIS,MICHAEL D.;OSTROM, 2014; ELINOR OSTROM, 1990). Em meio à limitação de recursos os agentes socioeconômicos são estimulados à competitividade, entendendo que esse é um caminho para se sustentarem ao longo do tempo.

Em grande medida as decisões estratégicas dos agentes acabam focando na busca por vantagens competitivas sobre os demais (PORTER,1999). Nessas circunstâncias a maximização dos resultados individuais torna-se o foco das decisões, embora sem a devida atenção dos níveis de reposição dos estoques de recursos do sistema (HARDIN, 1968). Caso essa circunstância envolva apenas dois agentes de decisão com limite de crescimento, já é suficiente para classificá-los na tragédia do bem comum (SENGE,2006; STERMAN,2000), o que significa que ocorrerá uma disputa pelos recursos limitados. 
A competição por uma fonte limitada de recursos por diversos agentes foi formalizada por Hardin (1968) como um problema sem solução, nominado tragédia do bem comum, tendo sido ele laureado com o prêmio Nobel em 2009. Todavia, tal problema ainda se encontra sem solução.

O processo de tomada de decisão da tragédia do bem comum sob a perspectiva computacional pode ser compreendido como problema perverso, ou adaptativo complexo. Já na perspectiva institucionalista é compreendido como um problema de lógica da ação coletiva.

A partir das aplicações corporativas de Sterman (2000) pode ser entendida a tragédia do bem comum no cenário corporativo como a falência, em virtude do esgotamento dos recursos básicos à continuidade da atividade fim.

Sob uma visão ampliada percebe-se que a cooperação entre os agentes é um caminho para o convívio sustentável (MCGINNIS,MICHAEL D.;OSTROM, 2014; ELINOR OSTROM, 1990). Vale ressaltar que a cooperação exige que se abra mão de parte dos ganhos individuais. Assim, em meio a esse contexto competitivo surgem questões sobre quanto e quando isso pode ser feito.

A cooperação para a sustentabilidade coletiva considera o desempenho individual e o coletivo sobre a disponibilidade de recursos no sistema ao longo do tempo. São ilustradas duas situações nas figuras 1.1 e 1.2, que caracterizam o dilema na ilustração e nas três curvas. As curvas são: I consumo de recursos do indivíduo, C consumo geral de dos agentes no sistema e $\mathrm{R}$ a disponibilidade de recursos no sistema.

Na figura 1.1 os agentes competem entre si desconsiderando o limite de disponibilidade de recursos. A curva I indica que um indivíduo tem um consumo relativo superior ao consumo dos agentes do sistema. Em razão do comportamento de consumo sem limite, a curva de disponibilidade de recursos no sistema é reduzida até padrões insustentáveis, de forma a repercutir na curva e consumo dos demais agentes. 


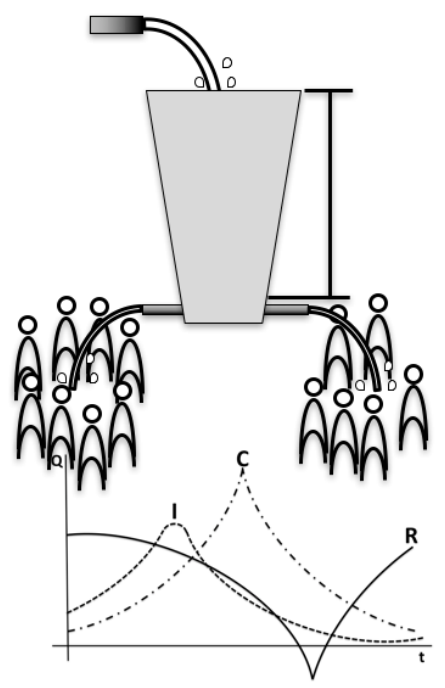

Figura 1.1 - Sem percepção do nível de risco de insustentabilidade.

Já na figura 1.2, os agentes competem entre si, mas cientes da limitação dos recursos. A curva de consumo pode ser ajustada em conformidade à restrição convencionada, resultando na minimização do risco de insustentabilidade.

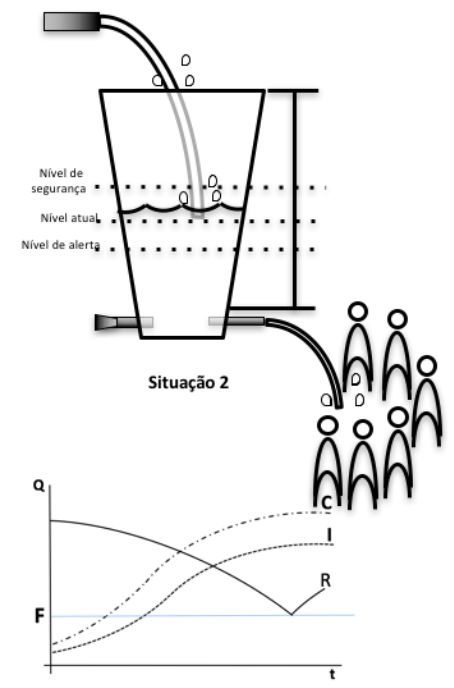

Figura 1.2 - Com percepção do nível de risco de insustentabilidade.

Mesmo com a definição do limite de risco de insustentabilidade, ainda assim alguns agentes podem decidir por competir ao invés de cooperar. Isso se dá principalmente pelo custo de transação, onde o agente faz a comparação entre o custo de cooperar e de competir e ainda assim ser beneficiado individualmente pelos esforços coletivos (WILLIAMSON, 1996) - figura 1.3. 


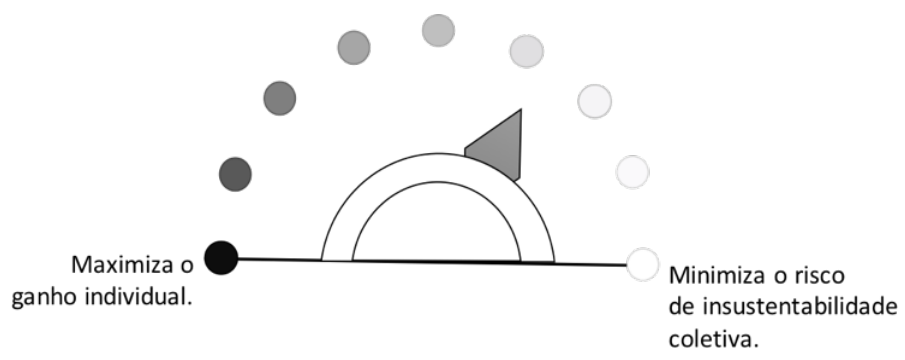

Figura1.3 - Intervalo de decisões.

O intervalo de decisões da figura 1.3 ilustra o dilema de escolha de cada agente do sistema, que compreende em maximizar os ganhos individuais e minimizar o risco de insustentabilidade coletiva. No entanto, a busca pela maximização dos ganhos individuais pode comprometer a disponibilidade de recursos, que por sua vez afeta a sustentabilidade coletiva. Por outro lado, ao se minimizar o risco de insustentabilidade coletiva é reduzido o ganho individual.

O mesmo paradoxo pode ser percebido em uma instituição de ensino superior. Segundo a UNESCO (ALTBACH, REISBERG, \& RUMBLEY, 2009) a indisponibilidade de recursos nas IES tem apresentado crescimento no número de matrículas, restrição orçamentária e aumento de responsabilidade docente, mas repercutindo em desinteresse pela carreira acadêmica. Esse cenário resulta na falta de renovação, sobrecarga de atividades e envelhecimento do corpo docente, que também gera ineficiência para os fundos de pensão. Isso indica que existe uma tendência global de não realimentação das fontes de recursos para atendimento da crescente demanda pelos serviços acadêmicos no mundo.

A busca pela maximização de ganho individual dos cursos da IES incorre no comprometimento econômico-financeiro ao se buscarem ganhos na qualidade do ensinoaprendizagem. Por outro lado, ao focar-se no ganho econômico-financeiro se acaba comprometendo a qualidade do ensino-aprendizado, figura 1.4. 


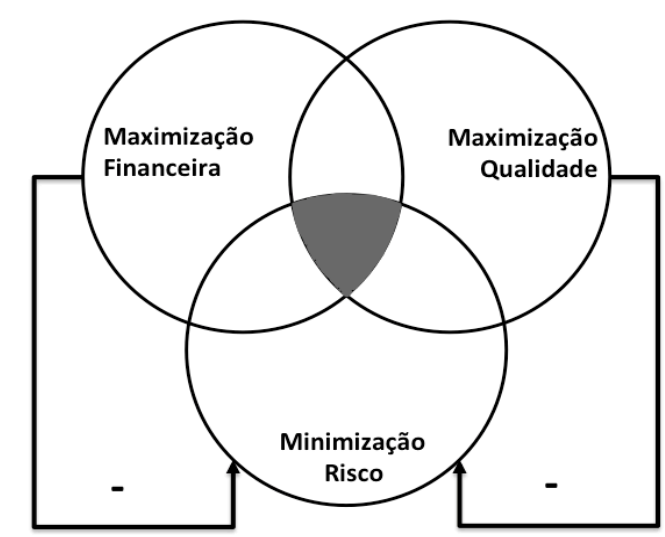

Figura 1.4 - Dilema de decisão individual do agente.

O foco exclusivo na maximização econômico-financeira ou na qualidade acarreta em prejuízo para a minimização do risco de insustentabilidade coletiva. A combinação dos ganhos econômico-financeiros com qualidade pode ser encontrada também na minimização do risco de insustentabilidade coletiva, conforme indica de forma geral a figura 1.4.

O dilema do agente de decisão entre maximizar o resultado financeiro ou maximizar a qualidade do ensino-aprendizagem é um problema multiobjectivo. Em seguida esse mesmo agente compõe um colegiado para decidir o planejamento da IES, mas nessa nova etapa é percebido que sua decisão - que compreende o dilema de maximizar retorno econômicofinanceiro ou maximizar qualidade de ensino - pode prejudicar o desempenho de outros agentes e por fim contribuir para o comprometimento da sustentabilidade coletiva. Ainda na etapa de decisão em grupo - no colegiado de planejamento da IES - entende-se que a competição por disponibilidade de recursos inscreve o conflito de interesses entre os agentes do sistema. Em razão disso, eles devem buscar uma decisão que considere seu ganho individual entre o econômico-financeiro e a qualidade do ensino-aprendizado, mas repercutindo o impacto dessa decisão sobre os demais agentes, a partir da limitação das fontes comuns de recursos ao longo do tempo. Na figura 1.4 são ilustrados esses dilemas, que por sua vez compõem o problema científico.

Em um ambiente competitivo indaga-se como seria possível a sustentabilidade de todos, uma vez que competem por uma fonte comum e limitada de recursos. Sob esse contexto é assumido o pressuposto de que a cooperação do uso de recursos entre os agentes - apesar de competitivos - é um meio de minimização do risco de insustentabilidade coletiva 
(MCGINNIS,MICHAEL D.;OSTROM, 2014; E. OSTROM, 2009; ELINOR OSTROM, 1990). Essa alternativa de cooperação entre os agentes sinaliza como uma opção - mesmo que momentânea - para a postergação do fracasso de todos, de forma que o campo de confrontos seja um ambiente propício à competição, mas em que as decisões tomadas busquem também a cooperação na preservação desse espaço comum.

Portanto, expressa-se a ideia principal do problema científico a fim de se buscar a minimização do risco de insustentabilidade coletiva por meio do uso cooperado de recursos entre agentes competitivos. Então surge a questão:

"Até que ponto a cooperação de agentes de decisão minimiza o risco de insustentabilidade coletiva?"

\section{2 - OBJETIVOS E JUSTIFICATIVAS}

Ainda que a cooperação seja um consenso entre os agentes de decisões, mesmo assim eles continuam com diferentes perspectivas para compor uma mesma decisão. Isso porque as múltiplas perspectivas exigem a composição multicritério para avaliações de alternativas, que por vezes podem ir de encontro às expectativas do outro.

Decisões colegiadas de planejamento são realizadas - em alguns momentos desassociadas da disponibilidade de recursos e da capacidade produtiva ao longo do tempo. Já no inicio do planejamento, esse tipo de evento acaba abrigando armadilhas de insustentabilidade coletiva, pois a tragédia dos comuns foi elaborada por decisões como essas (HARDIN, 1968; MCGINNIS,MICHAEL D.;OSTROM, 2014; ELINOR OSTROM, 1990).

Outro aspecto a ser considerado é a não linearidade do consumo de recursos ao longo do tempo, uma vez que o comportamento de consumo de recursos é reflexo das atividades específicas de cada agente de decisão. Assim, a amplitude de decisões diz respeito às especificidades de cada situação problema. 
Desse modo, o que se espera é uma decisão de planejamento que absorva as expectativas de seus agentes de decisões e concilie as diversas perspectivas dos agentes, de sorte que possam buscar o ganho de performance individual, sem prejuízo dela à sustentabilidade coletiva.

Em razão dessa diversidade de perspectivas e da limitação silenciosa dos recursos é que se faz necessária a proposição de um mecanismo de prognóstico, que permita aos próprios agentes de decisões perceberem o impacto de suas decisões sobre a sustentabilidade.

O objetivo geral é propor mecanismo de prognóstico de risco de insustentabilidade coletiva entre agentes de decisão sob conflito de interesses.

As decisões devem ser realizadas sob os critérios de expertos, embora esse seja o ingrediente para a tragédia dos comuns (HARDIN, 1968; MCGINNIS,MICHAEL D.;OSTROM, 2014; E. OSTROM, 2009; ELINOR OSTROM, 1990; SIMON,1947). Em razão disso é o propósito de propor um mecanismo de prognóstico que absorva a tendência de decisões dos agentes, mesclado com informações históricas qualitativas e quantitativas que sejam úteis para essa compreensão, de forma que assumam uma relação de eficiência entre risco e retorno não prejudicial à coletividade. Nesse caso é avaliado se o comportamento cooperativo pode contribuir para minimizar o risco de insustentabilidade.

\section{Objetivos específicos:}

- Compreender as atividades principais na estrutura de projetos, de forma a compor a análise de eficiência de portfolio;

- compreender a composição dos limites de recursos que sejam capazes de indicar a incapacidade do estoque em subsidiar as atividades dos agentes ao longo do tempo;

- avaliar a capacidade de impacto das variáveis de decisão dos projetos no portfolio, considerando sua capacidade em minimizar risco do portfolio;

- adaptar a abordagem de portfolio ao contexto de programas e projetos coorporativos; e

- refletir sobre o desempenho e contribuições do mecanismo de prognóstico como apoio à decisão multicritério para grupos de agentes competitivos em prol da minimização de risco de insustentabilidade coletiva. 
A proposição de um mecanismo de prognóstico de apoio a decisão deve ser capaz de gerar cenários com repercussão sobre a disponibilidade de recursos, tendo em vista a relação entre risco e retorno ao longo do tempo.

O desdobramento temporal da relação entre risco e retorno é fundamental para avaliar as decisões dos agentes ainda em fase de planejamento, a partir de uma estrutura que permita a comparabilidade entre as decisões e sua repercussão. Por isso a ideia de simular os cenários de portfolios integrados à disponibilidade orçamentária.

Os prognósticos vão depender da taxa de realimentação dos estoques de disponibilidades, bem como dos parâmetros que caracterizam os limites de controle dos níveis de disponibilidade de recursos.

A partir da definição do problema científico e do objetivo científico, o intuito é a busca pela minimização do risco de insustentabilidade coletiva, ainda que sob perspectivas divergentes de seus agentes de decisões, preservando o ambiente competitivo, mas proporcionando alternativa de construção de análise e decisão a partir da relação entre risco e retorno ao longo do tempo.

Para tanto, a estrutura do manuscrito foi organizada da seguinte forma: introdução; revisão bibliográfica; metodologia; mecanismo de prognóstico de risco; resultados e discussões; conclusões e recomendações; e referências bibliográficas.

No capítulo de introdução é apresentado o foco temático do trabalho científico, com o ponto de partida no problema científico com vistas à contribuição por meio da proposição justificada do trabalho de pesquisa.

A revisão bibliográfica está organizada em três capítulos: governança, portfolio de projetos e tomada de decisões.

Em uma perspectiva mais ampla, no capítulo de governança é apresentada a complexidade da tragédia do bem comum no contexto corporativo, em um cenário de busca por sustentabilidade a partir de indivíduos competitivos e restritos à disponibilidade limitada de recursos. 
No segundo capítulo é visto o portfolio de projetos como suporte interlocutor entre os agentes competitivos de uma Organização, com o impacto de suas decisões ao longo do tempo.

O terceiro capítulo evoca os dilemas que estão associados à tomada de decisão em ambiente corporativo, que envolve diversidade de perspectivas de agentes autônomos de decisão sob o dilema de escolha entre os ganhos individuais ou coletivos.

Saindo da revisão bibliográfica, no quarto capítulo consta a metodologia adotada e seu delineamento para realizar a validação do trabalho científico.

O quinto capítulo apresenta o modelo conceitual do mecanismo de prognóstico de risco, a estrutura de simulação e dos resultados.

Para o capítulo de resultados e discussões será apresentada a origem dos agentes envolvidos no estudo, de forma que a partir deles seja possível absorver as características comportamentais de decisão que impactam no consumo de recursos. 


\section{2 - REVISÃO BIBLIOGRÁFICA}

O problema científico aponta para a decisão cooperada como um fator preponderante na minimização do risco de insustentabilidade coletiva.

Apesar de a sustentabilidade ser o principal serviço da governança, com ela é contada uma escola de pesquisadores interessados no dilema da cooperação em prol da sustentabilidade, em especial Elinor Ostrom (2009), que descreve achados para a governança a partir do dilema da tragédia do bem comum (HARDIN, 1968).

São utilizados os portfolios de projetos e sua base teórica como plataforma de apoio a decisão e como uma unidade de medida para comparar o impacto de risco ao longo do tempo entre as decisões dos agentes.

Por fim, o capítulo de tomada de decisão, que fundamenta a temática e o foco do trabalho no fenômeno da racionalidade limitada (SIMON,1947), manifesta-se sob a forma da tragédia dos comuns, que por sua vez delineia o problema científico sob o dilema de escolha entre maximizar o ganho individual ou minimizar o risco da insustentabilidade de todos. 


\section{1 - GOVERNANÇA SOB ENFOQUE COLABORATIVO}

A governança também é sobre tomada de decisão coletiva e especificamente sobre a tomada de decisões coletivas que incluem agentes de decisão públicos e privados (ANSELL, 2008). A governança colaborativa é um tipo de governança em que o grupo de agentes de decisão trabalha coletivamente de maneiras distintas, usando processos particulares, para estabelecer leis e regras para a provisão de bens comuns (ANSELL e GASH, 2008).

A governança é a forma específica pela qual a transação entre as partes é realizada (WILLIAMSON,1996). A estrutura de governança tem o propósito de manter a dinâmica das transações ao longo do tempo. Por essa razão os desdobramentos das decisões são norteados para atender as expectativas de resultados das partes afetadas de forma sustentável.

Segundo recomendação de Elinor Ostrom (1990) é fundamental a participação das partes afetadas na instituição da governança, no processo de desenvolvimento da governança, caso contrário os agentes tendem a se comportarem de forma competitiva, de forma a buscar a otimização de seus resultados individuais. Isso pode desembocar no limite de desenvolvimento, por conseguinte na tragédia do bem comum (HARDIN, 1968), que é caracterizada pela insustentabilidade do sistema.

Os estudos de Simon (1947) apontam para limites da racionalidade que limitam o agente de decisão, o tomador de decisão. Sua conclusão é fundamentada na indisponibilidade de alternativas para serem comparadas no processo de decisão e na impossibilidade de repercutir o impacto da escolha de uma alternativa de decisão sobre as demais ao longo do tempo.

A tragédia dos comuns é um problema complexo, e foi formalizado por Hardin (1968) e retrata a limitação da racionalidade (SIMON,1947). Ainda que todos agentes de decisão busquem otimizar seus resultados, ao competirem por uma mesma fonte de recursos podem ser levados ao fracasso. 
O trabalho de campo de Elinor Ostrom (1990) identifica que grupos de agentes de decisão que conseguiram enfrentar o contexto sob a tragédia de Hardin (1968). Embora os estudos de Elinor Ostrom (1990) e Hardin (1968) cooperem com a ideia de racionalidade limitada de Simon (1947), Ostrom (1990) percebe que o grupo de agentes de decisão, mesmo sem o conhecimento de todas as alternativas, conseguiu elaborar regras de convivência em grupo para preservar a sustentabilidade coletiva ao longo do tempo.

Nesse caso, o trabalho descritivo de Elinor Ostrom (1990), indica que os agentes de decisão partem de uma referência crítica de fracasso, para então elaborarem os contornos do campo de tomada de decisão para a sustentabilidade.

Em outras palavras, a proposta não é buscar o melhor resultado - uma vez que é reconhecida a limitação da racionalidade como um pressuposto - mas trata-se de evitar o pior resultado, em favor de uma busca por resultados satisfatórios.

A tragédia dos comuns evidencia o problema do tipo em que os agentes de decisão buscam a solução ótima, por isso acabam repercutindo negativamente sobre os resultados dos outros agentes. Isso descreve a característica principal de um problema adaptativo (HOLLAND,2006). Sob uma perspectiva ampliada esse tipo de problema exige a cooperação entre os agentes, o que é confirmado por Ostrom (1990) e MCGinnis et al. (2014). Isso conduz ao pressuposto de que o desenvolvimento unicamente competitivo é insuficiente para realizar as atividades produtivas dentro do sistema de forma sustentável.

Em razão do trabalho de Hardin (1968) admite-se que agentes envolvidos na tragédia dos comuns são incapazes de lidar com tamanha dificuldade, o que é ratificado pelo trabalho de ruptura do pensamento clássico de Simon (1947), que assume a racionalidade limitada para compreender problemas dessa natureza.

É também feito o alerta da insuficiência na prática do interesse de se obter cooperação que seja capaz de minimizar o risco de insustentabilidade coletiva, em razão da dificuldade de se congregarem os interesses individuais em prol do interesse comum (WILLIAMSON,1996). 
Se os agentes de decisão estão competindo por um recurso que é insuficiente para atender a todos em sua plenitude, a conquista desse recurso por um agente resulta na perda por parte de outros agentes (OLIVEIRA e LOPES, 2014).

O dilema é posto aos agentes tomadores de decisão que enfrentam a necessidade de definir até que ponto eles devem competir como concorrentes e até que ponto cooperar com concorrentes (KOCK, BENGTSSON, e SLOTTE-KOCK, 2005).

A questão de saber se uma empresa deve optar por cooperar ou competir, ou mesmo tentar combinar competição e cooperação, tornou-se uma questão estrategicamente importante (KOCK et al., 2005).

Em um período de crescente concorrência entre as universidades, essas alianças representam uma curiosa forma de cooperação. Então Gunn \& Mintrom (2013) sugerem as questões: quando a cooperação faz sentido? Quais as oportunidades e riscos que as alianças apresentam aos seus membros? Essas questões têm acompanhado as IES que buscam atender os complexos critérios de avaliação no contexto global.

Em razão dessas limitações, a ideia de um mecanismo que apresente as consequências das escolhas feitas pelos agentes - sejam elas cooperadas ou competitivas - não se propõe a ser um instrumento de convencimento e sim uma visão que ofereça transparência da disponibilidade de recursos e das consequências das decisões sobre seus níveis. $\mathrm{O}$ mecanismo deve oferecer parâmetros de apoio ao processo decisório governado. 


\section{2 - PORTFOLIO DE PROJETOS}

A teoria moderna de portfolio (TMP) é um referencial para a abordagem de portfolio de projetos. Ainda que os pressupostos socioeconômicos sejam teoricamente comuns à realidade organizacional, nesta proposta o foco é aproximar a variável de decisão à atividade produtiva.

Uma vez que o processo de análise da TMP considera os padrões de comportamento das séries temporais para realizar a análise de eficiência do portfolio, ciente da possibilidade de conversão de atividades produtivas também em séries, entende-se que a atividade produtiva pode ser analisada na TMP.

Com efeito, o portfolio de projetos pode ser entendido como um interlocutor entre agentes de decisão a frente das atividades produtivas de uma Organização, para verificação do impacto de suas decisões ao longo do tempo.

Enfim, uma vez entendido que a atuação individual do agente pode ser expressa sob a estrutura de projeto, e seu resultado com os demais é a expressão do desempenho coletivo no portfolio. O que leva sugere, que a estrutura da TMP pode oferecer capacidade de suporte a diversidade de decisões entre agentes. Pois por ela (TMP) os projetos podem ser submetidos a análise individual e coletiva pela análise eficiência da TMP.

\subsection{1 - Introdução}

Em 1952 Harry Markowitz introduz o conceito de portfolio para o setor financeiro e desenvolve uma base teórica de portfolio para diversificação de investimentos, sob a perspectiva racionalista de busca de uma melhor relação entre risco e retorno por portfolio.

A análise da curva de eficiência de Markowitz (1952) permite trabalhar com alternativas de portfolio, sob um critério multiobjectivo para seleção de portfolio. As alternativas de portfolios são obtidas por meio da ponderação da participação de cada ativo na composição do portfolio, mediante a expectativa de retorno ou de risco do investidor. 
O desenvolvimento das pesquisas de métodos multiobjectivos por Charnes et al. (1955), resultou no desenvolvimento de métodos de otimização por objetivo (CHARNES et al., 1955) e na integração de métodos com flexibilidade de absorção da percepção de problemas estocásticos, multiobjectivos, multicritérios e nebulosos (AOUNI, COLAPINTO, e LA TORRE, 2014).

\subsection{2 - Plataforma de apoio a decisão}

Peter Weill (2004) afirma que um passo crítico na implementação da governança está no desenvolvimento de uma disciplina de acompanhamento do progresso e, também, no desempenho de projetos.

O portfolio de projetos pode ser entendido como uma plataforma capaz de congregar projetos ou programas propostos por diversos agentes de decisão (HARRINGTON,2005; COOPER et al., 1999; PADOVANI,2013).

O processo de seleção de portfolios é amplamente utilizado no mercado financeiro, sendo objeto de diversas pesquisas. No entanto, recentemente autores como Castro et al. (2010) têm afirmado que o gerenciamento de portfolio de projetos ainda é pouco presente nas Organizações e que a falta dele é um dos fatores que dificultam a implementação adequada das ações estratégicas definidas pelos executivos.

Pela simplicidade da estrutura de projetos, entende-se que a estrutura do portfolio pode agregar a complexidade das atividades coletivas de uma Organização ao compor seu portfolio. Isso porque qualquer agente de atividades de apoio às atividades fim tem domínio de escrita ou leitura sobre a estrutura de projetos e programas, bem como da programação de seus recursos. A simplicidade da estrutura de projetos é ilustrada na figura 2.5, também na elaboração e representação de programas. 


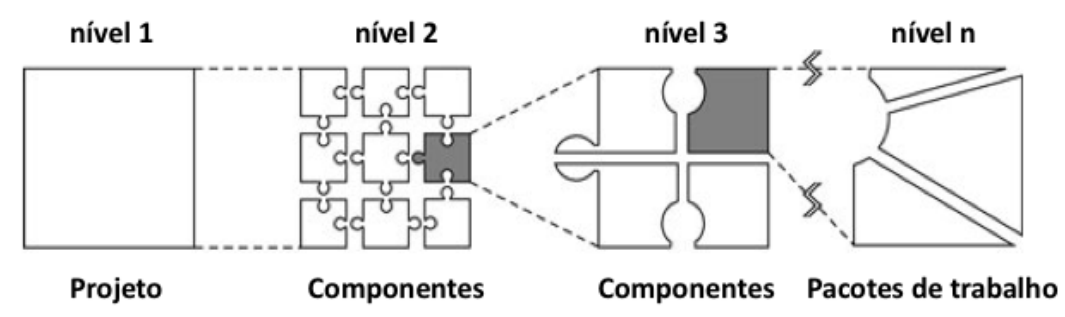

Figura 2.5 - Desdobramento de projeto.

Essa ilustração de Wiley Brand representa o desdobramento dos componentes do projeto, que por sua vez são compostos por pacotes de trabalho, que absorvem recursos que impactam na seleção de portfolio no período seguinte.

O portfolio de projetos é definido como "... um conjunto de projetos ou programas e outros trabalhos que são agrupados para facilitar o gerenciamento eficaz de trabalho, no atendimento das necessidades estratégicas de negócio" (ACHER et al.,1999).

Na totalidade do investimento de uma organização são realizadas mudanças por meio de projetos sobre os programas existentes, para alcançar seus objetivos estratégicos. Por essa razão entende-se que os projetos são desdobramentos das ações estratégicas do planejamento da Organização.

Em vista da necessidade de integração entre a disponibilidade de recursos e seu planejamento de consumo, a abordagem por portfolio mostra-se aderente às diretrizes de governança colaborativa observada por Elinor Ostrom (1990).

\subsection{3 - Análise de projetos}

Uma decisão de investimento envolve mensurar os fluxos de caixa associados às propostas de investimentos e avaliar a sua atratividade econômica, pela comparação com o custo do dinheiro. Uma proposta de investimento é atraente quando o seu retorno for superior às taxas de remuneração requeridas pelos proprietários de capital (ROSS, S.; WESTERFIELD, R.; JEFFREY, 2013; ASSAF, 2010). 
A atividade produtiva é uma proposta de investimento com atratividade econômica, que estabelece comparação também com os custos (SLACK et al, 2011). Em uma visão ampliada, o fluxo de caixa é uma estrutura dependente dos insumos da atividade produtiva.

A viabilidade do projeto de investimento deve ser verificada do ponto de vista técnico eem seguida, deve-se considerar a expectativa do investidor.

A medida de valor presente líquido é obtida pela diferença entre o valor presente dos fluxos de caixa descontado, em conjunto com o valor presente do investimento do projeto. Formalmente, é representado pela equação (2.1) (ROSS et al., 2013; ASSAF, 2010):

$$
V P L=\left[\sum_{t=1}^{n} \frac{F C_{t}}{(1+k)^{t}}\right]-\left[I_{0}+\sum_{t=1}^{n} \frac{I_{t}}{(1+k)^{t}}\right]
$$

onde:

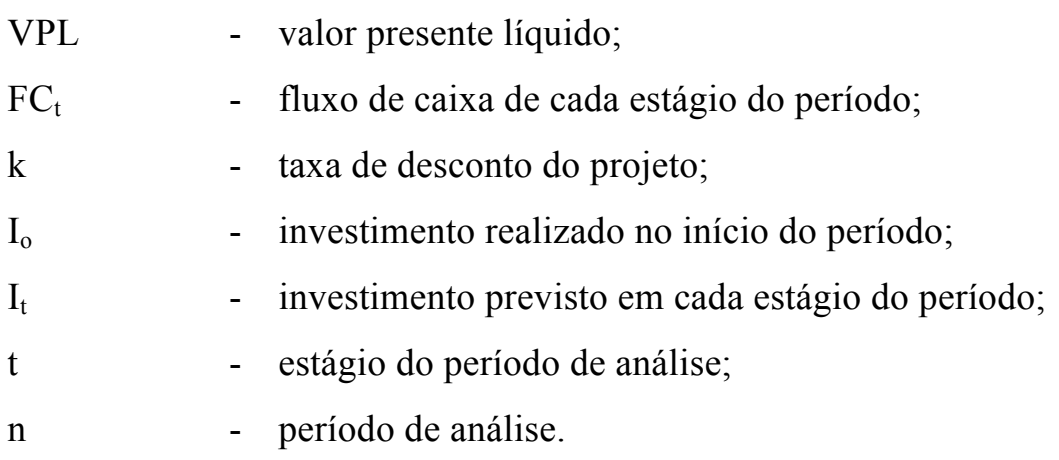

O cálculo do valor presente líquido exige a definição antecipada da taxa de desconto para a transição temporal da aplicação. Essa média indica também se ocorre agregação de valor. Isso significa que o projeto indica uma predisposição à viabilidade do investimento empregado.

\subsection{4 - Análise de portfolio}

O mesmo saldo do fluxo de caixa que é utilizado para análise do VPL também é utilizado para obter as séries temporais que vão ser submetidas à análise de eficiência na TMP.

A expressão do desempenho contínuo da relação discreta entre os saldos dos fluxos de caixa é normalizada para análise da série (ROSS et al., 2013) - equação (2.2). 


$$
\begin{aligned}
& \qquad r_{t}=\ln \left(1+\frac{S_{t}-S_{t-1}}{S_{t-1}}\right) \\
& \text { Sa.: } \\
& r_{t} \text { - retorno contínuo no instante } \mathrm{t} \\
& \boldsymbol{S}_{t-1} \text { - saldo discreto do fluxo de caixa descontado no instante t }
\end{aligned}
$$

A equação (2.2) relaciona saldos para se obter o retorno. Durante o horizonte de atividade produtiva a formação dos retornos estabelece a série de retornos.

A série de retornos é a expressão comum de desempenho entre um projeto produtivo e um ativo financeiro. Essa também é a forma com que a TMP pode realizar sua análise de eficiência de portfolio.

Para análise de eficiência considera-se as alternativas de retornos e riscos obtidos dentre as alterações de participações de projetos que compõem o portfolio na formação de seu desempenho.

A formalização original da abordagem de Markowitz (1952) considera a normalidade dos padrões de comportamento das séries de retornos. Por isso, ao assumir as propriedades gaussianas, a esperança matemática é a média dos retornos e o risco a variância dos retornos em torno da média.

A forma geral do modelo identifica a melhor relação risco e retorno, que considera o risco a partir da covariância entre a participação dos ativos no portfolio, conforme indicado na equação (2.3):

$$
\begin{aligned}
& \text { Min } Z=\sum_{i}^{n} \sum_{j}^{n} \operatorname{cov}\left(R_{i}, R_{j}\right) \mathcal{W}_{i} \mathcal{W}_{j} \\
& \text { Sa.: } \\
& \sum_{j=1}^{n} r_{i} \mathcal{W}_{j} \geq P \\
& \sum_{j=1}^{n} \mathcal{W}_{j}=1 \\
& \mathcal{W}_{j} \geq 0 \text { para } j=1,2,3 \ldots n
\end{aligned}
$$

onde:

$\mathrm{R}_{\mathrm{i}} \quad$ - série de retornos do projeto $\mathrm{i}$.

$w_{i j} \quad$ - peso obtido a partir da minimização do risco do portfolio.

$\mathrm{P} \quad$ - retorno do portfolio.

$r_{i} \quad-$ retorno médio da série $R_{i}$ de retornos do projeto $i$.

$\operatorname{cov}\left(R_{i}, R_{j}\right)$ - covariância entre séries de retornos dos projetos i e j. 
O registro de resultados é identificado na composição que apresenta o melhor grau de eficiência entre risco e retorno. Essa identificação considera os registros dos resultados dos portfolios, que são comparados sob o critério de maximização da relação risco e retorno, bem como pela minimização do risco. Assim, o portfolio que apresenta a composição com o melhor grau de eficiência é selecionado. O grau de eficiência é representado pela equação (2.4):

$$
\begin{gathered}
\alpha\left(\xi_{\mathrm{n}}\right)_{\operatorname{maxmin}}=\arg \max _{\alpha} \min _{\mathrm{SP}}(\mathrm{SP}, \alpha) \\
\alpha\left(\xi_{\mathrm{n}}\right)=(\mathrm{E}(\mathrm{rp})-\mathrm{TMA}) / \mathrm{SP}
\end{gathered}
$$

\footnotetext{
Sendo:

$\alpha=$ Coeficiente angular.

$\xi_{\mathrm{n}}=\mathrm{A}$ estrutura de ativos, que compõe o portfolio.

$\mathrm{E}(\mathrm{rp})=\mathrm{a}$ taxa esperada de retorno do portfolio.

TMA = Taxa mínima de atratividade que representa o retorno mínimo esperado.

$\mathrm{SP}=$ taxa de risco do portfolio, a partir da ponderação da matriz de covariância e variância.
}

A partir dessas construções de retorno e risco do modelo processam-se reiterados ciclos de otimização minimizando o risco e parametrizando diferentes taxas de retornos, o que resulta na dinâmica de pesos dos ativos para a composição da curva de portfolios. Por fim, a seleção - equação (2.4) - do portfolio com melhor relação entre risco e retorno, está representada pela figura 2.6 . 


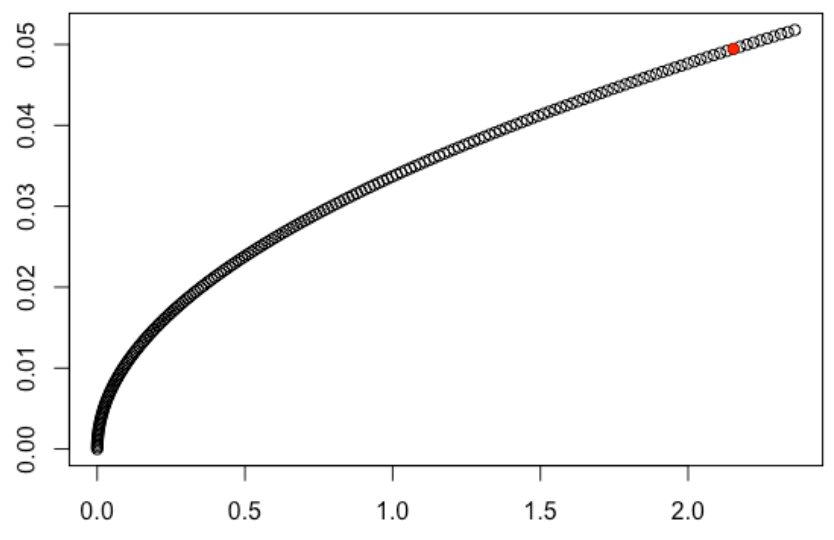

Figura 2.6 - Curva de eficiência.

Portanto, para a aplicação da abordagem da TMP na IES considerou-se o projeto pedagógico como decisão estratégica do curso, de forma que sua realização é uma projeção da atividade produtiva do curso para compor a decisão de planejamento colegiado. Assim as participações de projetos dos cursos na IES sugerem alternativas de portfolios para composição da curva de eficiência - figura 2.6. 


\section{3 - TOMADA DE DECISÃO}

A tomada de decisão em ambiente corporativo é realizada por agentes com perspectivas diversas sob uma mesma fonte de recursos, que por eles mesmos é realimentada. Desse modo, as decisões individuais acabam repercutindo na disponibilidade de recursos que mantêm todos os agentes, daí a importância de minimizar o risco de insustentabilidade.

\subsection{1 - Introdução}

A decisões são compromissos de aplicação de recursos que podem envolver pessoas, materiais, ferramentas, estrutura e custos na programação de eventos que vão consolidar uma entrega, sendo esperada a recompensa por tal esforço (ROSS,2013; SLACK et al., 2011;CORREA et al. 1999).

Para Howard (1983) “tomar decisão é alocar irreversivelmente recursos”. É o mesmo que o risco da escolha, pois a sua correção demandaria o comprometimento de mais recursos.

Para Hardin (1968) existe um contexto social em que os agentes de decisão não conseguem consumir recursos de forma sustentável.

\subsection{2 - Complexidade no processo de decisão}

A complexidade é estudada por diversas áreas do conhecimento, apesar da iniciativa da Pesquisa Operacional em propor métodos racionalistas para lidar com problemas estruturados. Existem áreas que vêm inovando em considerar aspectos mistos para definição de problemas para o envolvimento de heurísticas na busca de soluções dos modelos.

Para Keeney (1982) os fatores que contribuem para a complexidade no processo decisório, são:

- Multiplicidade de objetivos;

- dificuldade para identificação de boas alternativas;

- dificuldade de mensurar fatores críticos que são intangíveis;

- implicações futuras de alternativas que devem ser incluídas no processo decisório; 
- diferentes percepções de impactos por grupos impactados;

- risco e incerteza associados a fenômenos naturais;

- risco à vida e à integridade física a partir da numerosa rede de decisões que impactam a probabilidade de ocorrência de eventos;

- interdisciplinaridade de profissionais para o fornecimento de insumos relevantes sobre os fatores chave do processo decisório;

- $\quad$ vários tomadores de decisões que exigem um controle crucial do processo decisório;

- importantes decisões que envolvem trade-offs de valores críticos para indicar a oportunidade dependente do impacto ambiental e dos custos econômicos ao longo do tempo;

- os custos sociais imediatos contra futuras prestações sociais;

- o impacto negativo de um pequeno grupo contra o impacto positivo menor para um grupo maior;

- por vezes o valor de uma vida humana contra os benefícios gerados por uma tecnologia perigosa;

- os riscos das alternativas devem ser comparados, mesmo que elas sejam conhecidas; e

- natureza sequencial das decisões. Raramente existe uma decisão totalmente desconectada de outra. Essas conexões se dão por alternativas e pelas consequências sob outras decisões no futuro.

Para Gomes (2004) os problemas complexos para tomada de decisões são comuns em diversas áreas. Tais problemas apresentam as seguintes características:

- Critérios de resolução de problemas conflitantes entre si;

- baixo nível de clareza na definição de critérios e alternativas com suas respectivas consequências;

- os critérios e as alternativas que podem estar interligados;

- solução de uma situação problema que depende de um grupo de pessoas com perspectivas diferentes sobre ela;

- definição insuficiente para restrições do problema, o que pode gerar confusões entre o que é critério e o que é restrição;

- critérios quantificáveis, enquanto outros dependem do juízo de valor efetuados sobre uma escala; e

- a escala para definição de critério por cardinalidade, verbal ou ordinal. 
O dilema multiobjetivo da tragédia do bem comum apresenta uma órbita de resultados entre os interesses individuais e coletivos, sua conciliação é abrigada em um ambiente competitivo por recursos comuns (OSTROM,2009; BUENO,2011; STERMAN,2000; ELINOR OSTROM,1990; HARDIN,1968).

Para um processo de decisão multicritério são envolvidos alguns componentes para seu desenvolvimento (GOMES, ARAYA, \& CARIGNAN, 2004):

- O agente responsável pela decisão, seja ele um indivíduo ou um grupo;

- um analista que suporte a compreensão do agente tomador de decisão;

- conjunto de escolha ou de alternativas;

- atributos e critérios que norteiem a escolha;

- pesos de importância; e

- identificação do tipo de problema enfrentado, como selecionar, aceitar alternativas que interessam, ordenar as alternativas.

O entendimento de complexidade por Keeney (1982) e Gomes et al.(2004)colabora com a perspectiva de cooperação de Elinor Ostrom (1990), presente em seu trabalho de investigação da ação coletiva sob a tragédia do bem comum (HARDIN, 1968).

\subsection{3 - O dilema da escolha}

A escolha entre maximizar o retorno e minimizar o risco envolve o tomador de decisão em um dilema de seleção que antecede a escolha. Esse dilema foi estudado por Markowitz (1952), que desenvolveu os pressupostos teóricos de risco e retorno.

No entanto, Simon (1947) em sua busca científica constata a racionalidade limitada do decisor, em razão de sua incapacidade de comparar as alternativas de decisão com suas consequências.

A teoria do prospecto de Kahneman et al. (1979) confirma a racionalidade limitada, pois ao realizarem experimentos com um mesmo problema para diferentes tomadores de 
decisões, identificaram que as diferentes decisões tomadas tiveram a intuição como fator comum.

Ainda que a intuição ou empirismo influencie o decisor e a racionalidade limitada restrinja seu campo de escolha, é fato que o decisor lida diariamente com trade-offs em busca de equilíbrio dos resultados aparentemente excludentes (LI, LIU, ZHENG, \& LEI, 2011).

As decisões realizadas em grupo de forma cooperada, sob o apoio de um sistema que norteie o processo de escolha rumo a sustentabilidade, têm maiores condições de obter sucesso frente a trade-offs como a tragédia do bem comum ( MCGINNIS,MICHAEL D., OSTROM, 2014; E. OSTROM, 2009; ELINOR OSTROM, 1990; BASURTO, GELCICH, \& OSTROM, 2013; GOMES et al., 2004) . 


\section{4 - SÍNTESE DO CONTEÚDO DA REVISÃO À PESQUISA}

A governança norteia o processo decisório em favor da sustentabilidade, de forma que seja possível a coexistência entre diferentes perspectivas de agentes em um mesmo contexto socioeconômico.

Apesar de os processos decisórios de planejamento serem definidos por um pequeno grupo de decisores, atualmente também existe o direcionamento de um processo decisório inclusivo que considera as perspectivas de agentes envolvidos na atividade produtiva. Entende-se que assim fazendo seja favorável à ampliação do processo de compreensão e proposição de soluções frente a uma situação problema.

O foco da pesquisa está centrado no risco de insustentabilidade do sistema, em meio ao dilema entre seus agentes de decisão que competem por uma fonte comum e limitada de recursos

Entende-se que a estrutura básica de projetos pode compreender a decisão de planejamento dos agentes do sistema, de forma a elaborar a análise de desempenho de diversos agentes em uma perspectiva coletiva.

Em um contexto em que agentes de um sistema buscam maximizar seus resultados individuais, julgando que assim estão contribuindo para o bom desempenho do sistema, ao utilizarem a mesma fonte de recursos, contudo, todos ficam sujeitos ao risco de insustentabilidade do sistema.

Visto que os agentes de decisão estão sujeitos ao pressuposto de racionalidade limitada que sugere a dificuldade deles em compreenderem uma mesma situação problema, se propõe um mecanismo de apoio a decisão em grupo de agentes competitivos, de forma a identificar até que ponto a cooperação minimização o risco de insustentabilidade do sistema. 


\section{3 - METODOLOGIA}

O método hipotético-dedutivo é empregado por considerar as buscas de soluções por tentativas - conjecturas, hipóteses, teorias - que permitem compreender na estrutura de hipótese as diversas perspectivas de agentes de decisão envolvidos na mesma situação problema (SIMON, 1947).

Uma vez que as proposições científicas são suportadas pelas hipóteses (LAKATOS et al., 2003; POPPER, 2002), as principais etapas do método hipotético-dedutivo para sua compreensão e verificação, são:

- Problema que surge de expectativas, conflitos e de uma base teórica existente.

- Conjectura de soluções a priori do problema científico em questão, que seja passível de testes.

- Falseamento pelo uso de testes para refutação, entre outros meios, pela observação e experimentação.

A validação da proposição a princípio é fundamentada no teste da hipótese pelo método de simulação (KLEIBOER,1997), em razão da própria proposta de Popper (2002), ao considerar o uso de meios diversos, como: observação, experimentação, dentre outros. Por outro lado, a composição multiobjectivo e multicritério do problema exige que os cenários oriundos da simulação sejam submetidos a verificação de aderência do arquétipo da tragédia do bem comum ao contexto da IES, bem como as alternativas disponibilizadas de cooperação.

Uma vez que a tragédia do bem comum não dispõe de uma solução única e definitiva para seu dilema (MCGINNIS et al., 2014; OSTROM, 2009; OSTROM, 1990; HARDIN, 1968), considerando também que o objetivo não tem a pretensão de obrigar os agentes a cooperarem, mas sim, o de disponibilizar informações à dinâmica das decisões dos agentes, é deduzido que o teste de hipótese e a confirmação do ajuste do arquétipo da tragédia do bem comum ao contexto da IES são suficientes para validar o trabalho de investigação científica por simulação. 
A simulação é indicação de Kleiboer (1997) como ferramenta de pesquisa em ciências sociais por apresentar a vantagem de agregar uma grande quantidade de variáveis ao mesmo tempo. Ainda que a interação das variáveis seja inicialmente simples, o comportamento dinâmico do modelo pode se tornar complexo (STERMAN, 2000) e a lida com diversas variáveis exponenciais simultaneamente é limitante ao entendimento humano, daí a racionalidade limitada (SIMON, 1947). A simulação possibilita realizar testes e análises que seriam de custos proibitivos na realização dos prognósticos.

\section{1 - ESTRATÉGICA DE PESQUISA}

O problema científico envolve conflito de interesse entre agentes de decisão. Trata-se de um desafio multiobjectivo já na perspectiva individual do agente, que encerra o conflito de interesses entre os agentes tomadores de decisões, por exigir a conciliação de interesses divergentes em prol da minimização do risco de insustentabilidade do sistema.

A figura 3.7 indica o dilema multiobjectivo do agente ao realizar sua decisão individual, porém ao repercuti-la em grupo, o agente assume uma postura competitiva ou cooperada.

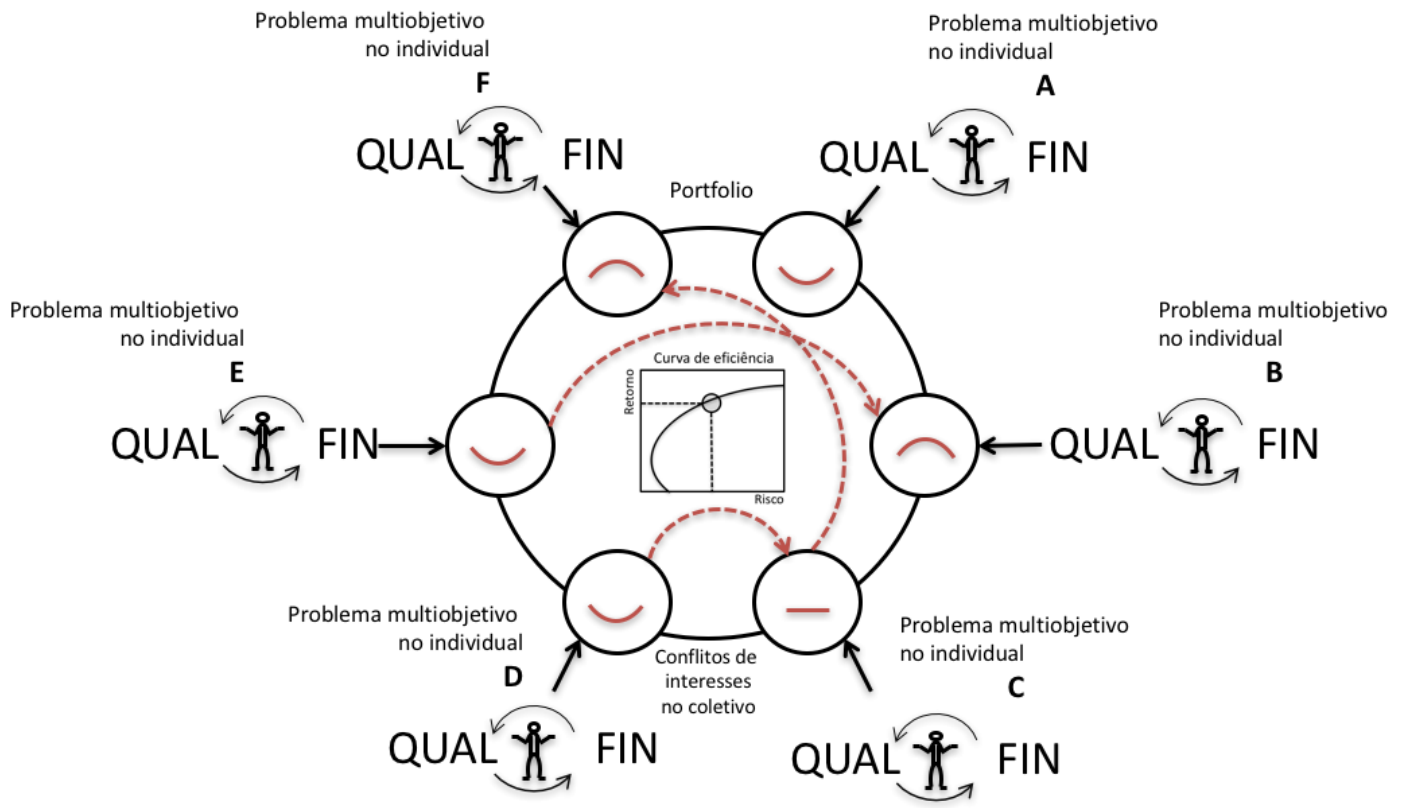

Figura 3.7 - Dinâmica do mecanismo de prognóstico de risco

No centro da figura 3.7 é indicada uma representação da curva de eficiência da figura 2.6 obtida como resultante das proposições dos agentes envolvidos, que por ela tem o desempenho de seus cursos avaliados sob a perspectiva do portfolio. Os fluxos pontilhados 
são os conflitos de interesses, que representam o impacto das decisões individuais sobre outros projetos de cursos.

Independente do critério que é adotado na IES, os cenários de planejamento devem ser conectados à realidade orçamentária da IES.

A projeção de cenários quantitativos - dada à natureza econômica - e os ajustes de prioridades qualitativas - em razão das incertezas relacionadas à dimensão temporal - são manifestações que ocorrem no desenvolvimento do planejamento.

Nesse prisma, a abordagem hipotético-dedutiva, tem o intuito de conciliar instrumentos que sejam capazes de absorver as informações qualitativas para enriquecer os registros quantitativos, que por vezes ocultam as expectativas que levaram à escolha de determinado critério ou alternativa.

Sob esse contexto, entende-se pela escolha do método multicritério (AOUNI et al., 2014) capaz de ser integrado à abordagem de portfolio de projetos e assim realizar simulações, pois o intuito é conciliar as expectativas dos multidecisores ou grupos de tomadores de decisão no desenvolvimento e na escolha de alternativas que minimizem o risco de insustentabilidade coletiva, enquanto também possam satisfazer as expectativas de resultados individuais.

A estratégia de pesquisa depende do teste de hipótese, onde é verificado se a cooperação minimiza o risco de insustentabilidade coletiva. Essa verificação exige dados, informações multiatributos e a estruturação de redes de cooperação potencial para alocação de recursos - alocação de horas de docentes, alocação de espaços - entre os cursos da IES, de forma que satisfaça o interesse de ganho financeiro e de qualidade, ainda no nível individual.

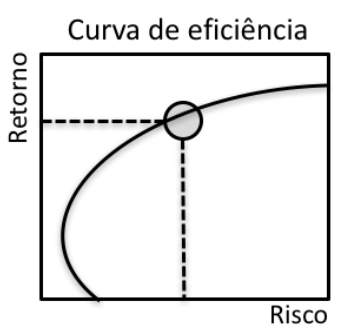

Figura 3.8 - Diagrama da curva de eficiência. 
A figura 3.8 ilustra o comportamento da curva de eficiência da TMP, conforme subseção 2.2.4 e figura 2.6. Essa ilustração, ao compor os próximos diagramas, tem o intuito de representar a curva de eficiência, que neste trabalho é utilizada como uma medida de fator de risco e desempenho do portfolio.

Essa medida é obtida a partir da curva de eficiência de H. Markowitz (1952) pode ser integrada às variáveis de decisão de projetos na formação da curva de eficiência - figura 3.9 .

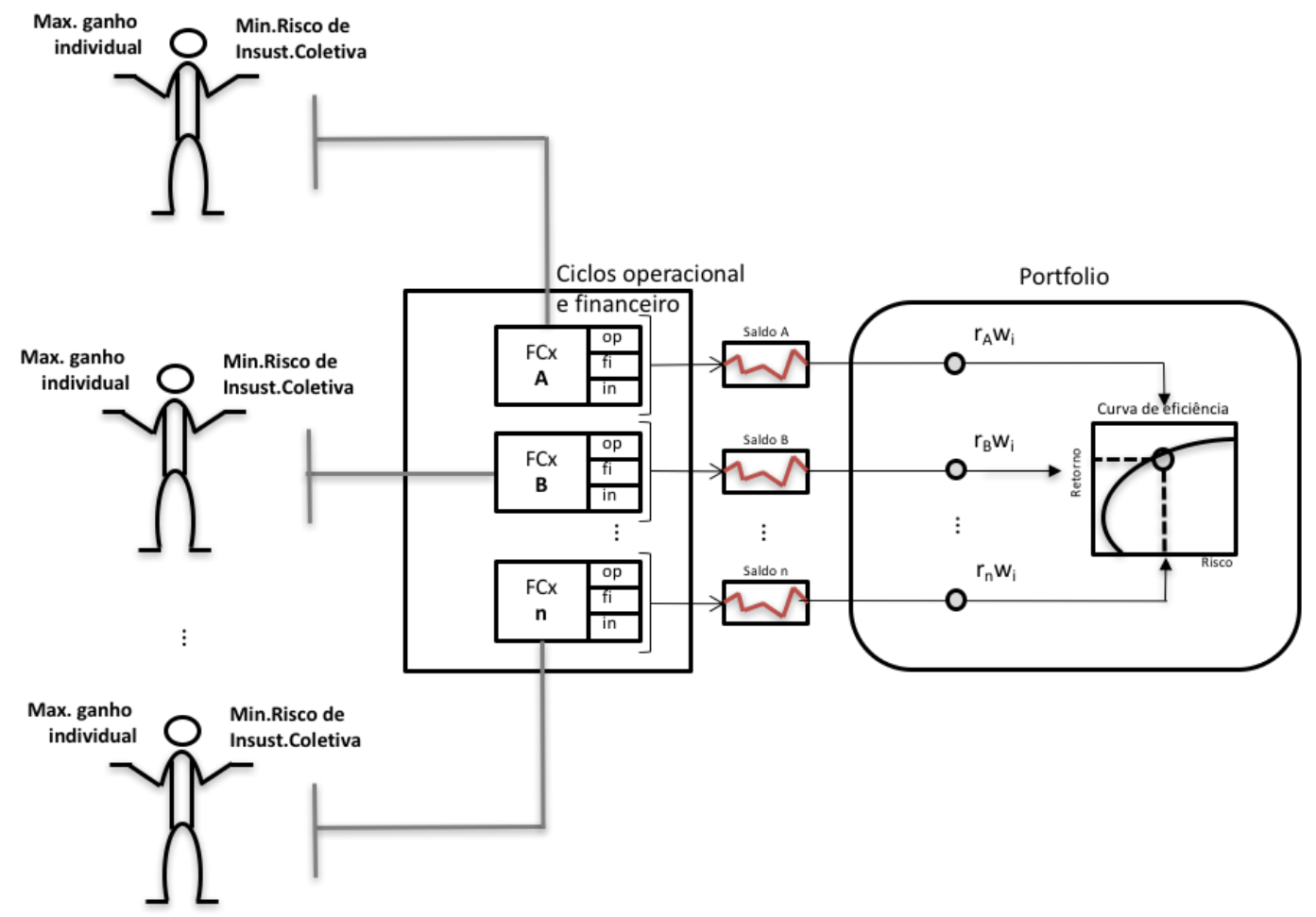

Figura 3.9 - Etapas para composição de portfolio de projetos.

$\mathrm{Na}$ figura 3.9 é ilustrado o dilema dos agentes de decisão, onde eles se veem em circunstâncias de equalizar sua decisão de ajustes no projeto do curso, no intuito de que seus resultados atendam os interesses entre a maximização do ganho individual do projeto do curso, em relação à minimização do risco de insustentabilidade do portfolio da IES.

Os pontos críticos são a inclusão de variáveis qualitativas dos projetos dos cursos no processo de análise quantitativa do portfolio, e os ajustes nas variáveis de decisão que impactam nas decisões dos demais. O impacto dos ajustes é percebido na composição do portfolio de projetos, que acaba reduzindo a participação de um projeto pelo outro. 
Em razão desses pontos críticos é que a compreensão dos componentes do problema científico se faz importante. Outro benefício disso é a definição das categorias de dados a serem obtidos e por esses motivos foram estratificados nos seguintes tópicos:

- a medida de risco individual e coletiva dos cursos;

- como se dá a cooperação entre os cursos da IES; e

- a insustentabilidade de recursos no atendimento das demandas dos projetos pedagógicos dos cursos.

A variância é a medida de risco a partir da expectativa de resultado sobre um curso. Já a covariância do desempenho de resultado esperado entre os cursos é a medida de risco entre os cursos. A minimização desse risco provoca uma busca por maximizar o resultado esperado do curso e do portfolio de cursos da IES. Espera-se que o imediatismo dessa análise repercuta negativamente na disponibilidade dos recursos (MARKOWITZ, 1952; H. M. MARKOWITZ, 2010). É analisada a decisão de escolha do portfolio para o mesmo instante observado.

A cooperação entre os cursos se dá pelos recursos de horas docentes e de espaço de ensinoaprendizagem; e é expressa na formação de turmas compostas por alunos de vários cursos e sessão de horas de docentes para formação de turmas de outros cursos em sessão de espaço de ensino-aprendizado entre os cursos da IES (MCGINNIS,MICHAEL D.;OSTROM, 2014; E. OSTROM, 2009; ELINOR OSTROM, 1990).

Para compreensão da sustentabilidade coletiva deve-se considerar o desempenho individual ao se observar o desempenho do projeto coletivo por meio do desempenho do portfolio que relaciona o desempenho entre os projetos sobre a disponibilidade de recursos da IES ao longo do tempo.

O prognóstico de tomada de decisões tem o propósito de apoiar o processo de desenvolvimento e seleção de portfolios, que indica o planejamento fora do escopo de insustentabilidade. 
Ainda que exista a interlocução entre os agentes, isso não é garantia para minimização do risco de insustentabilidade (HARDIN, 1968; MCGINNIS,MICHAEL D.;OSTROM, 2014; ELINOR OSTROM, 1990).

Em razão disso, foram elaborados alguns quesitos que suportam a compreensão dessa situação problema, com o foco no processamento das relações de risco e retorno ao longo do tempo, a partir de:

- séries temporais;

- informações intuitivas;

- informações históricas;

- realização de projeções a partir de séries, informações históricas ou intuitivas;

- análise da relação entre risco e retorno; e

- geração de informações para análises transversais e longitudinais.

Esses quesitos foram inspirados nas necessidades de materiais de processos produtivos (CORREIA at. al.,1999), conjugados com os modelos de regressão multivariados para projeção (GUJARATI,2010) e orientados por trabalhos de revisão e estado da arte (AOUNI,2014; BALLESTEIRO,2012). A proposição de inclusão da análise multicritério é revisada considerando o comportamento dinâmico dos limites de controle para ajuste da eficiência por meio dos projetos.

\section{2 - MÉTODOS DE COLETA E DISCUSSÃO DOS DADOS}

O propósito é identificar as variáveis de decisão com efeito individual e coletivo. Para tanto, considerou-se o desdobramento da atividade produtiva em ciclos que permitam a realização da atividade fim, bem como sua avaliação quantitativa e qualitativa.

\subsection{1 - Métodos de coleta}

Os dados foram obtidos a partir de bancos de dados, que por sua vez suportam os principais sistemas da IES - acadêmico e financeiro. A escolha das categorias de dados utilizados na pesquisa surge do desdobramento do modelo simplificado de sistema para IES (JULIATO,2005) e inspirada a partir da programação do método MRP II (CORREA et al.,1999). 


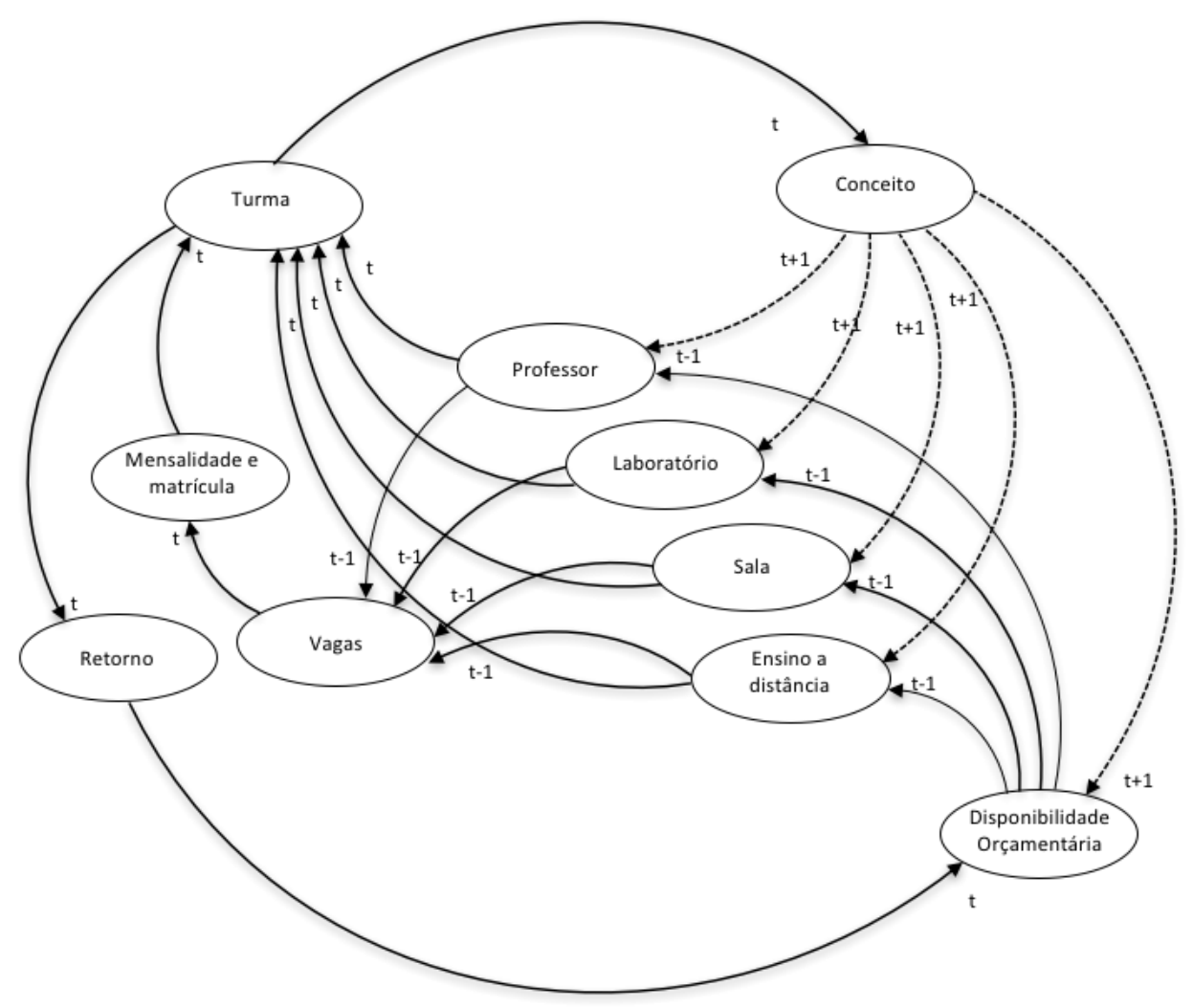

Figura 3.10 - Modelo mental da atividade produtiva do curso.

O modelo mental - figura 3.10 - é a base para a compreensão do ciclo operacional, econômico-financeiro e qualitativo no desenvolvimento da entrega. Vale ressaltar as coletas de dados qualitativos que foram realizadas utilizando o método SWOT + Ishikawa para diagnóstico e proposições de soluções. A ideia é procurar integrar essas informações que se encontram em anexo A.2.

Para escolha e definição da coleta de dados foram utilizados:

- As categorias de contas econômico-financeiras para análise dinâmica de Fleuriet (2003);

- os parâmetros de qualidade de curso de IES - indicados pelas normativas anuais, pelos instrumentos de avaliação de cursos do SINAES (2016), pelas séries do ENADE da IES, bem como pela a avaliação semestral institucional realizada pela própria IES; e, principalmente: 
- o arquétipo sistêmico da tragédia do bem comum, como um fio condutor para captação de dados e construção do modelo (SENGE,2006; STERMAN,2000; FORRESTER, 1962).

\subsection{2 - Discussão dos dados}

As principais variáveis estão relacionadas na tabela 4.1 e surgem do desdobramento do arquétipo da tragédia dos comuns, considerando os agentes como unidades produtivas com fluxo de caixa e desempenho econômico-financeiro e de qualidade. Daí a busca por disponibilidade de recursos comuns entre os cursos da IES, a disponibilidade de docentes e espaço de ensino-aprendizado no detalhamento dos recursos para a cooperação, o que resulta na disponibilidade orçamentária da IES.

As variáveis do setor de ensino são relacionadas para compreender as interconexões socioeconômicas dos cursos e IES - Tabela 4.1:

Tabela 4.1 - Variáveis do setor de ensino superior

\begin{tabular}{|c|c|c|}
\hline 1 & a disponibilidade de recursos comuns & Em horas \\
\hline 2 & a disponibilidade orçamentária da IES & Em horas \\
\hline 3 & docentes & Quantidade em Reais \\
\hline 4 & discentes & Quantidade em Reais \\
\hline 5 & disciplinas & Quantidade em Reais \\
\hline 6 & ponto de equilíbrio turma & Reais \\
\hline 7 & turmas & Quantidade em Reais \\
\hline 8 & espaços de ensino-aprendizagem & Quantidade em Reais \\
\hline 9 & publicações & Quantidade \\
\hline 10 & cursos & Quantidade em Reais \\
\hline 11 & média da nota do SAEB & Percentual \\
\hline 12 & média da nota de seleção do ENEM & Percentual \\
\hline 13 & média da nota de matriculas do ENADE & Percentual \\
\hline 14 & média da nota de curso do ENC & Percentual \\
\hline 15 & média da nota de curso do CPC & Percentual \\
\hline 16 & média da nota de curso do IGC & Percentual \\
\hline 17 & média da nota da IES do SINAES & Percentual \\
\hline 18 & benefício por conceito & Reais \\
\hline 19 & ranking de IES no brasil e no mundo & Orden \\
\hline 20 & alunos concluintes & Quantidade em Reais \\
\hline 21 & matrículas por vagas oferecidas & Quantidade em Reais \\
\hline 22 & procura por vagas & Quantidade \\
\hline
\end{tabular}




\begin{tabular}{|r|l|l|}
\hline 23 & mensalidade em relação aos concorrentes & Reais \\
\hline 24 & abandono de cursos & Quantidade em Reais \\
\hline 25 & cursos mais procurados & Ordem \\
\hline 26 & macroprojeto de ensino, pesquisa e extensão & Quantidade em Reais \\
\hline 27 & conexões de recursos entre os macroprojetos e programas & Quantidade em Reais \\
\hline 28 & níveis de demanda & Quantidade \\
\hline 29 & horas de docentes em instituições concorrentes & Horas \\
\hline 30 & discentes matriculados em concorrência por curso & Percentual \\
\hline 31 & cursos online por instituições nacionais e internacionais & Quantidade \\
\hline 32 & evasão de segundo grau & Quantidade em Reais \\
\hline 33 & concorrência por vaga em institutos tecnológicos de 3o grau & Quantidade \\
\hline 34 & formação de docentes & Percentual \\
\hline 35 & formação de cientistas & Percentual \\
\hline 36 & formação de trabalhadores & Percentual \\
\hline
\end{tabular}

Essas são as variáveis consideradas para inclusão ou manutenção de projetos e programas no portfolio de projetos no contexto da IES, dentro de seu setor de atuação.

Para elaborar o mecanismo de prognóstico foram consideradas as variáveis dos cursos listadas na Tabela 4.2:

Tabela 4.2 - Variáveis da atividade produtiva do curso de ensino de uma IES.

\begin{tabular}{|c|c|c|}
\hline 1 & $\begin{array}{l}\text { Número de vagas disponíveis no semestre para todos os } \\
\text { períodos do PPC }\end{array}$ & Número de vagas \\
\hline 2 & Capacidade de alunos por sala & Número de alunos \\
\hline 3 & Capacidade de alunos por laboratório & Número de alunos \\
\hline 4 & Capacidade de alunos nos grupos EAD & Número de alunos \\
\hline 5 & Número de períodos do projeto pedagógico do curso & Número de semestres \\
\hline 6 & Parcelas mensais da semestralidade do curso & Quantidade em Reais \\
\hline 7 & Despesa fixa com sala de aula & Quantidade em Reais \\
\hline 8 & Despesa fixa com laboratório & Quantidade em Reais \\
\hline 9 & Despesa fixa com ead & Quantidade em Reais \\
\hline 10 & Despesa fixa com professor & Quantidade em Reais \\
\hline 11 & $\begin{array}{l}\text { Percentual a mais sobre a despesa fixa na contratação de } \\
\text { recursos extras, como: sala, laboratório, ead e professor }\end{array}$ & Percentual \\
\hline 12 & Número de turnos que o curso funciona & Número de turnos \\
\hline 13 & Número de disciplinas disponíveis por período & Número de disciplinas \\
\hline 14 & Limite inferior de oscilação de demanda por matrículas & Percentual \\
\hline 15 & Limite superior de oscilação de demanda por matrículas & Percentual \\
\hline 16 & $\begin{array}{l}\text { Referência de demanda de laboratório para o gerador de } \\
\text { números aleatórios }\end{array}$ & Número de alunos \\
\hline 17 & $\begin{array}{l}\text { Referência de demanda de EAD para o gerador de números } \\
\text { aleatórios }\end{array}$ & Número de alunos \\
\hline
\end{tabular}




\begin{tabular}{|r|l|r|}
\hline 18 & Disponibilidade de disciplinas por período do PPC & Número de alunos \\
\hline 19 & Número de salas do curso & Número de salas \\
\hline 20 & Número de laboratórios do curso & Número de laboratórios \\
\hline 21 & Capacidade de ensino a distância do curso de alunos \\
\hline 22 & Número de professores & Número de docentes \\
\hline
\end{tabular}

Em especial as variáveis da Tabela 4.2 são desdobramentos do modelo mental da figura 3.10, que possibilitam identificar o ciclo produtivo da atividade principal do curso, a partir das variáveis de entrada, produção e entrega.

Com o intuito de identificar a medida de risco, bem como relacionar ajustes nas variáveis de decisão individuais com efeito coletivo, de forma que as proposições de soluções indicadas pelos agentes sejam falseáveis, é que se buscam os seguintes tratamentos de dados:

- análise de variância e covariância multivariada;

- testes de aderência a distribuições de probabilidade, para realizar análise e inferências;

- método de otimização por objetivo, com ajuste estocástico para análise de curva de eficiência entre risco e retorno;e

- otimização de alocação de recursos nos regimes de decisão cooperada e competitiva.

A agregação de conhecimento da capacidade produtiva da IES é obtida dos ciclos de planejamento, e este desdobrado até ações estratégicas dentro da realidade aproximada da IES da atividade principal de ensino.

Portanto, o sistema de apoio à decisão dispõe de um recurso autônomo que se ajusta às grandes bases de dados e por outro lado confirma seu aprendizado a partir do conhecimento de grupos de decisores.

\section{3 - DISCUSS ÃO DOS MÉTODOS}

Foram analisados métodos que possibilitam o tratamento e análise em prol da minimização de risco de forma cooperada e com o objetivo de projetar e repercutir as consequências da decisão sobre o risco de insustentabilidade. 
Nesse propósito foram utilizados os dados orçamentários de entradas e saídas de recursos de um horizonte de análise de cinco anos, originados nas atividades acadêmicas de uma organização composta por mais de 50 cursos de ensino superior, com um quadro de 1.800 docentes para atender 25.000 alunos. Seguem os métodos e a percepção adquirida pela respectiva aplicação:

- Análise envoltória de dados - apesar de não lidar com série temporal é possível utilizála como portões de portfolio de projetos. Todavia, por ela é feita análise transversal que desconsidera as peculiaridades de cada unidade acadêmica, que acaba forçando metas inatingíveis. Em vista dessa circunstância foram realizadas análise de desempenho por categorias de cursos. Essa alternativa apresentou dificuldades em repercutir resultados de uma categoria para outra, por isso dificultou o processo de análise.

- Rede neural de Elman - apresenta leitura de séries temporais, com ajuste a curvas e projeções de série para o futuro, embora não reduza a dificuldade do decisor em compreender o resultado obtido. É uma ferramenta que encapsula os pesos de entradas que podem acelerar o processo de entrega de resultado, ou mesmo interromper com resultados inconclusivos. Ao lidar com essa ferramenta surgiram fora dificuldades para realizar análise de sensibilidade, com o intuito de verificar se algumas medidas estratégicas apresentavam os efeitos desejados e o que poderia ser feito para se compreender essa dinâmica.

- HoltWinters - método utilizado amplamente no mercado financeiro pela aderência ao comportamento da curva e o poder de predição, ainda com intervalos de desvio de projeção. Embora o portfolio não seja sua especialidade, pode ser introduzido como um ativo ou projeto individual para a análise da curva de eficiência de Markowitz (1952) ou Programação estocástica por objetivos.

- Análise dinâmica de Fleuriet (2003) - oferece uma análise com detalhamento do comportamento das variáveis que formam a amplitude da variância da curva para a próxima unidade de tempo. No entanto, a análise dinâmica não lida com variáveis externas, em razão de sua especialidade em lidar com comportamento econômico financeiro de dados internos da Organização. 
- Análise da curva de eficiência de risco e retorno de Markowitz - método seminal de análise de portfolio (MARKOWITZ,1952), parte da construção de um portfolio de alternativas a partir de séries históricas disponíveis. Apesar de flexível por permitir ajustes, o método é focado na formação de carteiras de mercado financeiro, por isso gera um resultado transversal a partir de séries quantitativas possibilitando a escolha entre alternativas por análise de sensibilidade em torno de cenários externos e internos.

- Programação por objetivos (em inglês: Goal programming) - permite trabalhar com comportamentos estocásticos de séries temporais, com entrada de informações nebulosas, multi-critério. Trata-se de uma derivação do trabalho de Markowitz (1952) e Charnes et al.(1955). Para esse método ainda não foram desenvolvidos estudos aplicados, sua referência surge de pesquisas de publicações de revisão e estado da arte de Aouni (2014), sobre a evolução da proposta de Charnes et al. (1955).

- Algoritmo genético - é uma heurística que apresenta flexibilidade no processo de modelagem por ser originada de estudos de sistemas adaptativos complexos e problemas adaptativos (HOLLAND,2006), como é o processo de composição dos portfolios para seleção. Trata-se de uma alternativa de apoio a ser conjugada com a TMP de Markowitz.

O método de análise de Markowitz (1952) é escolhido como plataforma para tratamento e análise de dados, pois sua medida de risco contribui na proposição de uma referência de desempenho coletivo. Por apresentar aderência ao requisito de falseabilidade do método hipotético-dedutivo, bem como sua capacidade de absorção de informações históricas. Em suma, essa abordagem permite a integração a outros métodos de apoio, bem como a campos diferentes de atividades.

Para lidar com o contexto dinâmico de apoio a decisão é demandado o algoritmo genético, por permitir realizar ajustes individuais a cada agente, de forma a obter as combinações de ajustes que permitam avaliar qual regime de decisão a ser tomada fora do risco tolerado pelo grupo de agentes. 
Os métodos aqui utilizados para a proposição do mecanismo de apoio a decisão - TMP e Algoritmo genético - são objeto de pesquisa da Engenharia da Computação, a qual por sua vez é uma modalidade de pesquisa da Engenharia Elétrica.

Portanto, em razão dos métodos utilizados e do problema de pesquisa abordado é que se conclui que se trata de uma investigação de Engenharia Elétrica que se vale do estudo em IES como objeto de demonstração da proposta do mecanismo.

Assim, evidencia-se que os métodos e o problema tratado são próprios da Engenharia da Elétrica e a proposição do mecanismo representa a busca de resposta à pergunta científica, uma vez que as variáveis de decisão dos agentes são integradas à análise de risco de insustentabilidade coletiva. Esses mesmos agentes poderão compreender até que ponto a cooperação de ajustes de variáveis de decisão de projetos minimizam o risco de insustentabilidade do portfolio de projetos ao qual pertencem. 


\section{4 - MECANISMO DE PROGNÓSTICO E DE FATOR DE RISCO}

Uma vez que a base de referência para tomada de decisão é composta por um histórico de decisões competitivas, para dispor de alternativas de ruptura é sugerida a simulação como técnica de elaboração de cenários cooperados, no intuito de apoiar o processo decisório.

Ainda que a proposição de cenários atenda a perspectiva individual, seus efeitos podem repercutir sobre uma plataforma comum de simulação e análise. Uma vez que a ideia central da plataforma era possibilitar a coexistência de perspectivas diferentes para formação de uma decisão colegiada, a busca da abordagem para sua estruturação foi norteada pela capacidade de reajustes de parâmetros para análise de sensibilidade e da possibilidade de escolha de resultados que melhor conciliassem os interesses entre os agentes, mas sempre em vista à minimização de risco do portfolio.

Enfim, a proposta foi desenvolvida para apoiar a coalisão de perspectivas de decisão que flexibilizam o processo de tomada de decisão, uma vez que contam com variáveis de decisão que sejam capazes de explicar o desempenho individual e coletivo.

\section{1 - Introdução}

O objetivo da simulação é permitir que cada agente visualize o impacto das alternativas de cenários gerados pelos ajustes das variáveis de decisão.

A simulação é definida pela entrada de parâmetros de decisão de consumo e disponibilidade de recursos, que desencadeia a geração aleatória de resultados a partir da estrutura produtiva de cada projeto.

Os desempenhos individuais dos projetos são conduzidos para uma análise de portfolio, que vão ser comparados de forma a indicar um resultado de referência para minimizar o risco do portfolio.

A composição da estrutura do portfolio, ou mesmo a participação do projeto no consumo de recursos, é reajustada pelos agentes gestores dos projetos, até que se obtenham alternativas que sejam atraentes e que possibilitem a minimização do risco do portfolio. 


\section{2 - Identificação das informaç̃̃es do mecanismo}

A princípio o mecanismo deve ser flexível para receber parâmetros de um colegiado de tomadores de decisão com conflito de interesses. Também por isso a necessidade de realizar a análise de sensibilidades que foram convertidas para simulação.

O modelo de simulação possibilita gerar um comportamento aleatório próximo dos padrões observados no sistema.

Visto que a tomada de decisão de planejamento é colegiada e participante, o mecanismo assume o pressuposto de proposições de cenários de decisão de baixo para cima. Esse é mais um motivo para adotar-se a estrutura de projeto como anteparo das decisões dos agentes.

A percepção do modelo surge principalmente da pergunta científica, especialmente para identificar uma medida de eficiência do sistema, de forma que possa minimizar o risco. Entende-se, por assim dizer, que a abordagem da TMP tem o potencial para tornar-se um anteparo, uma plataforma, que detém uma medida reconhecida pela capacidade de selecionar opções de estruturas de desempenho ao longo do tempo.

Para integração dos projetos à entrada da TMP foi utilizada a estrutura da análise de ciclos operacionais e financeiros de Richards (1980), a fim de compreender a atividade produtiva para estrutura de série temporal para entrada no modelo de análise de eficiência da TMP.

A partir da integração do desempenho dos projetos na obtenção da eficiência do portfolio, os reajustes das variáveis de decisão podem ser realizados dentro de uma amplitude de ajustes dialogada, de forma que nessa estrutura integrada a decisão do agente é apoiada para exercer a opção por regime de decisão.

A medida de eficiência de portfolio (MARKOWITZ, 2010) é alimentada por meio do processo de otimização da equação (2.3) de forma a compor o portfolio a ser submetido ao processo de seleção por meio da equação (4.1) 


$$
e_{p}=\frac{r-t m a}{r i}
$$

onde:

e - nível de eficiência do portfolio.

p - indica qual portfolio está sendo avaliado.

r $\quad$ - retorno obtido da minimização de risco.

tma - taxa mínima de atratividade expressa a influência do setor sobre o desempenho do portfolio.

ri - é o risco do portfolio.

O nível de eficiência de cada portfolio indica sua inclinação que forma a curva de eficiência da TMP - figura 2.6 e representada pela figura 3.8. Pois quanto maior a inclinação maior a possibilidade de sua escolha. Por essa razão que ao realizar os reajustes nas variáveis dos projetos um portfolio selecionado no grupo de ajustes, no ajuste seguinte este portfolio é comparado.

A eficiência $\mathbf{e}_{\mathbf{p}}$ é obtida a partir do retorno do portfolio que congrega a ponderação dos retornos individuais dos projetos subtraída pela taxa mínima para atuação no setor de atividades produtivas, também expresso na tma, que indica desde os interesses dos agentes até mesmo o custo de oportunidade em continuar investindo neste portfolio. O resultado da subtração é dividido pelo risco ri do portfolio obtido em face a minimização da covariância ponderada das séries dos retornos dos projetos.

O somatório das covariâncias entre os desempenhos dos projetos forma o risco ri do portfolio de projetos. Ainda que o retorno $\mathbf{r}$ seja superior a tma, o risco ri sendo superior a $\mathbf{r}$ indica que a capacidade do portfolio em gerar retorno $\mathbf{r}$ é inferior ao risco que é exposto. Essa relação é uma medida de referência para insustentabilidade do portfolio de projetos. Nesse caso, os agentes envolvidos podem convencionar o limite do fator risco ri na composição da eficiência do portfolio de projetos.

A título de proposição do mecanismo de prognóstico e análise de seus resultados convenciona-se uma fronteira de risco de insustentabilidade coletiva, quando a diferença entre o retorno $\mathbf{r}$ e a tma apresenta uma relação com ri inferior a 1. 


$$
e_{p}=\frac{r-t m a}{r i}, e_{p} \begin{cases}\geq 1 & \text { sem indícios de insustentabilidade } \\ <1 & \text { com indícios de insustentabilidade }\end{cases}
$$

A proposta não busca determinar um limite geral de risco por entender que existem diferentes tolerâncias de risco entre agentes de decisão (KAHNEMAN, 1973; SIMON, 1947), bem como fatores socioeconômicos do setor de atividade que limitam a minimização de risco do portfolio (SHARPE, 1964). O processo de análise moderna de portfolio considera a participação dos retornos em relação ao risco como um critério importante na seleção de portfolio eficiente (MARKOWITZ,1952). Nesse caso são considerados resultados superiores os que apresentam participação de retornos maior relativamente ao risco - equação (4.2).

Portanto, a minimização do risco de insustentabilidade coletiva é verificada na eficiência de portfolio, de forma que quanto maior que 1 também será maior a capacidade do portfolio de projetos em atender a taxa mínima de atratividade e bem enfrentar o risco associado às atividades do portfolio - equação (4.2).

\subsection{1 - Processo para obter as variáveis de decisão.}

As perspectivas do agente de decisão são importantes na composição do portfolio porque por elas são definidas as amplitudes de ajustes de projetos, que vão permitir a composição de portfolios e, por fim, realizar as análises de eficiência para decisão de planejamento. Por conseguinte, essas perspectivas são incluídas na plataforma de análise de eficiência da TMP, podendo realizar análises de desempenho individual e coletivo, figura 4.11.

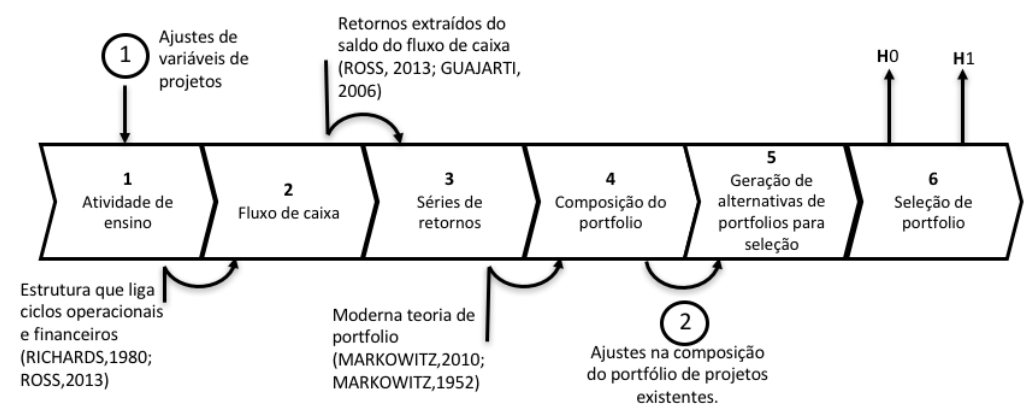

Figura 4.11: Processo de ajuste do projeto à seleção de portfolio. 
Os ajustes - (1) da figura 4.11 - têm o propósito de adequar o desempenho do projeto já existente - (2) da figura 4.11, de forma que indiretamente impactem em sua participação e na eficiência do portfolio.

Foram obtidas categorias dos fluxos de caixa a partir do levantamento das rubricas orçamentárias realizadas nos períodos de 2006 a 2016.

Para compreender as entradas da operação com efeito no caixa são relacionadas quatro contas principais da IES - figura 4.12.

\begin{tabular}{l|r}
\hline Receitas escolares & $94,95 \%$ \\
\hline Taxas emolumentos & $1,15 \%$ । \\
\hline Convênios & $0,86 \%$ । \\
\hline Receitas diversas & $\mathbf{3 , 0 4 \%}$ \\
\hline \multicolumn{1}{|c|}{ Total } & $\mathbf{1 0 0 \%}$
\end{tabular}

Figura 4.12: As principais categorias de entradas de fluxo de caixa

Já nas contas de saídas foram identificadas onze contas, como: pessoal e encargos, contas de manutenção e contas de funcionamento da atividade de ensino, como despesas - figura 4.13 .

\begin{tabular}{l|r}
\hline Pessoal e encargos & $63,76 \%$ \\
\hline Material de consumo & $2,82 \%$ \\
\hline Serviços de terceiros & $13,34 \%$ \\
\hline Encargos e/ou despesas financeiras & $0,62 \%$ \\
\hline Despesas com Fornecimento de Água e Esgoto & $0,33 \%$ \\
\hline Despesas com Fornecimento de Energia Elétrica & $0,97 \%$ \\
\hline Despesas com Serviços de Telecomunicações & $0,16 \%$ \\
\hline Despesas com Serviços de Correios e Telégrafos & $0,16 \%$ \\
\hline Investimentos e material permanente & $1,55 \%$ \\
\hline Amortização de Financiamentos - Médio/ Curto & $2,30 \%$ \\
\hline Reservas Técnicas & $13,99 \%$ \\
\hline
\end{tabular}

Figura 4.13: As principais categorias de saídas do fluxo de caixa.

O conjunto das principais receitas da IES é composto por mensalidades escolares, que representam 94,95\% do volume operacional bruto.

A atividade produtiva acontece nas turmas, onde os alunos pagam as mensalidades referentes às disciplinas dos cursos. Cada aluno pode estar em uma ou mais turmas e cada turma consome a disponibilidade de espaço físico e horas de docentes para realizar as disciplinas oferecidas nos cursos. Esses recursos são responsáveis por mais de $78 \%$ das despesas operacionais. 
As principais despesas são, figura 4.13: as contas despesa de pessoal e encargos 63,76\%, Material de consumo 2,82\%, Serviços de terceiros 13,34\%, Amortização de financiamentos $2,30 \%$ e Reserva técnica $13,99 \%$, que estão em torno de $75 \%$ da receita operacional mensal da IES.

Em síntese, a análise das receitas e despesas estão associadas às receitas escolares, despesas com pessoal, material pedagógico e disponibilidade financeira para contingências. Essas categorias presentes no ciclo operacional e financeiro são candidatas a impactar a eficiência do portfolio. Assim, ao invés de ajustar diretamente os pesos de participação dos projetos, os ajustes serão realizados a partir das variáveis dos projetos, para obter de forma indireta a participação na estrutura do portfolio.

Depois da verificação de algumas categorias orçamentárias e registros documentais de projeto pedagógico de curso, plano de gestão participativa e plano de desenvolvimento institucional, elabora-se um esquema conceitual da dinâmica da atividade produtiva do curso.

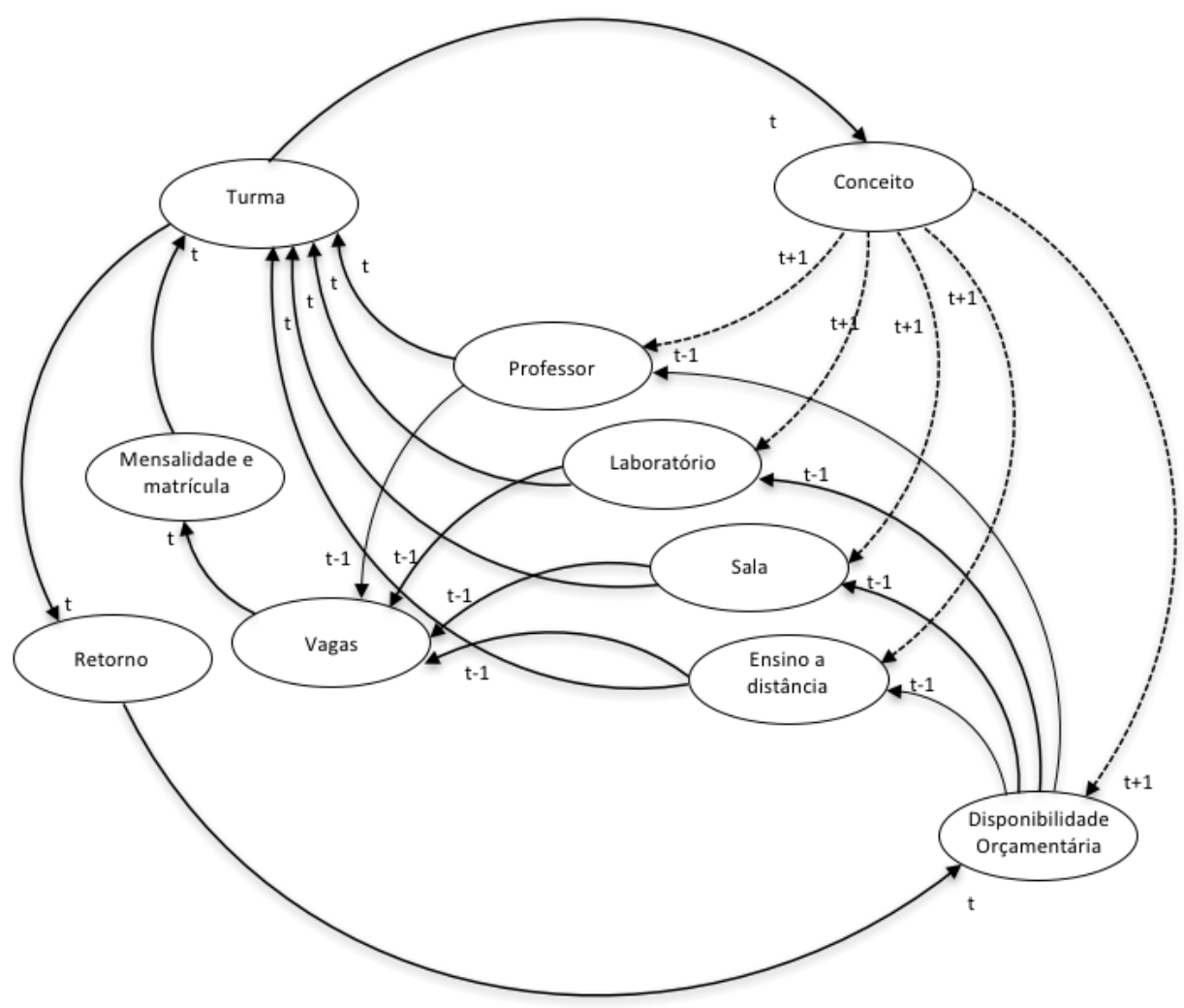

Figura 4.14: Esquema conceitual da dinâmica operacional da atividade de ensino. 
O esquema conceitual da atividade de ensino - figura 4.14 - é obtido a partir dos documentos de projetos pedagógicos dos cursos e de entrevistas com as equipes de programação acadêmica, avaliação institucional e divisão de contabilidade e finanças, os quais foram organizados sob o quadro de observação de ciclos operacionais e financeiros da atividade principal (Richards \& Laughlin, 1980; ROSS, S.; WESTERFIELD, R.; JEFFREY, 2013; Slack et al., 2011).

\subsection{2 - Processo para obter as séries temporais dos projetos.}

Normalmente é utilizada a análise de prazos médios para verificar a capacidade do capital de giro em gerar liquidez. Contudo, aqui seu propósito é ampliado, uma vez que sua estrutura já está integrada na atividade produtiva e assim se propõe o resgate dessa integração de forma a acessar as variáveis de decisões nela associadas - figura 4.15.

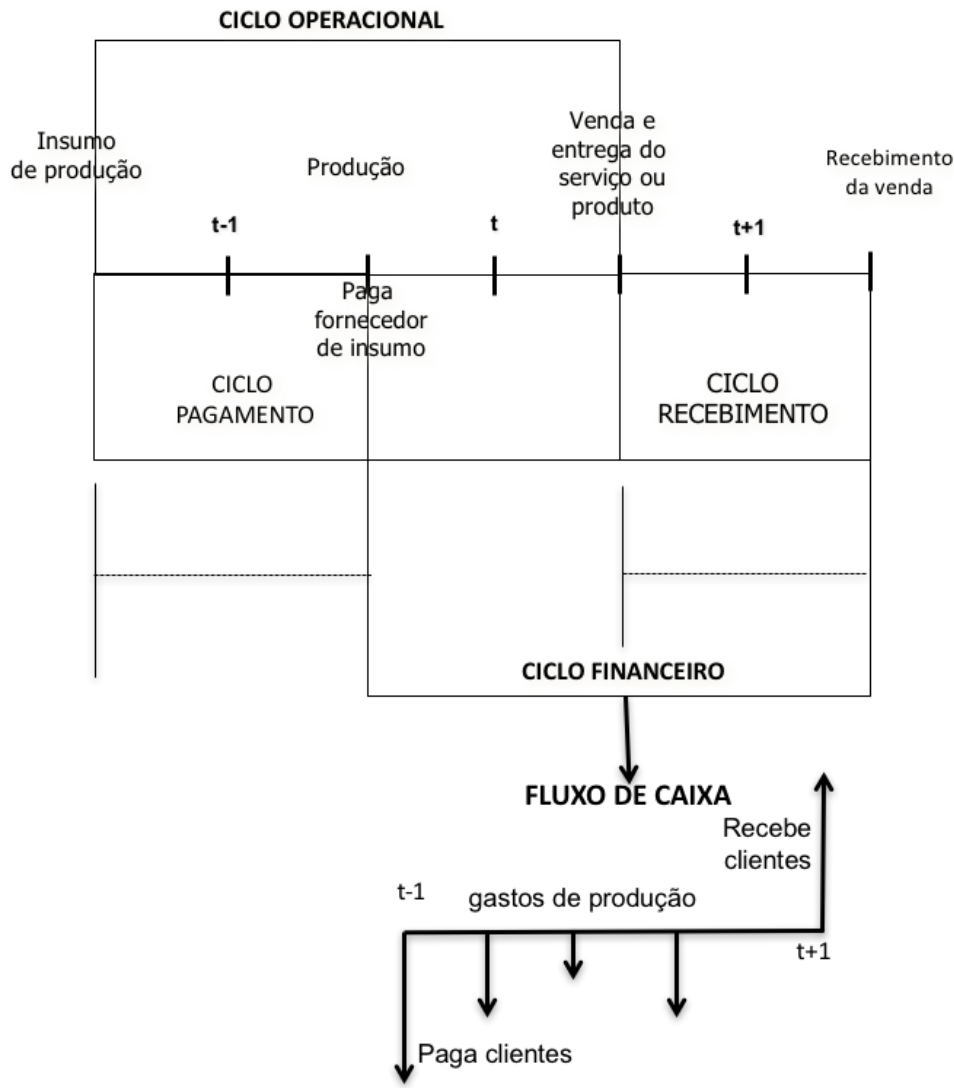

Figura 4.15: Relação do ciclo operacional com o financeiro - adaptação pelo autor de Richards(1980) em Ross (2013). 
Com o modelo conceitual obtido sob a perspectiva do quadro de observação (RICHARDS \& LAUGHLIN, 1980; ROSS, S.; WESTERFIELD, R.; JEFFREY, 2013; SLACK ET AL., 2011) foi possível a priori identificar os principais componentes de consumo de disponibilidade orçamentária, que são: docente, espaço e vaga - figura 4.16.

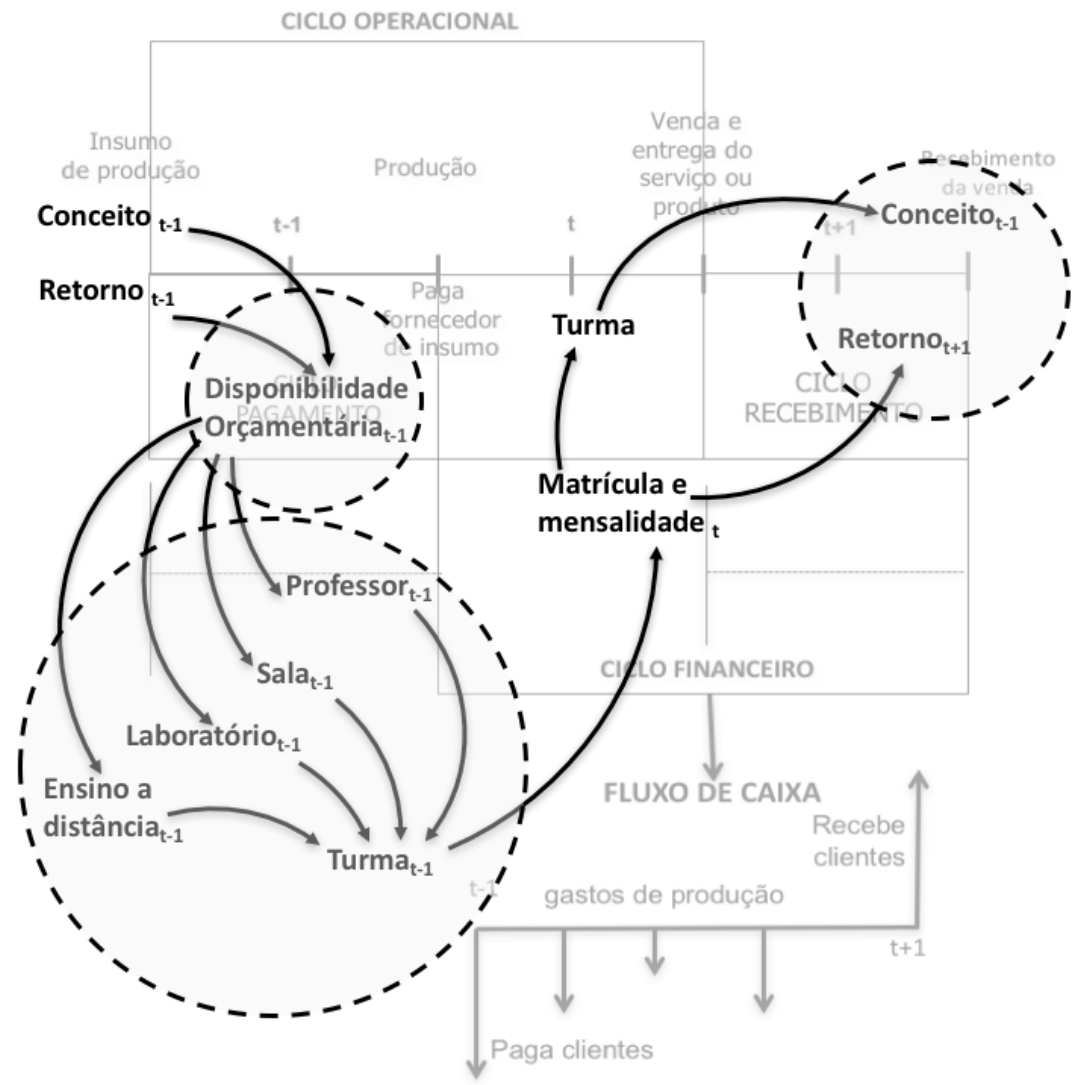

Figura 4.16: Variáveis de decisão do projeto.

As séries de retornos dos projetos são obtidas a partir da relação dos ciclos operacionais e produtivos, que desencadeiam no saldo de caixa descontado e a partir de então são extraídos os retornos contínuos, de forma a compor a série para ser utilizada como insumo à análise da TMP (H. MARKOWITZ, 1952; H. M. MARKOWITZ, 2010). Antes disso são realizados testes de normalidade e de correlação negativa do comportamento das séries que, respectivamente indicam se a análise de eficiência da TMP pode ser utilizada no portfolio e o potencial de diversificação do portfolio, figura 4.16 (MANGRAM,2013; MARKOWITZ,2010; 1952; SHARPE,1964).

4.2.3 - Relação das variáveis de decisão na minimização do risco. 
O conjunto de informações coletadas nos documentos da IES e seus cursos, sob a perspectiva de um modelo de produção e a análise de ciclos operacional e financeiro à concepção do modelo de projeto de curso vão gerar as séries de retornos que vão ser utilizadas na análise TMP para realizar a análise de eficiência do portfolio, a fim de obter dele a maior eficiência. Portanto, os ajustes das variáveis dos projetos repercutem na maior ou menor eficiência do portfolio.
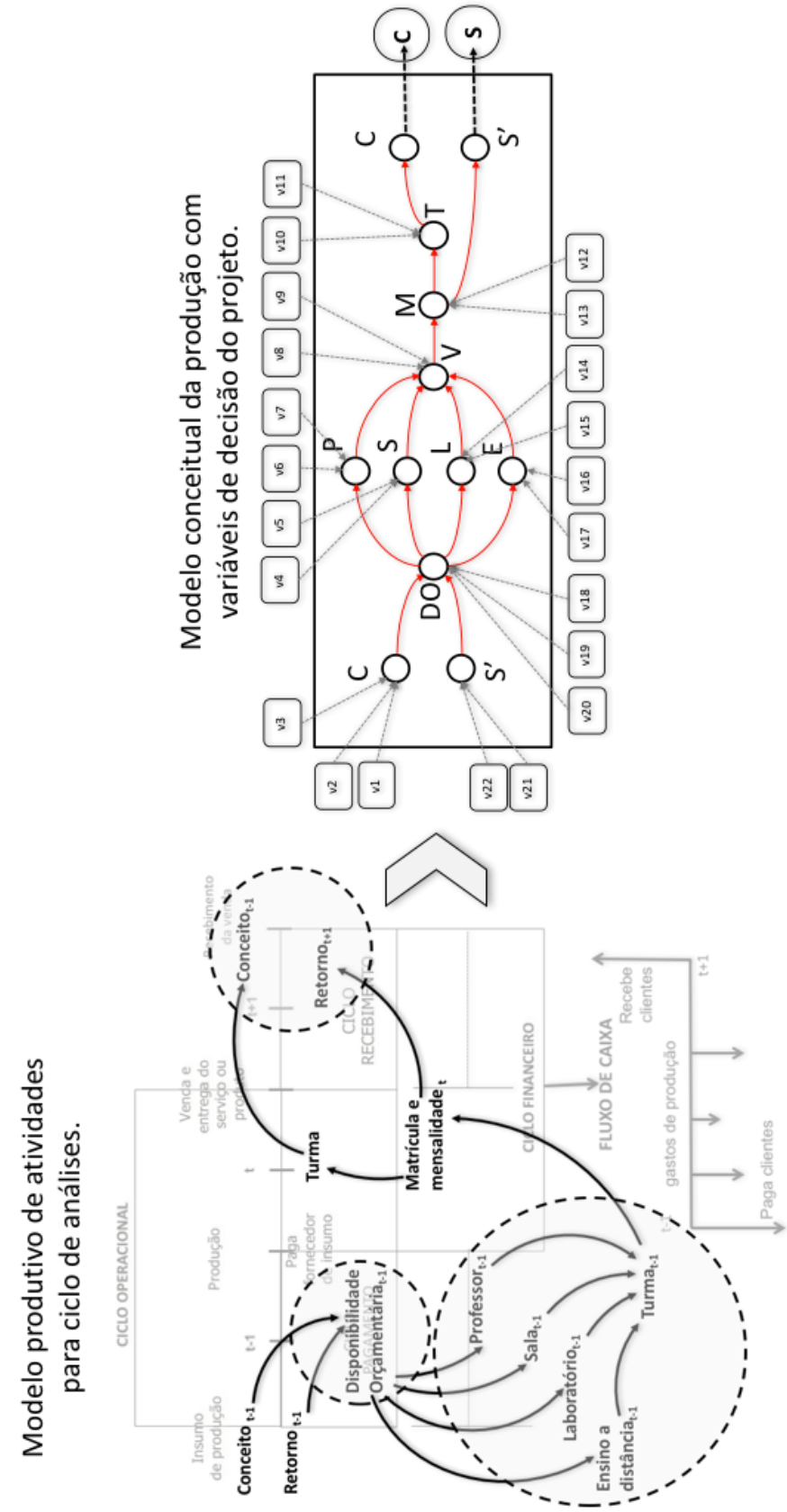

Figura 4.17: Modelo conceitual da atividade de ensino do curso.

$\mathrm{Na}$ figura 4.17 é ilustrado o caminho utilizado para obter o modelo conceitual da atividade de ensino do curso, obtendo assim suas variáveis de decisões. Esse caminho foi inspirado 
no modelo básico de produção (SLACK et al., 2011) - entrada, processamento e saída integrado na estrutura de análise de ciclos (RICHARDS \& LAUGHLIN, 1980; ROSS, S.; WESTERFIELD, R.; JEFFREY, 2013).

De posse das variáveis foram elaborados testes para verificação de significância das variáveis de decisões identificadas na atividade produtiva do curso, com efeito na relação risco e retorno do portfolio.

Para empreender as verificações supracitadas, as seguintes hipóteses foram propostas:

- H0 - Existe impacto na relação entre retorno e risco do portfolio ao se provocar ajustes nas variáveis de decisão de seus projetos.

- H1 - O ajuste na variável de decisão do projeto provoca uma alteração radical na participação de um projeto, entre diferentes portfolios selecionados.

Para realização da simulação foi estabelecido que o portfolio selecionado inicialmente seria a referência para os ajustes futuros no próprio portfolio. Isto posto, as verificações ulteriores das hipóteses H0 e H1 serão passíveis de falseabilidade (POOPER, 2002).

A medida adotada para promover o teste de H0 é a relação entre retorno e risco. Caso a razão entre retorno e risco no instante t pela razão retorno e risco no instante t-1 seja 1 , sugere-se a rejeição de impacto dos ajustes nas variáveis de decisão do projeto - equação (4.3).

$$
k_{t}=\left(\frac{r_{t}}{\sigma_{t}}\right) /\left(\frac{r_{t-1}}{\sigma_{t-1}}\right), k_{t}= \begin{cases}=1, & H_{0}=\text { tem evidencias para rejeitar } \\ >1, & H_{0}=n a \tilde{a} \text { tem evidencias para rejeitar } \\ <1, & H_{0}=n \tilde{a} \text { tem evidencias para rejeitar }\end{cases}
$$

onde:

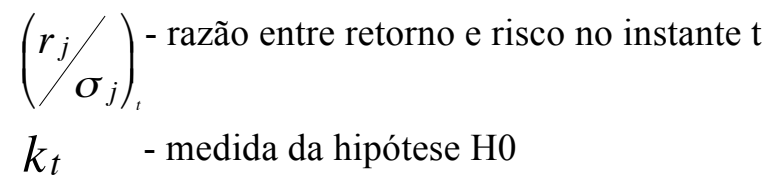

No teste de H1 é verificada a qualidade do impacto percebido em H0, de modo a verificar se a decisão contribui para a alteração da participação $\mathrm{w}$ de um projeto $\mathrm{j}$ no instante $t$ em função da participação desse mesmo projeto j no portfolio em outro instante t-1. 
Os resultados ótimos obtidos a partir dos sucessivos ajustes das variáveis de decisão, registram as participações dos projetos no portfolio. Ao considerar um portfolio referência em t-1, calcula-se a razão da participação $\mathrm{w}$ de um projeto $\mathrm{j}$ em $\mathrm{t}$, pela participação desse mesmo projeto $\mathrm{j}$ no instante $\mathrm{t}-1$. Se o resultado for negativo, significa que houve alteração para uma decisão diferente daquela obtida no instante t-1 - equação (4.4).

$$
y_{t}=w_{j_{1}} / w_{j_{t-1}}, y_{t}= \begin{cases}\geq 0, & H_{1}=\quad \text { tem evidencias para rejeitar } \\ <0, & H_{1}=n a \tilde{o} \text { tem evidencias para rejeitar }\end{cases}
$$

onde:

$w_{j_{t}}$ - é o peso no instante $t$ de um projeto $j$

$y_{t} \quad$ - medida da hipótese H1.

A partir dessas hipóteses são realizados testes de capacidade das variáveis de decisão para realmente impactar na minimização do risco do portfolio.

\section{3 - O mecanismo e sua a aplicação.}

A identificar o comportamento adaptativo foi adotado o método heurísco algoritmo genético para lidar com o problema adaptativo complexo, conforme argumento de (4.5). Uma vez que Holland (2006) tenha focado no estudo de sistemas adaptativo complexo resultou na geração do método heurístico algoritmo genético - GA, em especial para lidar com problemas adaptativos complexos.

A busca por maximizar a função objetiva (4.1) por meio da minimização da equação (2.3) com a escalar $\mathrm{f}: \mathrm{S} \rightarrow \mathrm{R}$ pode ser formalmente representada como encontrar o conjunto (SCRUCCA,2013).

$$
\Theta^{*} \equiv \arg \max \theta \in \mathrm{f}(\theta)=\left\{\theta^{*} \in \Theta: \mathrm{f}\left(\theta^{*}\right) \geq \mathrm{f}(\theta), \forall \theta \in \Theta\right\},(1)
$$

onde $\Theta \subseteq \mathrm{S}$. O conjunto $\mathrm{S} \subseteq \mathrm{R}$ define o espaço de busca, isto é, o domínio dos parâmetros $\theta=(\theta 1, \ldots, \theta p)$, em que cada $\theta \mathrm{i}$ varia entre os limites inferiores e superiores correspondentes. $\mathrm{O}$ conjunto $\Theta$ indica o espaço de busca viável, que pode ser definido como a interseção de $\mathrm{S}$ e um conjunto de $\mathrm{m} \geq 0$ restrições adicionais: 


$$
\text { gj }(\theta) \leq 0 \text { para } j=1, \ldots, q, \operatorname{hj}(\theta)=0 \text { para } j=q+1, \ldots, m \text {. }
$$

O conjunto de soluções $\Theta^{*}$ em (1) pode ser um ponto único, ou uma coleção de pontos. Cada $\Theta$ ao representar o portfolio, e sua seleção é obtida para indicar o conjunto de soluções $\Theta^{*}$.

A equação (4.1) de eficiência é parametrizada por meio de ajustes nas variáveis de decisão dos projetos que compõem o portfolio, pois os ajustes sugeridos pelo GA vão obedecer a amplitude de recursos informada pelos próprios agentes, de forma a atender seu propósito em maximizar a eficiência do portfolio.

O modelo de simulação foi estruturado para realizar os ajustes diretos nas variáveis de decisão e assim obter os resultados de impacto na eficiência do portfolio. No entanto, ao desenvolver as rodadas de ajustes foram encontrados desafios de natureza adaptativa complexa (HOLLAND, 2006), onde os ajustes realizados para melhorar o desempenho de um projeto pioravam o de outro. Por esse motivo foi incluído à estrutura de simulação o algoritmo genético (HOLLAND, 2006), para lidar com problemas de natureza adaptativa complexa.

As amplitudes de ajustes das variáveis de decisão dos projetos passam a ser o alvo de discussão entre os agentes, uma vez que o simulador adaptativo gera os cenários de dentro da amplitude de ajustes definidos pelos agentes de decisões. Embora o simulador possa ser usado sem o algoritmo genético para encontrar a melhor combinação das variáveis dos projetos, o problema desse movimento é a qualidade dos resultados, em razão das diversas combinações que podem ser realizadas que sugerem resultados superiores.

\subsection{1 - O mecanismo.}

Dentro do já exposto, o processo de simulação foi estruturado para considerar quais variáveis de decisão vão ser ajustadas, o número de projetos, a disponibilidade de recursos, os custos de decisões e dentro de qual amplitude podem ser realizados os ajustes. 
A cada ajuste realizado é gerada uma análise de eficiência de portfolio, de forma que a busca pela combinação de ajustes para gerar o resultado é obtida pela comparação com as curvas de eficiência já encontradas.

$\mathrm{Na}$ figura 4.18 o algoritmo genético tem seus cromossomos compostos por genes, onde o gene corresponde ao projeto, composto por todas as variáveis de decisão. Assim, cada ajuste na variável de decisão gera uma simulação de atividades produtivas de todos os projetos, de forma a gerar uma curva de eficiência do portfolio. Em cada interação são realizados ajustes aleatórios e identificada o indivíduo com a melhor eficiência, ou inclinação - equação (4.1), até completar o limite de interações a serem realizadas. Posteriormente esses resultados de eficiência de portfolio obtidos são comparados de forma a identificar o conjunto de ajustes realizados nas variáveis de decisão de cada projeto responsáveis por tal desempenho.

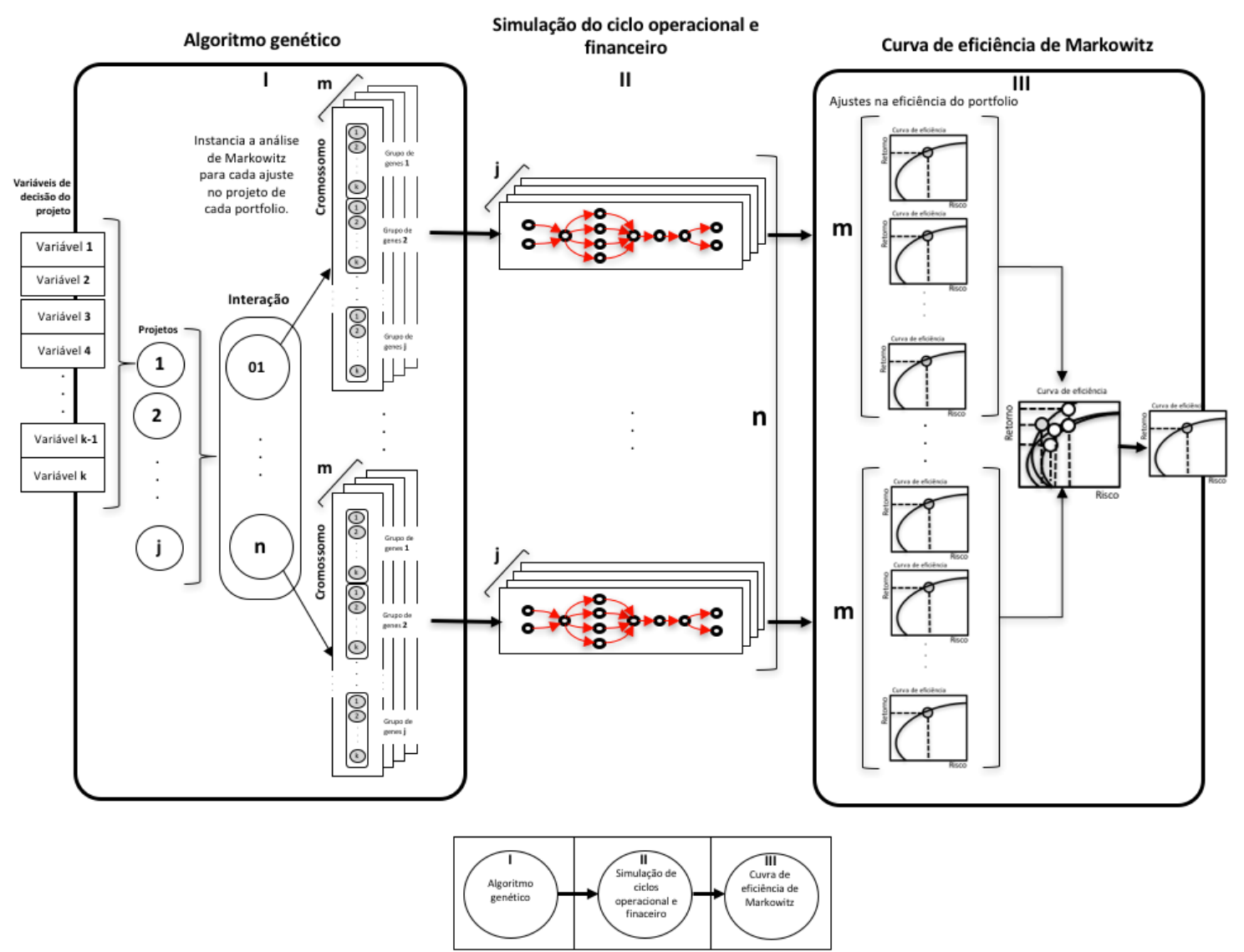

Figura 4.18- Modelo conceitual do processo de simulação. 
As três etapas utilizadas no processo de simulação para apoio a tomada de decisão permitiram organizar o processo de implementação do algoritmo de simulação.

Para discutir a estrutura de implementação foi estipulado o início da implementação a partir da etapa II da figura 4.18, que trata a simulação de ciclos operacional e financeiro dos $\boldsymbol{j}$ projetos nas $\boldsymbol{n}$ interações indicadas na etapa I, pois assim indica o caminho de desenvolvimento a partir da compreensão da geração da curva de eficiência da TMP e a aplicação do algoritmo genético.

A etapa III corresponde às $\boldsymbol{m}$ análises de eficiência do portfolio, conforme o número de ajustes que perfazem o limite de indivíduos em cada interação $\boldsymbol{j}$. A partir desses resultados na etapa I, no algoritmo genético é proposto reajuste nas $\boldsymbol{k}$ variáveis de decisão dos $\boldsymbol{j}$ projetos, que estrutura os seus cromossomos pela sequência de seus genes, no caso das variáveis de decisão. Em razão do conhecimento do número de variáveis de projetos são identificados os grupos de genes que correspondem a cada um desses - figura 4.18.

No modelo idealizado foi obtida uma amostra de dez projetos de curso com 22 variáveis cada. Nesse caso, na formação dos cromossomos levou-se em consideração a composição do portfolio. Por isso, cada cromossomo contem todos os projetos com suas variáveis de decisão a serem ajustadas. Assim, o cromossomo, que é o portfolio com dez projetos, com 22 variáveis cada, de forma que o cromossomo terá 220 genes.

\subsection{2 - As etapas de aplicação do mecanismo.}

O processo de experimentação foi realizado de forma aleatória por simulação, uma vez que era desconhecido o comportamento dos dados tratados, principalmente após a construção do modelo de simulação.

Os registros de tomada de decisões e de séries históricas foram obtidos para formação da estrutura dos ciclos operacionais e financeiros que compõem a atividade de ensino do curso. Os agentes utilizam estruturas de interface que permitem parametrizar as simulações - são ilustradas nas figuras 4.19 e 4.20 . 


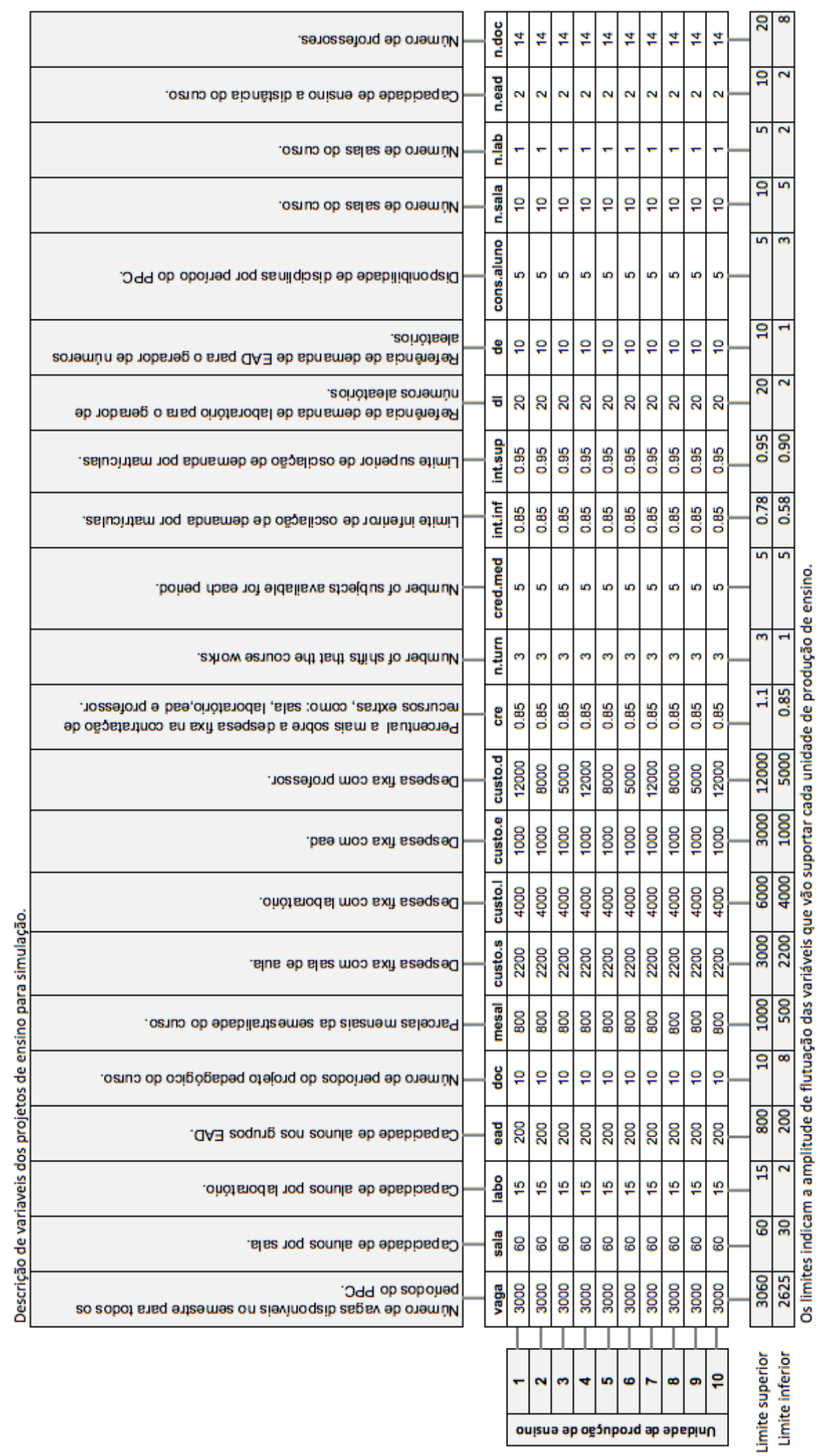

Figura 4.19 - Entrada de dados para simulação dos ciclos operacionais e financeiro. 
A matriz de entrada da figura 4.19 parametriza as entradas necessárias para a geração de números aleatórios para simulação dos ciclos operacionais e financeiros, os quais vão subsidiar o portfolio para análise de eficiência.

Na matriz da figura 4.20 são indicadas as amplitudes de ajustes de cada variável para cada projeto. A amplitude de ajustes é o ponto de conflito entre os agentes, pois ela define o consumo de recursos. 


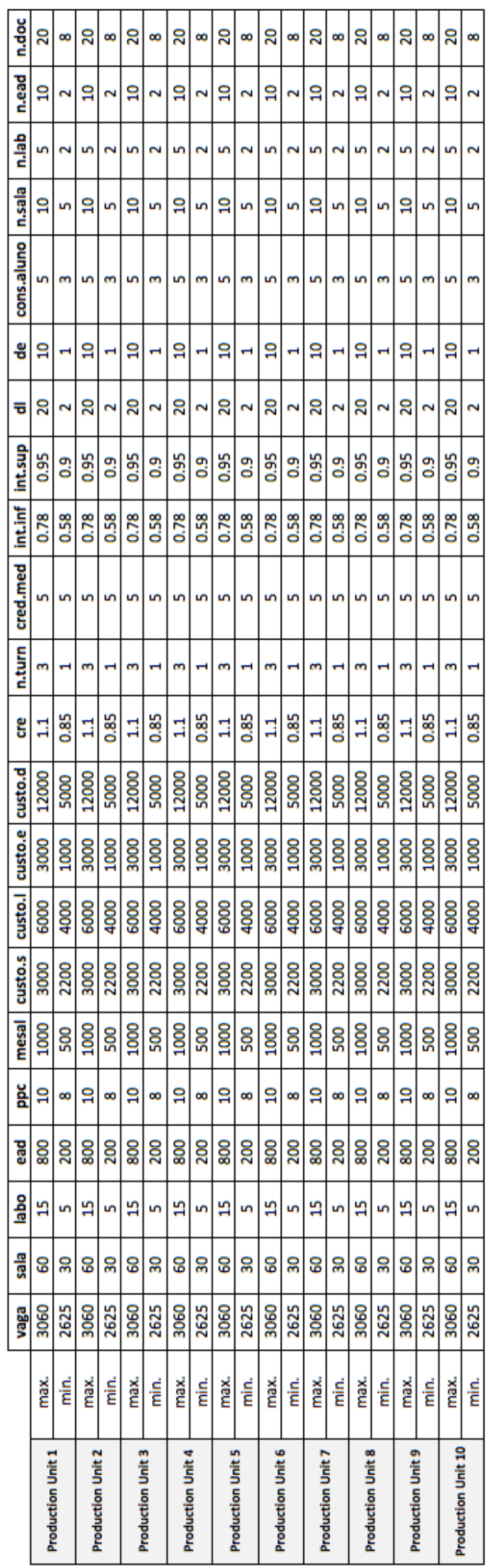

Figura 4.20 - Entrada da amplitude de ajustes de cada variável em cada projeto. 
O processo de busca de informações de regras de negócio baseou-se nos documentos institucionais que indicam as decisões da IES (pelo Plano de Desenvolvimento Institucional) e de seus cursos (Projeto Pedagógico do Curso). Em conjunto com as séries observadas para compreensão da dinâmica dos projetos foram agrupados esses achados, de forma que pudessem compor uma plataforma de apoio a tomada de decisão de planejamento colegiado, em razão da perspectiva de projeção da decisão coletiva. $\mathrm{O}$ propósito foi trazer a essa plataforma as limitações de recursos que afligem a atividade principal já no ato de planejamento.

O experimento é realizado a partir da parametrização da amplitude das variáveis de decisão de cada projeto. O fluxo de simulações é indicado na figura 4.21.

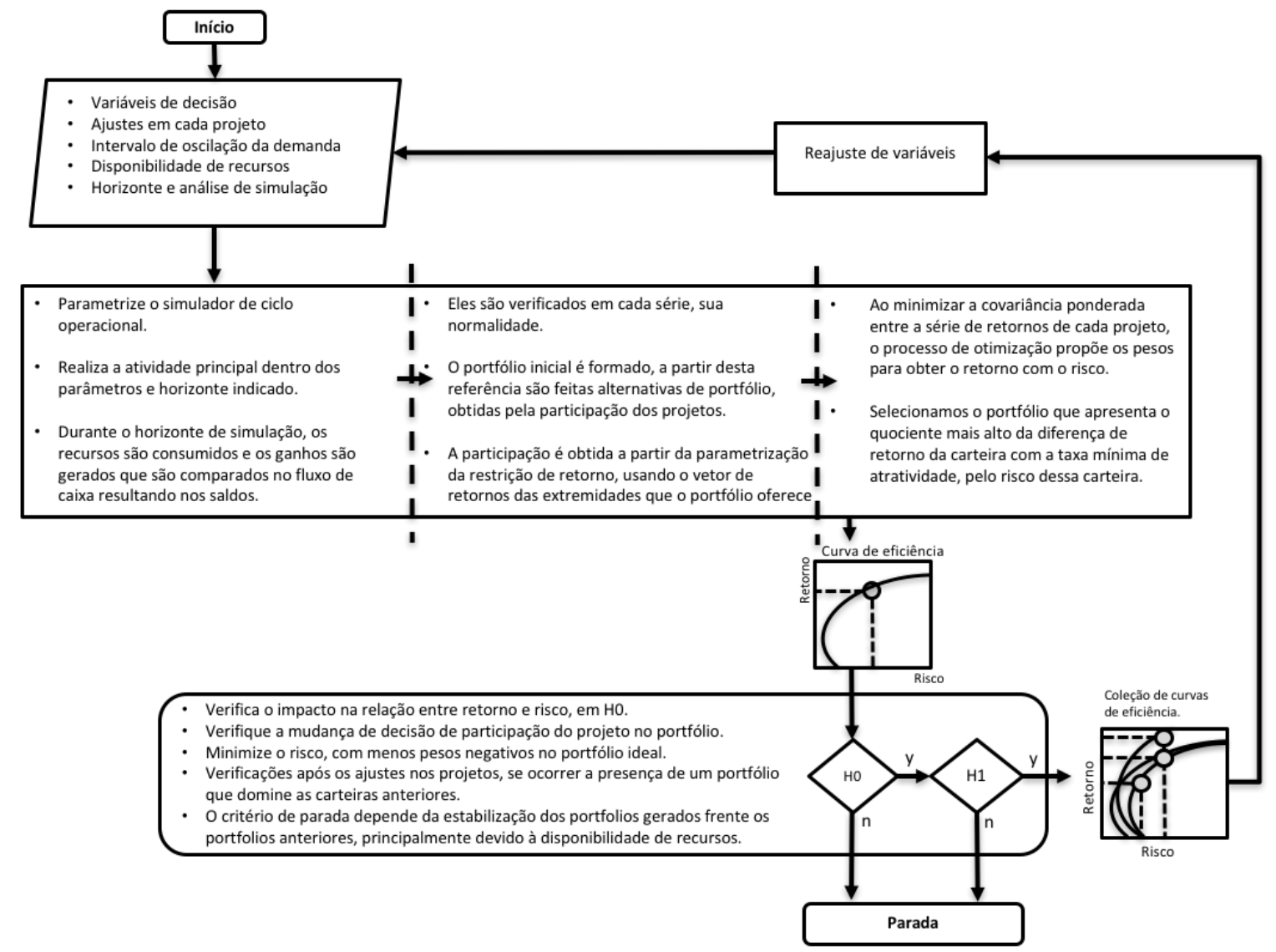

Figura 4.21 - Diagrama do processo experimental.

Quanto aos desafios relevantes ao processo de desenvolvimento e aplicação dos experimentos simulados, destacam-se: 
a. Conflito para permanência dos projetos no portfolio, no instante em que se reajustam as variáveis de decisão dos projetos, pois a limitação dos recursos acaba repercutindo na permanência do projeto no portfolio, de forma que resultado individual tenha repercussão no resultado coletivo, mas isso principalmente focando a minimização do risco de insustentabilidade.

b. Replicação de amostras pela simulação a partir da segurança de encontrar aderência do comportamento das séries reais com alguma distribuição conhecida. Por isso é preciso identificar o número de amostras aleatórias para se obterem representações de séries para análise (CWHIF e MEDINA,2015).

$$
n=\left[\frac{Z_{c} \times S(x)}{\varepsilon}\right]
$$

Subtítulo:

$n \quad$ - o número de amostras de simulações a serem realizadas.

$\mathrm{z}_{\mathrm{c}}$ - valor associado ao intervalo de confiança desejado.

$\varepsilon-$ desvio estimado.

$S(x)$ - desvio padrão da população.

c. Comportamento normal para análise de eficiência - a abordagem da TMP utiliza a distribuição normal como referência para compreensão de risco e retorno esperado. Essa foi uma etapa importante, pois lidar com distribuição não normal é um desafio fora do escopo investigado. No entanto, as séries apresentaram comportamento normal.

d. Correlação negativa no composto do portfolio - a correlação é um indicador importante para diversificação de risco. No entanto, ao compreendê-la no contexto corporativo e dentro dos sucessivos processos de diversificação, a correlação deixa de ser uma restrição para tornar-se referência de apoio a decisão.

e. Encontro com o comportamento adaptativo complexo, ao relacionar as intervenções dos agentes humanos sem apoio ao processo de decisão, mesmo que os agentes indiquem cenários de ajustes para otimização de seus interesses individuais. Projetos que na composição do portfolio foram considerados desejados para otimização da eficiência do portfolio, em um segundo momento passam a ser indesejados. 
f. O número de variáveis de decisão com a necessidade de replicações das amostras dificultou o detalhamento da atividade produtiva para simulação, uma vez que foi utilizada a combinação de método tradicional de otimização não linear multiobjectivo validando os ajustes propostos pelo algoritmo genético. O escopo da investigação se aproximou da necessidade de se desenvolverem estudos de desempenho de algoritmos que possam apoiar simulações de problemas com grande número de variáveis de decisões. Caso contrário, o uso da proposta como apoio a sistemas com número maior de projetos e de variáveis se torna ineficaz para atendimento imediato à decisão.

Enfim, durante o processo de desenvolvimento e de testes realizados foram obtidos resultados que possibilitam o mecanismo apoiar tanto os resultados individuais do projeto como os do portfolio e ainda assim disponibilizar parâmetros que podem subsidiar a integração de métodos de análise multicritério de auxílio na definição das amplitudes de ajustes das variáveis de decisão. Também o mecanismo apresentou desempenho satisfatório nos ajustes realizados pelo algoritmo genético, pois diferentemente da forma manual de ajustes, foram encontradas combinações de ajustes que levaram a identificação de portfolios com risco de insustentabilidade minimizados além da expectativa indicada na seção 4.2. No entanto, verificou-se que o mecanismo disponibiliza amplos registros de ajustes com desempenho com risco minimizado, que proporcionam referências de ajustes manuais apoiando participações emancipatórias de agentes em grupos de decisões colegiadas. Muito embora a participação emancipatória dos agentes de decisão seja o modelo de gestão a ser contemplado no mecanismo, ainda assim nenhuma restrição foi desenvolvida para impedir o apoio ao processo decisório com ajustes de decisão autocrática. 


\section{5 - RESULTADOS E DISCUSSÃO}

O processo de geração de resultados tem o intuito de investigar as seguintes questões:

- o desempenho e as contribuições do mecanismo de prognóstico como apoio à decisão multicritério para grupos de agentes competitivos em prol da minimização de risco de insustentabilidade coletiva; e

- se a decisão cooperada ou competitiva apresenta algum ganho de eficiência de forma a impactar na minimização de risco de insustentabilidade.

Com esse propósito foram obtidos 10 projetos de cursos para gerar os resultados mediante os parâmetros de amplitude de ajustes de cada uma das 22 variáveis de cada projeto.

Os resultados são oriundos de ajustes iniciais para verificar a interconexão das variáveis dos projetos na eficiência do portfolio e outras 2000 amostras de forma aleatória, considerando os intervalos de simulação para cada projeto que compõe o portfolio.

A partir dos projetos tem-se as variáveis de decisão para cumprir as metas de desempenho indicadas pelo VPL e o Conceito de cada projeto. Também são pelas variáveis de decisão que as composições dos portfolios vão afetar na formação da curva de eficiência. Para atender as perspectivas de consumo e disponibilidade de recursos dos agentes são realizados ajustes por meio dessas variáveis, dentro de uma amplitude pré-definida de ajustes para então realizar as simulações.

Os resultados são compreendidos em duas etapas, a primeira de desempenho individual de cada projeto e a segunda de análise de resultados com impacto na coletividade. Assim, verifica-se o impacto das decisões sobre os demais projetos e também é verificado qual portfolio apresentou a melhor composição de resultados.

\section{1 - OS RESULTADOS PRODUZIDOS}

Foram obtidas duas etapas de resultados, a primeira etapa compreende resultados com ajustes manuais nas variáveis de decisão e visa compreender a repercussão dos ajustes das variáveis de decisão na composição do portfolio, bem como verificar a minimização de 
risco do portfolio.

$\mathrm{Na}$ segunda etapa são obtidos resultados com ajustes automatizados nas variáveis de decisão dos projetos. Nessa etapa são realizadas sucessivas combinações de ajustes nas variáveis de decisão dos projetos, mas esses ajustes são realizados dentro de amplitudes pré-definidas nas matrizes de entrada para simulação, conforme figuras 4.19 e 4.20.

5.1.1 - Resultado de testes de ajustes no projeto sobre a eficiência do portfolio.

Ao proceder com alimentação do mecanismo é encontrado o portfolio ótimo e assim sucessivamente, até se obter uma relação de registros que seja satisfatória à análise.

Para a relação de resultados relacionados a seus respectivos ajustes nas variáveis de cada projeto, se procede a análise das hipóteses H0 e H1 - subseção 4.2.2 - no intuito de identificar alguma melhora e sua qualidade de impacto na eficiência do portfolio.

A hipótese $\mathrm{H} 0$ possibilita a verificação de impacto na eficiência do portfolio selecionado com o ajuste proposto. Já na hipótese H1 é verificado se o ajuste contribui para alterar a participação do projeto no portfolio.

A tabela 5.3 indica as variáveis de decisão que foram ajustadas e essa relação possibilita verificar seu impacto na formação da eficiência de portfolio.

Tabela 5.3 - Teste de impacto de H0 na eficiência do portfolio.

\begin{tabular}{|c|c|c|c|c|c|}
\hline variável de decisão & cenário & retorno & risco & Ho & r-reajuste \\
\hline- & 0 & 0,04934 & 0,89079 & - & $5,54 \%$ \\
\hline média salarial & 1 & 0,04940 & 0,88596 & 1,0067 & $5,58 \%$ \\
\hline número de vagas por sala & 2 & 0,04933 & 0,89249 & 0,9914 & $5,53 \%$ \\
\hline valor da mensalidade & 3 & 0,04935 & 0,92631 & 0,9639 & $5,33 \%$ \\
\hline número de turnos & 4 & 0,05031 & 0,98877 & 0,9549 & $5,09 \%$ \\
\hline $10 \%$ de intervalo de demanda & 5 & 0,05026 & 0,93036 & 1,0619 & $5,40 \%$ \\
\hline $20 \%$ de intervalo de demanda & 6 & 0,05020 & 0,91576 & 1,0147 & $5,48 \%$ \\
\hline $30 \%$ de intervalo de demanda & 7 & 0,04996 & 0,99069 & 0,9199 & $5,04 \%$ \\
\hline
\end{tabular}

Na tabela 5.3 a razão entre retorno e risco em cada cenário, de 0 a 7, apresenta relações do retorno com o risco vinculadas às colunas das variáveis de decisão do projeto que foram ajustadas. 
Apesar de o quociente apresentado indicar uma desproporção de $88 \%$ a $99 \%$ de risco, enquanto o retorno está em torno de $5 \%$, ainda assim foi possível perceber a sensibilidade do impacto das variáveis sobre sua relação - coluna H0 na tabela 5.3.

Ao observar o maior retorno e menor risco no portfolio encontra-se o retorno do cenário 4: 0,05031. Já o menor risco obtido está no cenário 1: 0,88596.

No entanto, o foco está nos retornos e riscos obtidos a partir da estrutura de pesos destinados para os projetos. O cenário 1 indica a melhor relação entre retorno e risco, com a taxa 5,58\% de retorno em relação ao risco.

Os ajustes das variáveis de decisão ofereceram uma estrutura de portfolio com uma razão dos retornos dos cenários 1 pelo 0 e resultaram em uma taxa de $0,125 \%$. Já a razão dos ricos dos cenários 1 pelo 0 resulta em uma taxa de $11,604 \%$, o que indica que o retorno aumentou e o risco reduziu do cenário 0 para o 1.

Ao aplicar a equação 4.3 foram obtidas as respostas na coluna H0, onde os cenários 1,5 e 6 registraram aumento na eficiência de seus portfolios, considerando um desvio 0,05 para ganho de eficiência e ainda assim o cenário 5 atende esse requisito. Já os cenários 2,3,4 e 7 registraram queda na eficiência dos portfolios. Considerando um desvio de 0,05 para queda de eficiência ainda assim o cenário 7 atende esse requisito.

Em vista do teste da hipótese H0 não foram encontrados indícios para refutar o impacto dos ajustes das variáveis de decisão dos projetos sobre a eficiência do portfolio.

Na tabela 5.4 seguem os testes da hipótese H1, de acordo com a equação (4.4). Os projetos estão relacionados nas colunas em relação aos cenários. $\mathrm{O}$ cenário 0 é a referência para verificar se a participação dos projetos ampliou ou reduziu na estrutura do portfolio. 
Tabela 5.4 - Teste de impacto de H1 na eficiência do portfolio.

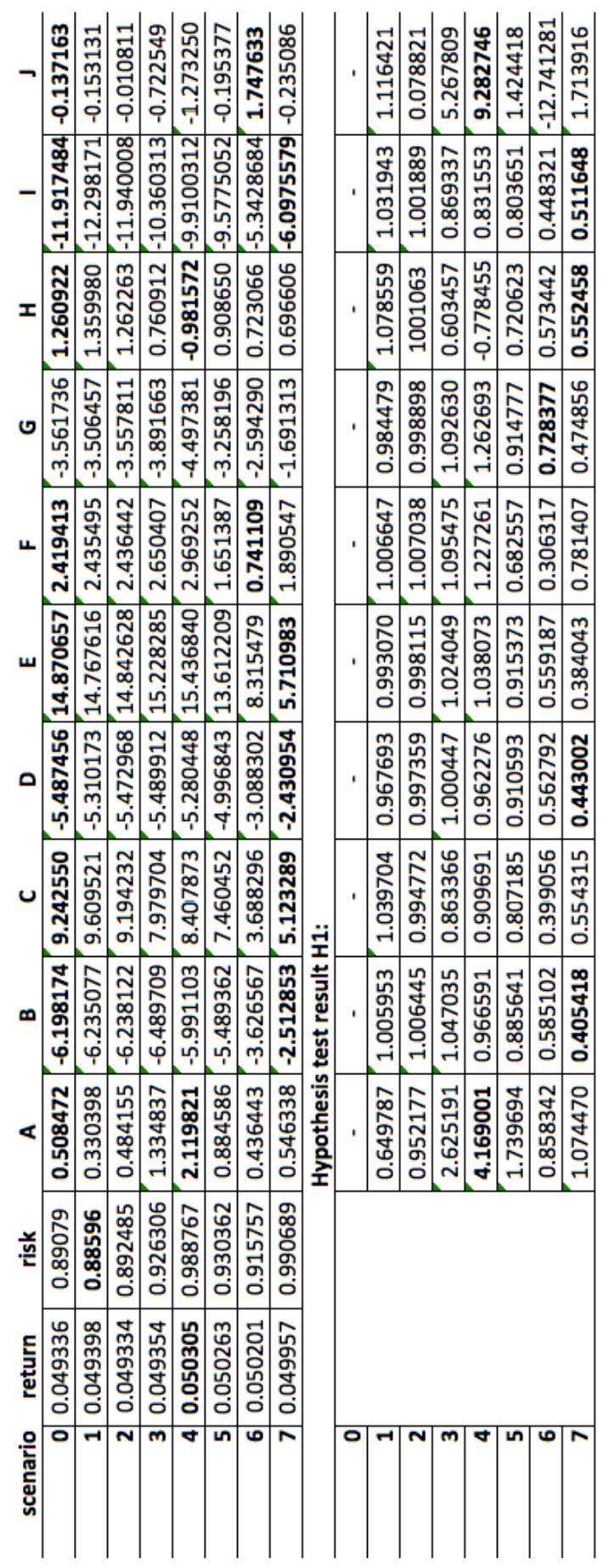

A tabela 5.4 é dividida em estruturas de participação dos projetos no portfolio, em relação aos ajustes das variáveis de decisão dos projetos, representadas pelos cenários de 1 a 7. Já na segunda parte são apresentados os quocientes que possibilitam o teste da hipótese H1, referente à equação (4.4). 
Todos os projetos apresentaram melhoria na composição dos portfolios subsequentes ao cenário 0. No entanto, só os cenários 4 e 6 apresentam inversão do sinal de seus quocientes, o que significa alteração na decisão no instante t em relação a um instante t-1. Isso indica que o ajuste da variável de decisão por meio do projeto pode propor novas estruturas de portfolios para análise de eficiência.

No instante t- 1 cenário 0 o projeto $H$ tinha uma sugestão de participação em 1,261 no portfolio, com o ajuste na quantidade de turnos em que o curso funciona. Foi então negativado o quociente em -0,778, no cenário 4 com participação -0,982.

No instante t-1 no cenário 6 , o projeto $H$ tinha uma sugestão de participação em $-0,137$ no portfolio, com o ajuste em $15 \%$ na amplitude de variação da demanda por matrícula. Foi então negativado o quociente em -12,741, no cenário 6 com participação 1,748.

Uma vez que os testes de hipóteses - tabela 5.5 - não ofereceram impedimentos para atuar sobre as variáveis de decisões dos projetos, então os ajustes das variáveis escolhidas tiveram potencial de impacto na formação da eficiência do portfolio, ou seja, na formação do resultado coletivo.

Tabela 5.5 - Resultados dos testes de hipóteses

\begin{tabular}{c|c|c|c}
\hline Hipóteses & \multicolumn{1}{c}{ medida } & \multicolumn{1}{c}{ observações } & cenario \\
\hline $\mathrm{H} 0$ & $\mathrm{yt}<>1$ & 7 & $1,2,3,4,5,6$ e 7 \\
\hline $\mathrm{H} 1$ & $\mathrm{yt}<0$ & 2 & 4 e 6 \\
\hline
\end{tabular}

Em razão disso, decidiu-se utilizar os resultados dos portfolios mês a mês, com verificação de desempenho semestral para a parte financeira e de avaliação do curso. O intuito é ajustar as variáveis de decisão dos projetos de forma a equalizar a participação dos 10 projetos no portfolio.

Portanto, entende-se que as variáveis de decisão escolhidas apresentam capacidade de impactar tanto no desempenho do projeto do curso, como na eficiência do portfolio. Também foram gerados mais cenários com ajustes manuais, que indicaram um padrão de comportamento adaptativo complexo. 
5.1.2 - Resultados a partir de ajustes manuais.

Em busca da decisão mediadora são realizados ajustes nas variáveis de decisão de cada projeto, de forma a permitir o encontro de um resultado que satisfaça os agentes de decisão sob os interesses individuais e coletivos.

No final são relacionados os portfolios com o melhor desempenho, a partir dos dados de retorno, risco, composição do portfolio e, principalmente, como os ajustes de cada variável de cada curso possibilitaram a obtenção de resultado superior.

$\mathrm{Na}$ tabela 5.6 são indicados cenários compostos por diferentes ajustes de variáveis de decisão e a partir deles podem ser observados os impactos dos ajustes sobre a eficiência do portfolio, que é composta pela relação entre retorno e risco. 
Tabela 5.6 - Cenários gerados de forma manual.

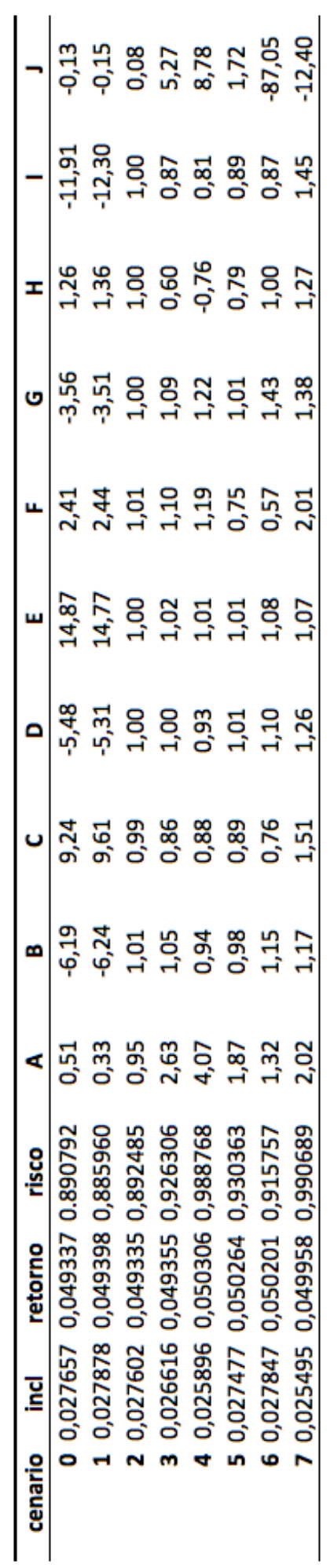

$\mathrm{Na}$ coluna incl da tabela 5.6 está o índice de eficiência do portfolio, em seguida o retorno e, por fim, o risco do portfolio. Nas colunas de $A$ a $J$ são indicadas as participações dos 
projetos no portfolio, cujo somatório é igual a 1, de forma que cada linha de cenário se tem um portfolio, com inclinação, retorno, risco e a participação de cada projeto.

Os retornos dos cenários indicados estão aquém do risco agregado à decisão, como é o caso do cenário 4, com retorno 0,0503, enquanto seu risco é de 0,9887. Essa relação desproporcional chama a atenção para uma investigação que é realizada a partir das tabelas 5.7, 5.8 e 5.9, onde encontram-se os resultados operacionais desdobrados em frações temporais mensais para obter as curvas de eficiências de portfolios.

A princípio era esperado que a estrutura de análise longitudinal ofereceria maior compreensão de quando e onde está o risco, de forma a apoiar a tomada de decisão no âmbito da seleção de portfolio. Contudo, deparou-se o problema adaptativo complexo na formação do portfolio, tornando necessária a resolução desse problema para se fazer a composição do portfolio.

A partir do cenário 0 - tabela 5.6 - foram gerados portfolios de projetos referentes aos cursos, com unidades de tempo mensais. Nas linhas está o portfolio selecionado, enquanto nas colunas encontram-se os pesos, ou participações dos cursos no portfolio para cada mês. 
Tabela 5.7 - Portfolios ótimo mensal por curso - cenário 0.

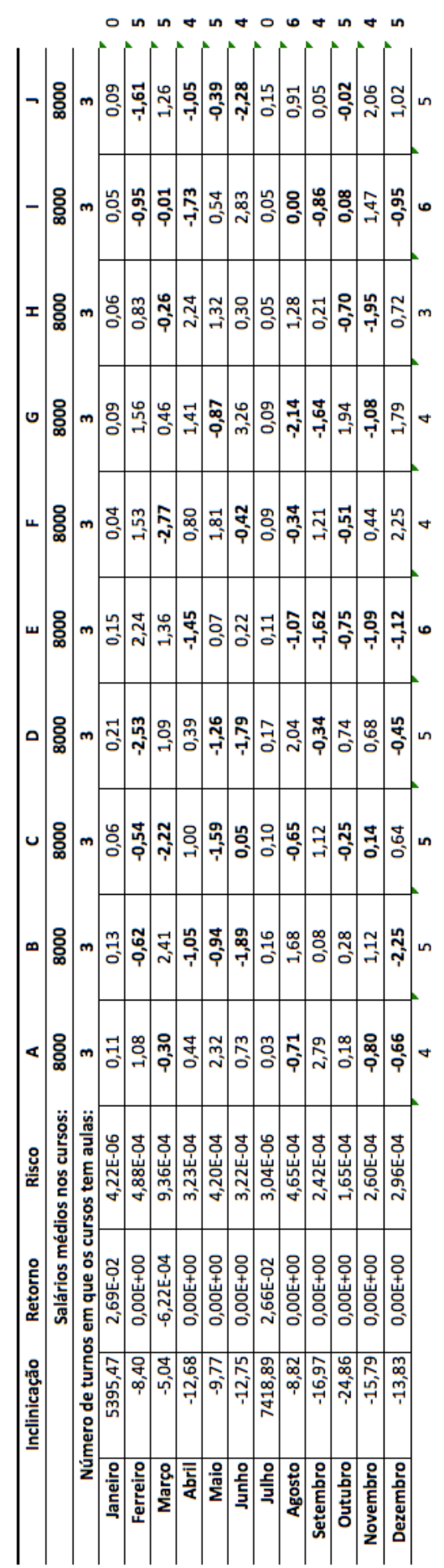

Os meses são obtidos de um horizonte de análise de 30 anos, por isso cada portfolio de mês é composto por 30 meses, considerando ainda seu vínculo a cada um dos cursos. 
A tabela 5.8 contém o detalhamento do cenário 0. Ela é o cenário de partida para todas as simulações, pois a partir dela são realizadas simulações de ajustes das variáveis de decisão dos projetos de forma que impacte na eficiência do portfolio.

Tabela 5.8 - Portfolios ótimo mensal por curso - cenário 1.

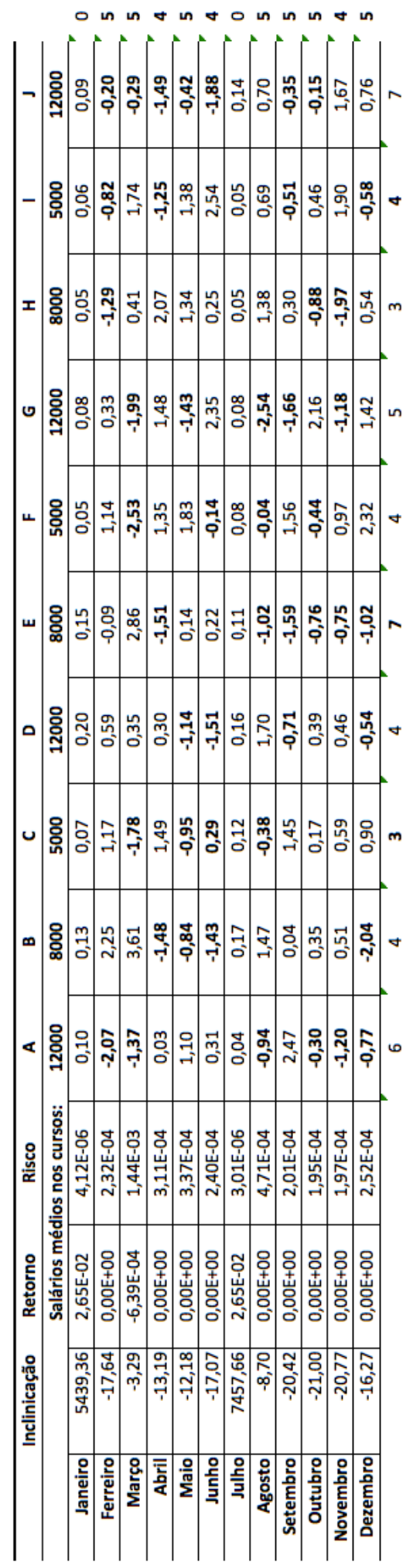


$\mathrm{Na}$ tabela 5.8 foram realizados ajustes mistos no salário docente com o intuito de buscar alguma melhoria na eficiência e na participação de projetos no portfolio.

Nas colunas abaixo da linha dos cursos é indicado o salário médio para cada curso. Percebe-se que o ajuste na variável de salário médio apresentou ampliação na participação. Nos cursos no cenário 1 em relação ao cenário 0 ocorreu uma redução de 31,24\% em participações negativas durante o ano. 
Tabela 5.9 - Portfolio ótimo mensal por curso - cenário 4.

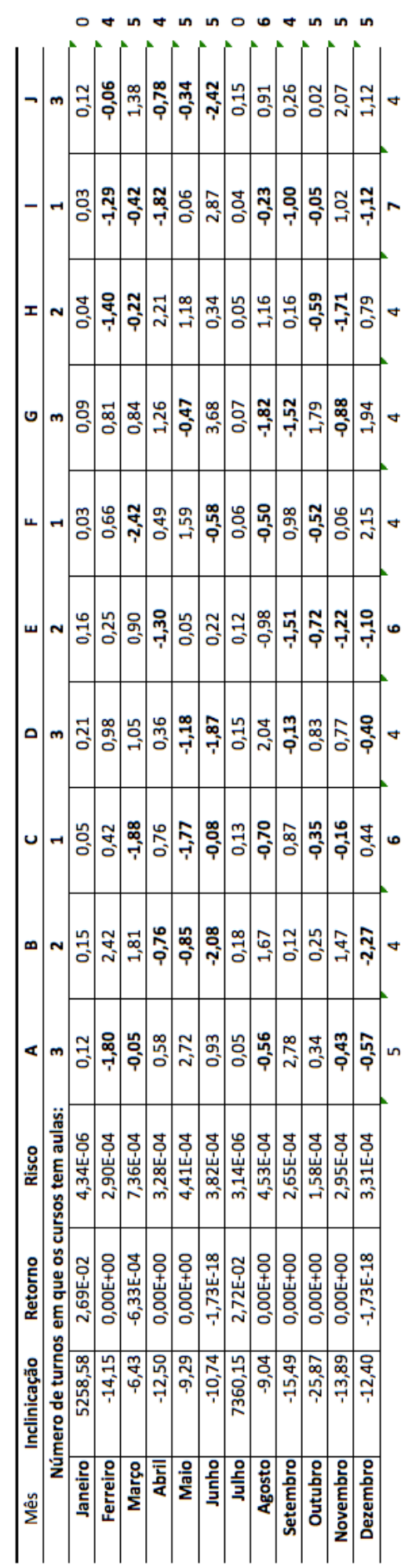

$\mathrm{Na}$ tabela 5.9 foram realizados ajustes mistos nos turnos de funcionamento em busca alguma melhoria. A proposta é reduzir a necessidade de investimentos em salas de aulas, ou espaços laboratoriais, ao utilizar mais turnos. 
No entanto, ao se realizar as atividades do curso em 3 turnos com baixa quantidade de matrículas, haverá um número excessivo de turmas nos cursos. Por fim, a média baixa de alunos nas turmas inviabiliza a permanência daquele curso no portfolio.

Ao obter esta estrutura em série dos vários ótimos ao longo dos meses, sob uma perspectiva de leitura ampliada, ao invés de um resultado estático tem-se uma leitura longitudinal do desempenho. Como já mencionado, torna-se uma tarefa complexa buscar a solução do problema de participação dos cursos no portfolio da IES, pois esse esforço de busca por melhor desempenho acaba restringindo o desempenho de uns sobre outros.

O desempenho está relacionado aqui com a participação do projeto no portfolio e o objetivo é alterar a participação negativa de projetos por meio de ajustes nas variáveis de decisão desses projetos, que além disso possam impactar em ganho de eficiência do portfolio.

Ainda que neste problema sejam apresentados dez cursos ao longo de doze meses, com três cenários, ainda resta a leitura de mais quatro cenários, que provocam outros reajustes nas variáveis e combinações com proporção exponencial. De fato, considerando que cada cenário é resultado de combinações entre o número de variáveis de decisão com amplitudes contínuas e discretas e o número de projetos de cursos participantes, a geração de cada cenário produz por meio da abordagem de Markowitz uma amplitude de participações desses projetos em $\mathbf{n}$ portfolios, dos quais é escolhido 1 portfolio para ser avaliado.

O problema é que os custos e resultados associados a cada objeto são determinados por agentes competitivos, de forma que a participação menor de um projeto de curso em detrimento de outro acaba gerando a necessidade de se proporem novas alternativas de portfolios por novos ajustes de variáveis de decisão.

No esforço de se resolverem os objetivos de cada curso, que diferem seu nível de participação no portfolio, a busca por satisfazer as particularidades de cada curso acaba repercutindo negativamente no desempenho de outro (JAYARAMAN,2017; GOMES, 2011; HOLLAND, 2006; SHARMES et. al, 1955) - figura 5.22. 


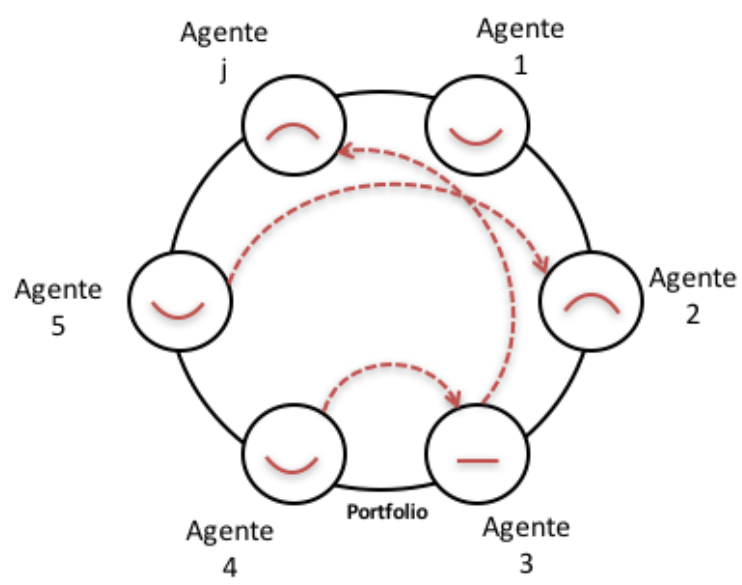

Figura 5.22 - Problema adaptativo na composição do portfolio de projetos.

$\mathrm{Na}$ figura 5.22 foi ilustrado o comportamento adaptativo gerado pelo impacto dos interesses de cada curso em majorar sua participação no portfolio, ainda considerando a limitação da disponibilidade de recursos no atendimento de todos. Aqui é ilustrado o impacto do interesse de um agente sobre a expectativa do outro, conforme é indicado também nas participações dos cursos nos portfolios mensais - tabelas 5.7, 5.8 e 5.9.

Para Holland (2006) esse tipo de sistema que envolve muitos componentes autônomos, por isso se adapta ou aprende à medida que interagem - estão no cerne de importantes problemas contemporâneos.

Durante o estudo verificou-se, também, a importância dos registros de consumo e resultado de cada projeto. Veja que a partir do desempenho dos cursos em consumir e renovar o reservatório de disponibilidades da IES, se possibilita nortear as decisões individuais e coletivas.

O fato de a estrutura de custos entre os cursos ser diferente deve ser considerado na distribuição dos recursos entre os cursos, de forma que sua estrutura de custos diferentes constitua um mínimo de recursos para funcionamento dos cursos.

Outro aspecto é a cooperação entre os cursos para lidar com a ociosidade de horas docentes, de salas e de laboratórios. Por essa razão a análise de sensibilidade para seleção dos portfólios acaba retirando ou colocando cursos para geração de portfólios. Em razão disso, considera-se importante o impacto dessas relações cooperadas no processo de simulação e análise de sensibilidade. 
Portanto, para uma maior aderência da complexidade do problema sob uma plataforma comum de análise de viabilidade, é aconselhável considerar os objetivos com peso de importância em uma mesma função objetivo, bem como os atributos ou critérios que os agentes consideram na tomada de decisão.

5.1.3 - Resultados a partir da automatização com ajustes adaptativos.

A partir da constatação da natureza adaptativa do problema na subseção 5.1.2, que alterou o curso da pesquisa, uma vez que as combinações de ajustes individuais exigiriam que os agentes competitivos chegassem a uma decisão final em que fosse permitido o ganho individual e de minimização do risco do portfolio, seguindo a recomendação de Holland (2006) adota-se o algoritmo genético como ferramenta integrada ao mecanismo para apoiar o processo de decisão entre os agentes. 
Tabela 5.10 - Cenários gerados de forma manual e automatizada.

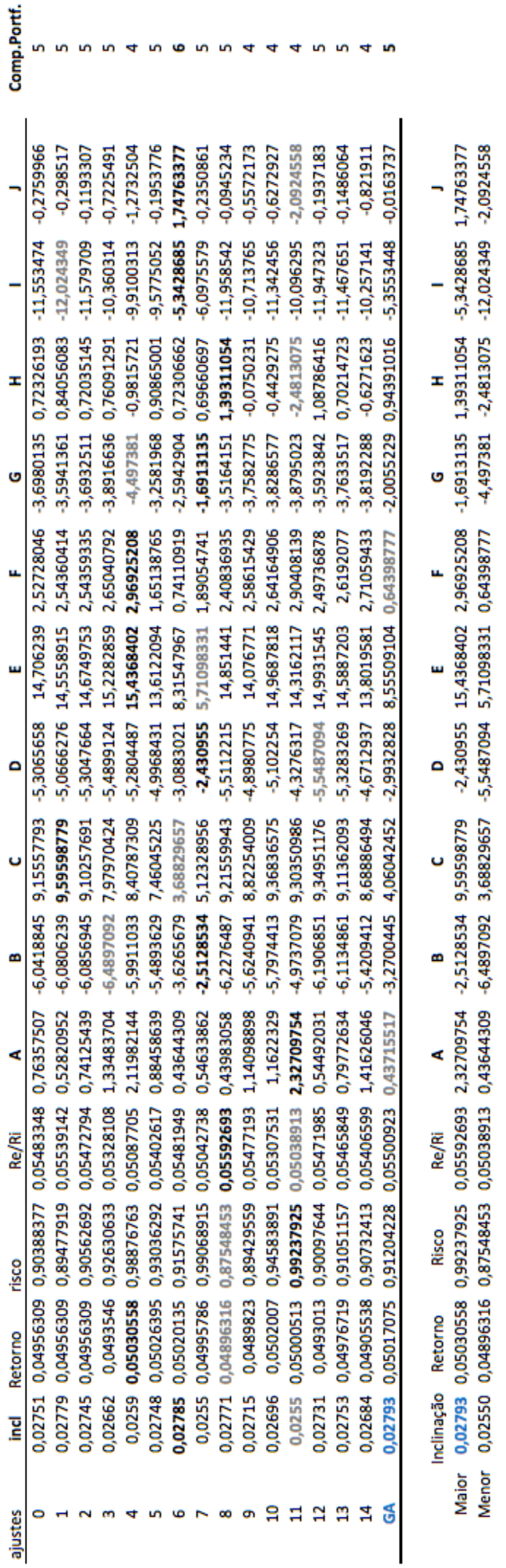

Após os testes foram amostradas 2000 interações, onde as gerações de cenários foram deixadas a cargo do algoritmo genético. Para apresentação dos resultados finais foram selecionados 200 portfolios de cada regime de decisão, que indicaram resultados 
superiores, primeiro pelo critério eficiência, depois por retorno e, por fim, de risco. Os indicadores de composição do portfolio e análise individual por VPL e de Conceito de projeto são indicados na tabela 5.11 .

Em um ranking das 200 melhores inclinações são indicados os melhores portfolios com desempenho superior de eficiência, obtidos a partir de ajustes nas variáveis de decisão dos projetos proporcionados pelo algoritmo genético - GA. Essas inclinações apresentam resultados que atendem à taxa mínima de atratividade do sistema e superam o risco do portfolio.

Ainda que o retorno continue baixo dentro da realidade dos projetos que compõem o portfolio, o risco foi dramaticamente reduzido ao serem comparados os resultados obtidos com ajustes manuais em relação ao mecanismo de ajustes adaptativos - Tabelas 5.10 e 5.11 . 
Tabela 5.11 - Comparação entre critérios do regime de decisão competitiva.

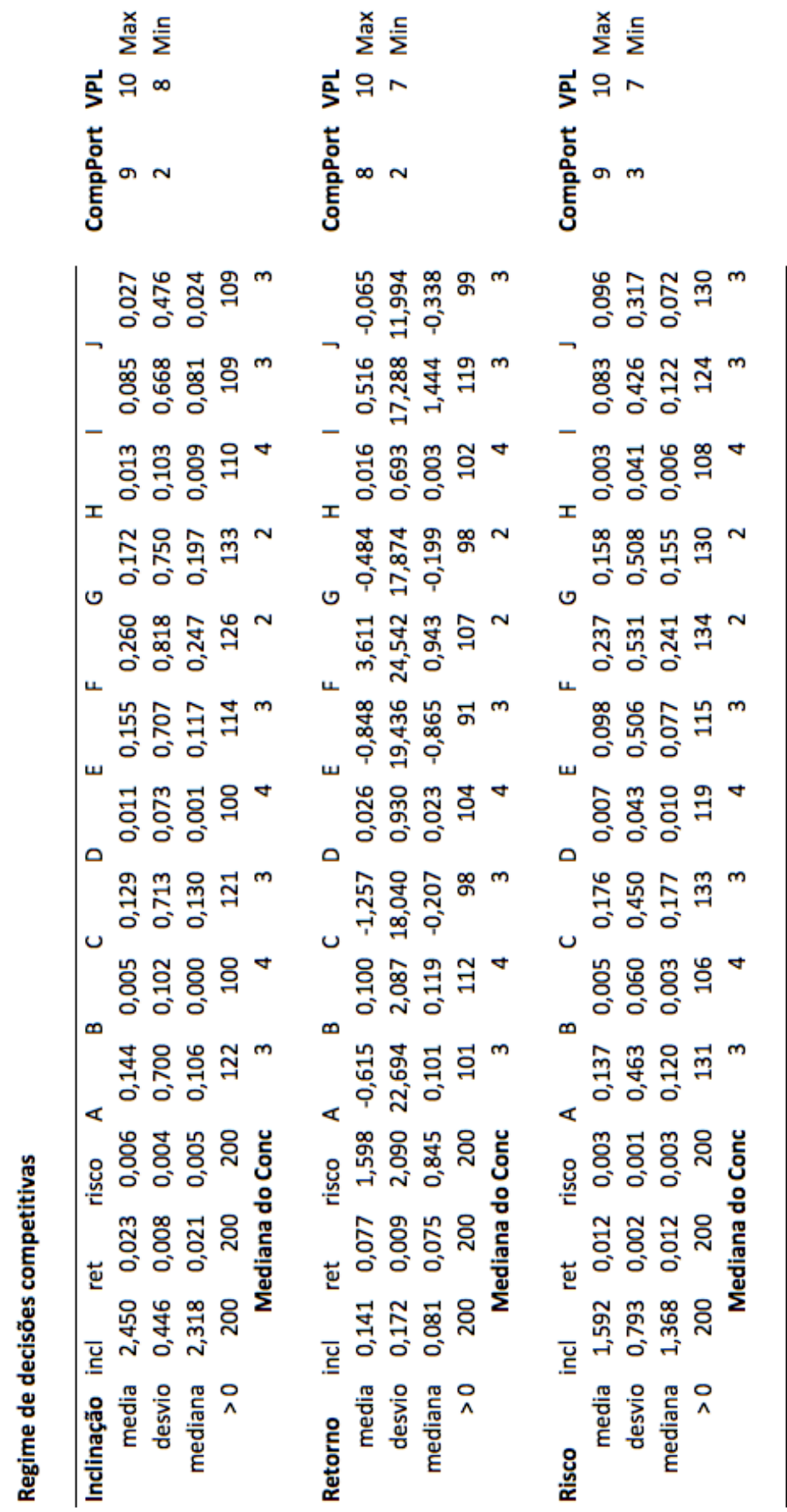

A relação entre o risco da tabela 5.11 de resultados realizados de forma deliberada com especialistas da organização obteve essa minimização do risco. Já os cenários do mecanismo de apoio a decisão proporcionaram uma redução do risco de 0,8859 - tabela 5.10 - para 0,03 - tabela 5.11, o que confirma o achado de Markowitz (1952), minimização do risco do portfolio a índices inferiores do ativo de menor risco do próprio portfolio. 
As atividades produtivas dos projetos tiveram suas variáveis de decisão ajustadas sob as perspectivas de decisão competitiva e cooperada, nas tabelas 5.11 e 5.12 . Nessas tabelas são relacionadas 200 amostras em cada, onde as médias obtidas são resultados superiores na perspectiva do portfolio e dos projetos dos cursos.

Já pela média de inclinação dos portfolios - tabelas 5.12 e 5.11, é indicado que a decisão cooperada 2,375 e competitiva 2,450 estão próximas, o que, contudo, é insuficiente para afirmar que a cooperação é responsável pela minimização do risco de insustentabilidade.

Os indicadores de retorno na coluna ret apresentam diferença relevante entre o competitivo de 0,141 para o cooperado 0,095 , embora o desvio dos retornos das decisões competitivas de 0,172 sejam maiores que o desvio dos retornos do cooperado de 0,127 . 
Tabela 5.12 - Comparação entre critérios do regime de decisão cooperativa.

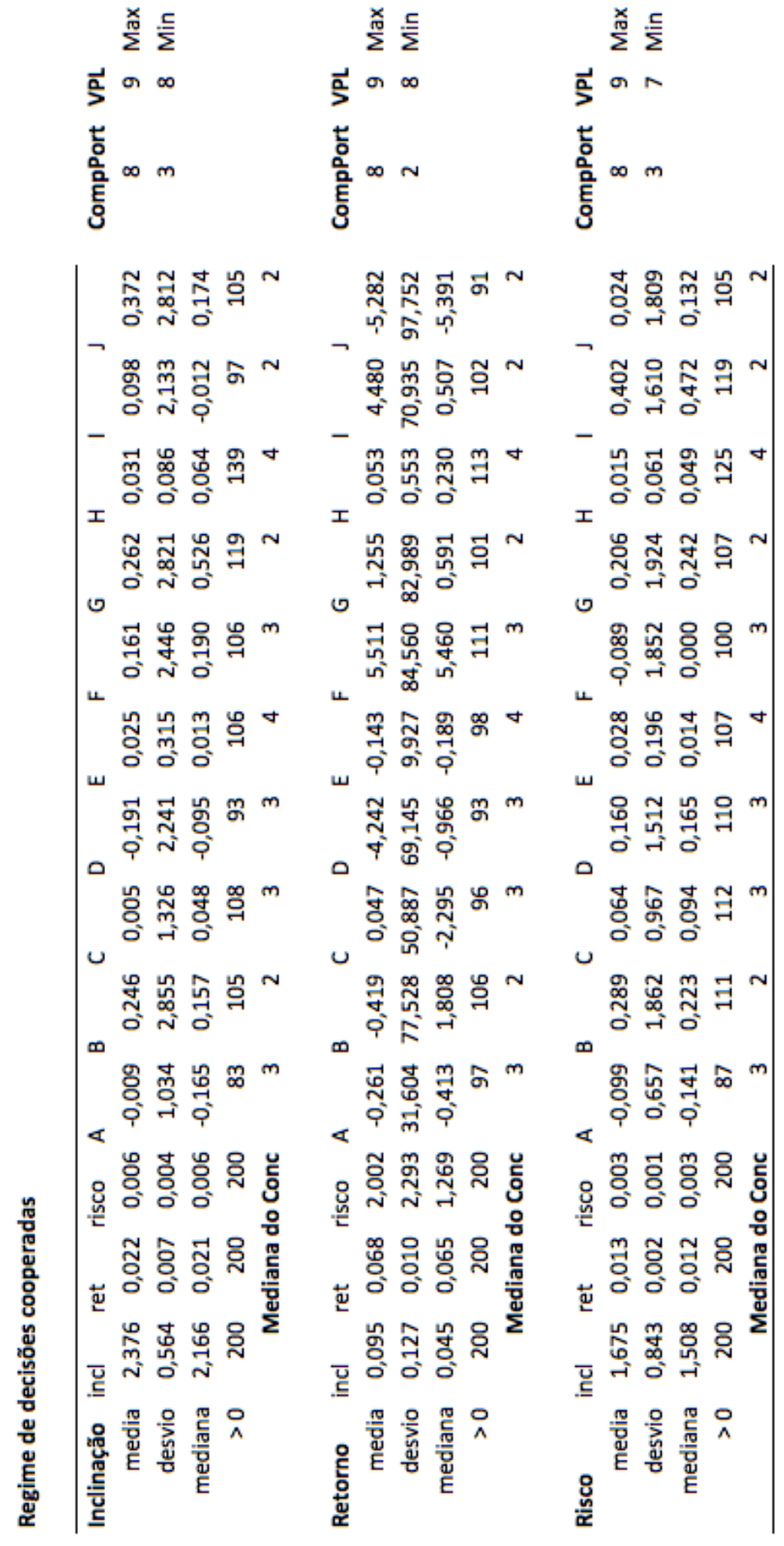

A partir das tabelas 5.11 e 5.12 é que o regime de decisão competitiva apresenta melhores resultados individuais por projetos de cursos e de eficiência do portfolio da IES.

A sugestão indicada por meio do mecanismo adaptativo no registro 1 da tabela 5.13, com eficiência de 5,150 com participação de 6 projetos dos 10 em sua estrutura de portfolio, 
apresenta o regime de decisão competitivo com o melhor resultado. No entanto, observa-se que o portfolio no registro 5 apresenta uma eficiência 4,351, mas tem uma composição maior de projetos na estrutura do portfolio e com o regime de decisão cooperado.

Tabela 5.13 - Relação de desempenho coletivo e individual por regime de decisão.

\begin{tabular}{lccccccc} 
& incl & ret & risco & Portfolio & VPL & Conc > 2 & RegDecisão \\
\hline 1 & 5,150 & 0,023 & 0,003 & 6 & 9 & 8 & Comp \\
2 & 5,024 & 0,015 & 0,001 & 5 & 9 & 6 & Coop \\
3 & 4,641 & 0,023 & 0,003 & 5 & 9 & 7 & Comp \\
4 & 4,452 & 0,020 & 0,003 & 7 & 9 & 8 & Comp \\
5 & 4,351 & 0,015 & 0,002 & 8 & 9 & 6 & Coop \\
6 & 4,270 & 0,015 & 0,002 & 7 & 8 & 6 & Coop \\
7 & 4,019 & 0,020 & 0,003 & 5 & 9 & 8 & Comp \\
8 & 3,936 & 0,013 & 0,001 & 4 & 8 & 6 & Coop \\
\hline
\end{tabular}

Por fim, de posse das projeções de resultados, o mecanismo apresenta um rol de alternativas de decisão - tabelas 5.11, 5.12 e 5.13 - de forma que a escolha possa ser exercida considerando os desempenhos de portfolios que romperam o limiar de risco de insustentabilidade. Entende-se que o produto deste prognóstico oferece insumos importantes para o processo de análise multicritério no desenvolvimento da decisão em grupo.

\section{2 - DISCUSSÃO ACERCA DOS ACHADOS}

Uma contribuição para a área de governança, por permitir encadear o processo de decisão de gerenciamento de projetos à seleção de portfolio com impacto real na eficiência do portfolio integrado às variáveis de decisão do projeto do curso da IES, é considerar o ciclo de análise de prazos médios de Richards (1980) com o modelo de sistema de produção de Slack (2011) e o fluxo de caixa (ROSS et al., 2013) para identificar as variáveis de decisão da atividade produtiva, ao passo que a estabelecem essas variáveis com o fluxo de caixa.

Entende-se que o gerenciamento de riscos das atividades produtivas utilizando a abordagem da TMP permite a avaliação de desempenho individual e coletivo em conjunto com ativos financeiros do mercado financeiro que possam ser prováveis concorrentes dos projetos que compõem o portfolio.

Em relação à questão científica proposta neste trabalho, até que ponto a cooperação entre agentes de decisão minimiza o risco de insustentabilidade coletiva, na seção 4.2 é indicada 
a curva de eficiência como a medida para percepção da minimização do risco no portfolio de projetos.

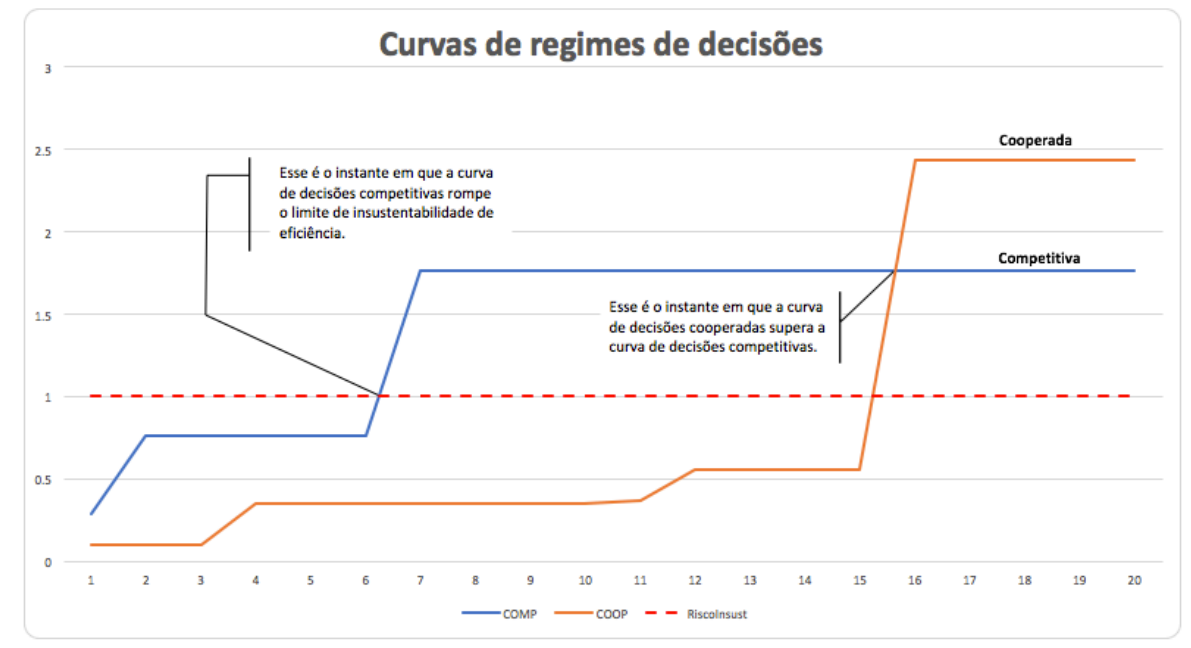

Figura 5.23 - O ponto de comparação das curvas de decisões

A figura 5.23 indica as curvas de decisão cooperada e competitiva, enquanto a tracejada q representa o limiar de risco de insustentabilidade. Abaixo dessa linha o risco é superior aos retornos que o portfolio pode oferecer. Acima dela, os retornos são superiores aos riscos inerentes à atividade produtiva, até encontrar o limite dos riscos não diversificados.

Ainda que o cenário utilizado tenha indicado melhor desempenho final para a curva de decisão competitiva, ao focar o instante em que as curvas de decisão rompem a fronteira de insustentabilidade, a curva de decisões competitivas apresenta melhor desempenho na realização dos ajustes necessários para projetar o portfolio fora da zona de insustentabilidade, linha tracejada - figura 5.23.

Na seção 5.1.3 são apresentados os resultados, de forma que a percepção de escolha pode ser vista a partir de medida qualitativa, como é o caso do conceito do curso que foi utilizado para subsidiar a análise multicritério do resultado. Assim a medida de qualidade pode diferir a escolha entre os portfolios fora do limiar de risco, ou mesmo nortear a escolha de portfolio fora do risco de insustentabilidade. Em razão disso se entende a ideia de até que ponto a cooperação minimiza o risco, pois ao realizar essa análise são considerados aspectos qualitativos e quantitativos, para perceber o risco e a dimensão de minimização que se pretende obter de desempenho individual e coletivo. 
Já a ideia do regime de decisão foi compreendida no mecanismo. Entende-se que a pergunta estabelece uma fronteira que permite buscar uma alternativa a partir do regime de decisões além do estritamente competitivo, no caso, competitivo até o ponto em que todos devem conciliar ações em prol da continuidade do sistema, sobre o aspecto coletivo e individual. $\mathrm{O}$ aspecto fundamental dessa contribuição é a inclusão do fator de risco do sistema como referência ao processo de tomada de decisão individual entre agentes competitivos.

É uma contribuição fundamental por tratar-se de um dilema que desafia a ciência e que até então está em aberto, de forma que os agentes de decisão envolvidos nessa circunstância estão sem uma referência além da perspectiva de tragédia.

O mecanismo oferece uma referência de risco para o processo de decisão em grupo, de forma que o agente de decisão possa optar por alternativas que apresentem potencial de minimização de risco de insustentabilidade do sistema - figura 5.24.

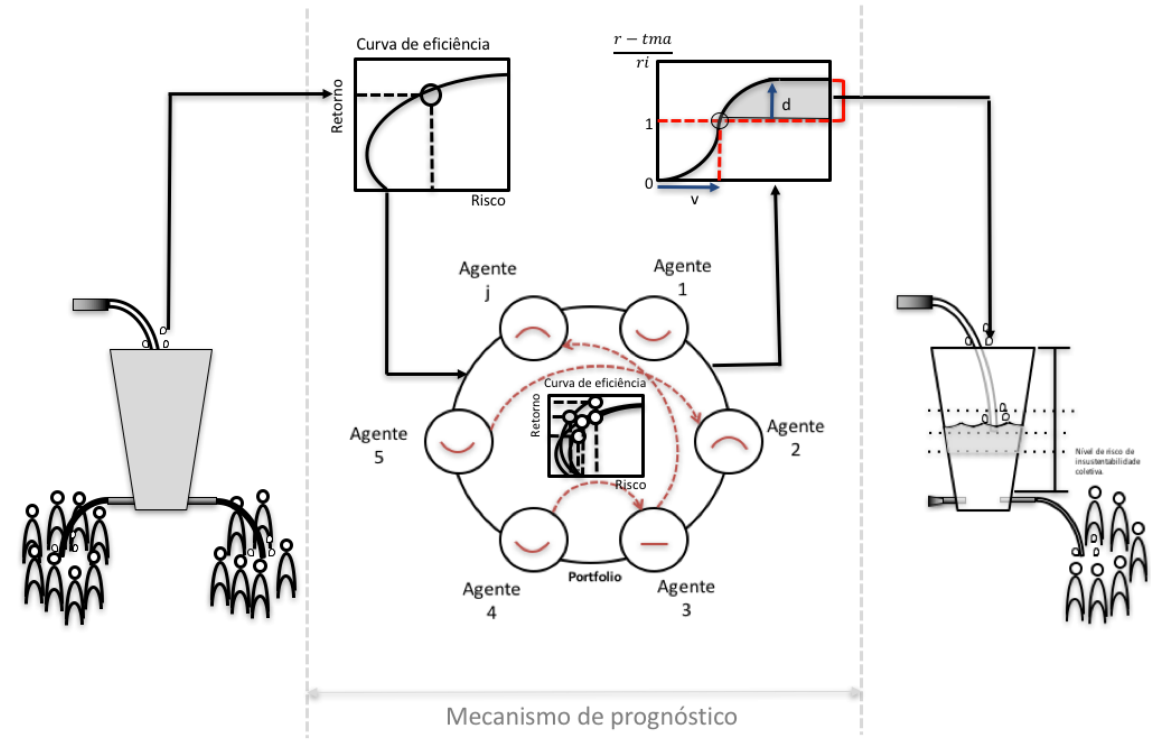

Figura 5.24 - Contribuição com a proposição do mecanismo de prognóstico.

Ainda que a cooperação seja excluída como alternativa direta no compartilhar de recursos ociosos, entende-se que ainda assim a participação dos agentes em uma plataforma comum de análise disponibiliza um ambiente de aprendizado. 
Enfim, a proposição do mecanismo apresenta um prognóstico de alerta aos agentes de decisão, que passam a visualizar seu desempenho individual em relação ao sistema, vislumbrando a priori seus interesses individuais dentro de limites aceitáveis de competição estabelecidos pelo próprio grupo. 


\section{6 - CONCLUSÕES E RECOMENDAÇÕES}

À medida em que avança a interconectividade socioeconômica, mais os agentes de decisão são exigidos para responder à relação entre retorno dos esforços empregados e os riscos envolvidos na atividade. Ainda, sobre o paradoxo de resposta em tempo cada vez menor, o decisor é impelido a lidar com plataformas diferentes de análise de desempenho, com percepções fragmentadas que dificultam, ou mesmo impossibilitam, a conexão da Organização à rede socioeconômica em seus diversos extratos.

A constatação da racionalidade limitada dos tomadores de decisão é fundamental para o desenvolvimento dos sistemas de apoio a decisão, mas se eles são desenvolvidos de forma a subsidiar exclusivamente a especialistas, sem uma percepção aberta a outros setores, haverá a colaboração para a sofisticação de emaranhados inconclusivos de informações.

Ainda sob condições especiais, as interconexões ao serem realizadas em plataformas comuns de decisão e análise podem incorrer em competições por uma mesma fonte de recursos limitada, ou mesmo enfrentar um problema adaptativo complexo entre unidades produtivas que buscam a maximização de seus resultados individuais. Sob qualquer das dessas circunstâncias é recomendado que o tomador de decisão esteja preparado para lidar com o dilema de cooperar em contexto competitivo, em favor da minimização do risco de insustentabilidade coletiva.

Postas as características da complexidade que compõe o cenário do tomador de decisão, é proposto um mecanismo de prognóstico e fator de risco de insustentabilidade coletiva entre agentes de decisão sob conflito de interesses.

O pressuposto assumido é o de que em algum momento o agente tomador de decisão pode se valer da cooperação ao competir por uma fonte limitada de recursos. A proposta inicial contava com o desenvolvimento de ajustes do mecanismo com os agentes de decisão em circunstâncias de reuniões de planejamento participativo. No entanto, durante o processo o problema apresentou a sofisticação de problemas adaptativos complexos, o que acabou contingenciando a integração da proposta. 


\section{1 - DAS CONTRIBUIÇÕES E LIMITAÇÕES DA PESQUISA}

A princípio os extremos dos regimes de decisão poderiam levar ao exercício da escolha entre competir ou cooperar. No entanto, ao se considerar a dinâmica das necessidades ao longo do tempo, é percebido também que apesar de a adoção do limite discreto para indicar a insustentabilidade do desempenho do portfolio, os regimes de decisão oferecem desempenhos diferentes, o que sugere que a cooperação pode ser combinada com a competição de forma que o portfolio obtenha resultados superiores, uma vez que a alternância também beneficia o distanciamento do limiar de risco de insustentabilidade.

Durante o desenvolvimento e teste de aplicações do mecanismo os resultados obtidos já foram suficientes para atender objetivos específicos:

- Compreender as atividades principais na estrutura de projetos, de forma a compor a análise de eficiência de portfolio. Nas seções 4.2.2 e 4.2.3, em especial a ilustração da figura 4.15, indica o processo para realização da compreensão das atividades produtivas no projeto.

- Compreender a composição dos limites de recursos que sejam capazes de indicar a incapacidade do estoque em subsidiar as atividades dos agentes ao longo do tempo. $\mathrm{Na}$ seção 4.3.2, nas figuras 4.19 e 4.20 são indicadas as variáveis de decisão dos projetos, os projetos, os parâmetros de entrada de disponibilidade de recursos e, por fim, a amplitude de ajustes em que cada uma das variáveis pode ser ajustada.

- Avaliar a capacidade de impacto das variáveis de decisão dos projetos no portfolio, considerando sua capacidade de minimizar o risco do portfolio. A seção 4.2.2, na equação 4.1, é a expressão formal do impacto da medida para avaliar o impacto das variáveis dos projetos sobre o portfolio.

- Adaptar a abordagem da teoria moderna de portfolio ao contexto de programas e projetos coorporativos, pois a TMP foi desenvolvida inicialmente para atender o mercado financeiro. Ao longo das seções do capítulo 4 é indicada essa integração, inclusive com a citação de artigo submetido com resultados que comprovam as 
conclusões. Na figura 4.21 é ilustrado o fluxo do processo de simulação considerando a integração da TMP ao contexto corporativo.

- Refletir sobre o desempenho e contribuições do mecanismo de prognóstico como apoio à decisão multicritério para grupos de agentes competitivos em prol da minimização de risco de insustentabilidade coletiva.

No caso do objetivo geral o compromisso de propor um mecanismo de prognóstico de risco de insustentabilidade coletiva entre agentes de decisão sob conflito de interesses:

- A proposição do mecanismo de prognóstico. Na figura 4.18 é ilustrada a estrutura do mecanismo e no decorrer da seção 4.3.2 é indicada sua aplicação.

- $\mathrm{O}$ fator de risco de insustentabilidade. Também nas seções 4.2.2 e 4.2.3 é indicada a medida de eficiência do portfolio que congrega os fatores explicativos de seu desempenho, tanto pelos ajustes nos projetos, como na acomodação das participações dos projetos no portfolio, de forma que ajustados pela análise de covariância ponderada é possível minimizar o risco de insustentabilidade. No entanto, ainda permanece a questão se a minimização foi suficiente para impactar na insustentabilidade.

\subsection{1 - Contribuição científica.}

Ao considerar no mecanismo de prognóstico uma plataforma comum de análise tanto para o desempenho individual como para o coletivo - e isso entre diferentes agentes de decisão permite-se aos agentes discernir o consumo de recursos para seu ganho individual, em favor de manter níveis aceitáveis de recursos que esses mesmos agentes julgam ser suficientes - figura 5.24.

Nessa plataforma é obtido um quadro de visão - figura 5.23 - que integra os resultados dos portfolios aos ajustes das variáveis de decisão nos projetos. No quadro há um limiar de risco definido previamente pelos próprios agentes afetados e por ele é permitido categorizar o potencial de risco de desempenhos projetados, de sorte que é possível qualificar quais estão dentro ou fora do limiar de risco de insustentabilidade coletiva.

Essas contribuições repercutiram no limiar de risco de insustentabilidade coletiva, de forma a distinguir quais portfolios apresentam desempenhos coletivos com potencial de 
insustentabilidade já na etapa de proposição da decisão planejada, ainda que ela tenha sido desenvolvida de forma colegiada, participativa ou mesmo cooperada.

Em suma, o quadro possibilita aos agentes competidores anteverem o potencial de risco de insustentabilidade já na proposição de sua decisão planejada.

\subsection{2 - Limitações da pesquisa.}

Ciente das contribuições destacadas, cabe salientar algumas limitações importantes da pesquisa:

- Quanto ao solipsismo: possíveis vieses na compreensão das variáveis de decisão dos projetos podem exigir a aplicação de uma abordagem sistêmica para absorção da estrutura básica que representa a atividade produtiva para a estrutura de simulação.

- Quanto à estratégia de pesquisa: a estruturação dos simuladores para representação dos ciclos operacionais e financeiros pode gerar séries de retornos com padrões de distribuições não normais.

- Quanto à proposta de um mecanismo de simulação: por se tratar de uma proposta de estruturas controladas, mesmo a partir de base de dados reais é exigida a geração de amostras para estabilização das médias para validação do modelo. Esse procedimento gera alto custo computacional, dependendo da complexidade da estrutura a ser simulada.

- Quanto aos procedimentos metodológicos: o método hipotético-dedutivo exige conhecimento em detalhes da estrutura do problema, de forma a realizar investigações e proposições de hipóteses que possam contribuir para o processo de pesquisa de problemas que exijam interdisciplinaridade para sua compreensão.

\section{2 - RECOMENDAÇÕES E CONSIDERAÇÕES FINAIS}

Embora o regime de decisão cooperada tenha obtido excelentes resultados, foi relevante se obter o melhor resultado com o regime competitivo, mas ainda indicando que em circunstâncias outras é bom que os dois regimes sejam possíveis de execução.

O sucesso da realocação da variável de decisão para a atividade produtiva torna-se um termo antecedente e explicativo da participação do projeto no portfolio. Nesse caso o mecanismo compreende a abordagem da TMP em sua proposta original. Por isso a proposta está longe de ser uma contribuição à TMP, embora essa proposta tenha ampliado 
o espectro de aplicação da própria abordagem, pois trata-se de uma abordagem financeira de estudos do mercado financeiro, agora agregada a uma perspectiva ampla da economia real de produção.

O mecanismo de apoio a tomada de decisão compreende entradas multicritério dos agentes de decisões, combinadas ao processo de simulações ou ajuste diretos. Sua proposição é etapa inscrita nesta pesquisa e permite sua adaptação a outros contextos socioeconômicos, no intuito de compreender um observatório de novos contextos complexos para investigações e compreensão de problemas, bem como no estudo de eficiência de métodos de soluções de problemas.

O dilema social da tragédia dos comuns é formalizado como um problema sem solução a partir da visão dos próprios agentes de decisão (HARDIN, 2008). Sob essa perspectiva foram desenvolvidas pesquisas de campo que constataram a existência de convívio com o problema (BASURTO, GELCICH, \& OSTROM, 2013). Os achados deste trabalho disponibilizam partes de um mecanismo que possibilita os agentes de decisão elaborar suas decisões em meio ao conflito de interesses.

Buscou-se indicar o fator de risco de insustentabilidade coletiva como referência ao processo decisório entre agentes de decisão competitivos, considerando nesse processo de tomada de decisão a perspectiva individual ao relacionar as variáveis de decisão dos projetos na formação de eficiência do portfolio. O mecanismo possibilita a integração das decisões emergentes dos agentes vinculados à atividade fim, possibilitando a observação de desempenho individual nos projetos, com efeito na formação de decisão planejada. Em síntese, este trabalho busca apoiar a decisão ante a disponibilidade restrita dos recursos do sistema a serem alocados nos projetos, razão pela qual já no portfolio compreendem-se a disponibilidade de recursos e o fator de risco do sistema.

Ainda, ao estudar os fluxos de funções docentes entre as IES e a ociosidade de recursos integra-se ao estudo a disponibilidade de recursos no setor com impacto nos cursos. Entende-se que a integração do mecanismo ao setor pelos cursos pode minimizar o erro de estimação de recursos disponíveis a serem contratados ao longo do tempo, além de mapear as redes de interconexões por fluxo de recursos disponíveis entre os cursos no setor. A 
proposta é investigar alternativas de políticas públicas para minimizar o risco de insustentabilidade do setor de ensino superior pela cooperação de recursos do setor.

O próximo passo seria o estudo da dinâmica da demanda por serviços de ensino nas principais fases de ensino das escolas de engenharia na educação brasileira e latina americana, no intuito de compreender aquela do setor de ensino superior, investigando quais fatores influenciam na formação do fluxo e estoques de demanda pelo ensino fundamental, intermediário e médio (regular e técnico) até a formação da procura por ensino superior. O propósito final é a busca de integração do mecanismo de prognóstico de risco entre os cursos de engenharia das IES, cujos recursos docentes e laboratoriais podem ser compartilhados.

Esses dois estudos proporcionariam uma perspectiva dinâmica das curvas de oferta e procura por ensino, compreendidas pela atividade produtiva dos projetos pedagógicos dos cursos, procura por vagas e alocação dos recursos, de forma que a poderem subsidiar o setor de ensino com: políticas públicas, suporte de telecomunicações para cooperação de serviços de ensino a distância e compartilhamento de espaços laboratoriais a partir de propostas emergentes da realidade dos projetos dos cursos e de sua interconectividade com os demais de outras regiões. Portanto, assim como neste trabalho, trata-se de problemas atinentes ao campo da Engenharia Elétrica, haja vista a imprescindível utilização para a sua solução dos métodos algoritmo genético e TMP, que são objeto de estudo da Engenharia da Computação, um ramo de pesquisa da Engenharia Elétrica.

Retornando ao problema aqui proposto, este trabalho de pesquisa a todo instante procurou encerrar a proposta do mecanismo de prognóstico, para apresentá-lo como instrumento apto a lidar especialmente com o problema complexo da tragédia dos comuns com aplicação no contexto de cursos de uma IES, proporcionando aos agentes uma visualização das consequências da decisão ainda em fase de desenvolvimento do planejamento. 


\section{REFERÊNCIAS BIBLIOGRÁFICA}

Archer, N. P.; Ghasemzadeh, F. (1999). An integrated framework for project portfolio selection. International Journal of Project Management. v. 17, n. 4, p. 207-216, 1999.

Altbach, Philip G.; Rumbley, Liz Reisberg Laura E. (2009). Trends in Global Higher Education: Tracking an Academic Revolution - A Report Prepared for the UNESCO. World Conference on Higher Education. Published with support from SIDA/SAREC.

Ansell, C., \& Gash, A. (2008). Collaborative governance in theory and practice. Journal of Public Administration Research and Theory, 18(4), 543-571. https://doi.org/10.1093/jopart/mum032

Aouni, Belaid ;Ben Abdelaziz, F.; La Torre, D. (2012). The stochastic goal programming model: theory and applications. Journal of multi-criteria decision analysis J.MultiCrit. Anal.

, Belaid; COLAPINTO,Cinzia; LA TORRE, DAVIDE. (2014). Financial portfolio management thought the goal programming model: current state of the art. European Journal of Operational 234 536-545.

Assaf Neto, Alexandre. (2010). Finanças Corporativas e valor. São Paulo: Atlas.

Ballestero, E.; \& Garcia-Bernabeu, A. (2012). Portfolio selection with multiple time horizons: A mean variance - stochastic goal programming approach, preprint.

Basurto, X., Gelcich, S., \& Ostrom, E. (2013). The social-ecological system framework as a knowledge classificatory system for benthic small-scale fisheries. Global Environmental Change, 23(6), 13661380.https://doi.org/10.1016/j.gloenvcha.2013.08.001

Bryant, A. (2002). Re-grounding grounded theory. Journal of Information Technology Theory and Application, v. 4, n. 1.

Bueno, Newton Paulo. (2011). Introdução à dinâmica de sistemas: com aplicações para a economia. Viçosa, MG: Ed. UFV, ISBN: 978-85-7269-414-8. 
Castro, Henrique Gonçalves De; Carvalho, Marly Monteiro De. (2010). Gerenciamento do portfólio de projetos (PPM): estudos de caso - Produção, v. 20, n. 3, jul./set. 2010, p. 303-321 doi: 10.1590/S0103-65132010005000044.

Charnes, A.; Cooper; W. W.; Ferguson, R. O. (1955). Optimal estimation of executive compensation by linear programming. Management Science 1: 138-151. https://doi.org/10.1287/mnsc.1.2.138

Chwif, L.; Medina, A. C. (2015). Modelagem e simulação de eventos discretos - teoria e aplicações. 4a. edição revista e ampliada, ed.Campus, ISBN (versão eletrônica): 97885-352-7933-7.

Cooper, Robert; Edgett, Scott; Kleinschmidt, Elko. (2001) Portfolio management for new product development: results of an industry practices study. R\&D Management. V. 34, n. 4, p. 361-380.

, R. G.; Edgett, S. J.; Kleinschmidt, E. J. (1997). Portfolio management in new product development: lessons from the leaders - II. Research Technology Management, v. 40, n. 5, p. 43-52, 1997.

Copeland, Thomas E. (2002). Opções Reais: um novo paradigma para reinventar a avaliação de investimento. Tradução Maria José Cyhlar. - Rio de janeiro: Campus.

Corrêa, L. H.; Gianesi, I. G. N.; Caon, M. (1999). Planejamento, programação e controle da produção: MRP/ERP: conceitos, uso e implantação. 2ed. São Paulo - Atlas, ISBN:85-224-2103-X.

Creswell, John. (2010). Projeto de pesquisa - métodos qualitativo, quantitativo e misto. 3a.Ed. Bookman, armed.

Ehlers, Ricardo S. (2010). Análise de séries temporais, http://www.icmc.usp.br/ ehlers, 06/03/2016 18:24h.

Falcini, P. (1995). Avaliação econômico de empresa. 2 ed. São Paulo: Atlas.

Gomes, L. F. A. M.; Lima, M. M. P. P. (1992). From modelling individual preferences do multicriteria ranking of discrete alternatives: a look at prospect theory and the additive difference model. Foundations of computing and decision sciences, v. 17, n. 3, p. 171-184. 
Gomes, Luiz Flavio Autran Monteiro. (2011). Tomada de decisões em cenários complexos: introdução aos métodos discretos do apoio multicritério à decisão - São Paulo: Cengage Learning.

Gunn, A.; Mintrom, M. (2013). Global university alliances and the creation of collaborative advantage. Journal of Higher Education Policy and Management, v. 35, n. 2, p. 179-192, 2013.

Gujarati, Damodar N. (2006). Econometria básica / Damodar Gujarati; tradução de Maria José Cyhlar Monteiro. - Rio de Janeiro, Elsevier, - $4^{\mathrm{a} e d .}$

Hardin, G. (1968). The Tragedy of the Commons. Advancement Of Science, v. 162, n. 3859, p. 1243-1248, 1968.

Henderson, J. C., \& Venkatraman, N. (1993). Strategic Alignment: Leveraging Information Technology for Transforming Organizations. IBM Systems Journal, 32( 1), 4-16.

Hirschfeldhi, Henrique. (1998). Engenharia econômica - e análise de custos. 6 ed., São Paulo: Atlas.

Holland, J. H. (2006). Studying complex adaptive systems. Journal of Systems Science and Complexity, v. 19, n. 1, p. 1-8, 2006.

Howard, R. A. Et Al. (1983) Reading on the principles and applications of decision analysis. Menlo Park: Strategic Decision Group.

Hummel, Paulo Roberto Vampré; Taschner, Mauro Roberto Black. (1995) Análise e decisão sobre investimentos e financiamentos - engenharia econômica (teoria e prática). 4 ed., São Paulo: Atlas.

Jayaraman, Raja; Cinzia Colapinto; Davide La Torre; Tufail Malik. (2017). A Weighted Goal Programming model for planning sustainable development applied to Gulf Cooperation Council Countries.

Juliatto, Clemente Ivo. (2005). A universidade em busca da excelência: um estudo sobre a qualidade da educação / Clemente Ivo Juliatto; Apresentação de Manassés Claudino Fonteles. 2d. Curitiba: Champagnat: Ed. da PUC Goiás.

Kahneman, D.; Tversky, A. (1979). Prospect theory: an analysis of decision under risk. Econometrica, v. 47, n. 2, p. 263-292. 
Kassai, J. R. (2000). Retorno de Investimento: Abordagem matemática e contábil do lucro empresarial. 2 ed. São Paulo: Atlas.

Kaveh, Khalili-Damghani; Madjid, Tavana. (2014). A comprehensive framework for sustainable project portfolio selection based on structural equation modeling. Project Management Journal, 45(2), 83-97. doi:http://dx.doi.org/10.1002/pmj.21404

Keeney, Ralph L. (1982). Decision Analysis: An overview Operations Research 0030364X/82/3005-0802, Operations Research Society of America Vol.30, No.5, September-October.

Kleiboer, M. (1997). Simulation methodology for crisis management support. Journal of Contingencies and Crisis Management, v.5, n.4, p.198-206.

Kock, S.; Bengtsson, M.; Slotte-Kock, S. (2005).To Compete or Cooperate-A Strategic Dilemma. Strategic Management Journal, p. 1-20.

Lankhorst, Marc et al. (2005). Enterprise architecture at work - Modelling, Communication, and Analysis". Library of Congress Control Number: 2005924300 ACM Computing Classification (1998): H.1, D.2.11, J.1 ISBN-10 3-540-24371-2 Springer Berlin Heidelberg New York ISBN-13 978-3-540-24371-7.

Lakatos, E. M.; Marconi, M. De A. (2003). Fundamentos de metodologia científica. 5a. edição, editora Atlas S.A.

LI, H. et al. (2011). Resilience analysis for agricultural systems of North China Plain based on a dynamic system model. n. February, p. 8-17, 2011.

Mangram, Myles E. et al. (2013). A simplified perspective of the markowitz portfolio theory. SMC University, Switzerland. Global journal of business research, volume 7, number 1 .

Markowitz, H. (1952). Portfolio Selection. The Journal of Finance, v. 7, n. 1, p. 77-91. , H. (2010). Portfolio Theory: as I still see it. Annu. Rev. Financ. Econ. 2010. 2:123 First published online as a Review in Advance on September 29, 2010. The Annual Review of Financial Economics is online at financial.annualreviews.org. This article's doi: 10.1146/annurev-financial-011110-134602.

Mcginnis, M. D., Ostrom, E. (2014). Social-ecological system framework: initial changes and continuing challenges. Ecology and Society 19(2): 30. 
http://dx.doi.org/10.5751/ES-06387-190230 acessado no dia 24/10/2016 as 02:15h am.

Mintzberg, H. (1998). A criação artesanal da estratégia. IN MONTGOMERY, C.A. \& PORTER, M.E. Estratégia: a busca da vantagem competitiva. Rio de Janeiro: Campus, p. 419-437.

Morettin, Pedro A. (2004) Econometria financeira Um curso em séries temporais financeiras , Departamento de Estatística/IME, São Paulo.

Oliveira, C. C. G.; Lopes, H. E. G.(2014). Documentos e Debates - Coopetição em Redes Interpessoais: Redes são Redes. Revista de Administração Contemporânea, v. 18, n. 4, p. 508-522, 2014.

Ostrom, E. (1990). Governing of the Commons - The Evolution of Institutions for Collective Action. Indiana University. Cambridge University Press - ISBN: 0 521405998 paperback.

, E. (2009). A General Framework for Analyzing Sustainability of SocialEcological Systems. Science, v. 325, n. 5939, p. 419-422.

Padovani, M. (2013). Impacto da gestão de portfólios de projetos no desempenho organizacional e de projetos. Tese de doutorado apresentada ao programa de pósgraduação em engenharia de produção da Escola Politécnica da Universidade de São Paulo. São Paulo.

Pidun, U., Rubner, H., Kruehler, M., Untiedt, R., \& Nippa, M. (2011). Corporate portfolio management: Theory and practice. Journal of Applied Corporate Finance, 23 (1),6376.

Popper, K. (2002). The logic the scientific discovery. London and New York, the Taylor \& Francis e-Library - ISBN 0-203-99462-0.

Porter M.E. (1999). O que é estratégia? IN PORTER M.E. Competição - on competition: Estratégias competitivas essenciais. Rio de Janeiro: Campus, p. 46-82.

Richards, V. D.; Laughlin, E. J. (1980). A Cash Conversion Cycle Approach to Liquidity $\begin{array}{lllllll}\text { Analysis. Financial } & \text { Management, } & \text { v. } & \text { n, } & \text { n. }\end{array}$ http://www.jstor.org/stable/3665310. 
Ross, S.; Westerfield, R.; Jeffrey, J. (2013) Corporate finance. 10th ed. Published by McGraw-Hill/Irwin, a business unit of The McGraw-Hill Companies, Inc., 1221 Avenue of the Americas, New York, NY, 10020. Copyright (C) 2013 by The McGraw-Hill Companies, Inc. All rights reserved. Printed in the United States of America.

Scrucca, L. (2013). GA: A Package for Genetic Algorithms in R. Universita degli Studi di Perugia, Volume 53, Issue 4.

Sharpe, W. F. (1964). Capital Asset Prices: A theory of market equilibrium under conditions of risk. Blackwell publishing for the American Finance Association, The Journal Finance, vol.19, no.3.

Simon, Herbert A. (1947) Administrative behavior: A Study of Decision-making Processes in Administrative Organization, 1st ed., New York: The Macmillan Company.

Slack, Nigel. (2011). Essentials of Operations Management. Prentice Hall - financial times. Publisher: Pearson Education Limited. ISBN: 978-0-273-73046-0.

Strauss, Anselm; Corbin, Juliet. (1997). Grounded theory in practice. Thousand Oaks, Ca.: Sage.

Sterman, J. (2000). Business Dynamics: Systems Thinking and Modeling for a Complex World. Irwin, McGraw-Hill, ISBN:007238915X.

Tamiz, Mehrdad et al. - (1998). Goal programming for decision making: An overview of the current state-of-the-art European Journal of Operational Research 111 569-581.

Welch, J. \& Byrne, J.A. Jack - (2001). Definitivo: segredos do executivo do século. Rio de Janeiro: Campus.

Weill, P. E Ross, J.W. (2004). IT governance: how top performers manage IT decision rights for superior results, Harvard Business School Press, Boston, Massachusetts, E.U.A.

Williamson. Oliver E. (1996). The Mechanisms of Governance. New York: Oxford University Press. 
APÊNDICE 


\section{A.1 - CRONOGRAMA REALIZADO}

Tabela A.14: Cronograma de desenvolvimento da tese.

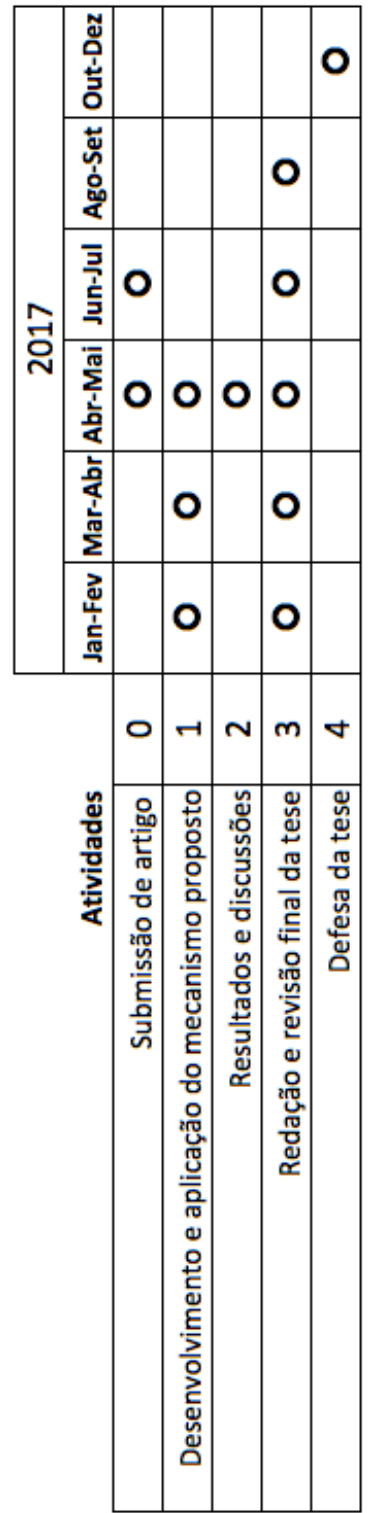




\section{A.2 - INFORMAÇÕES QUALITATIVAS}

Formulário SWOT + Ishikawa de coleta de informações, isso possibilitou o agente de decisão apresentar sua argumentação de forma descritiva, sob as categorias do instrumento. Foram aplicados esse instrumento de coleta nas diretorias das pró-reitoras, de forma a emergir as percepções dos agentes de decisão ao processo de planejamento.

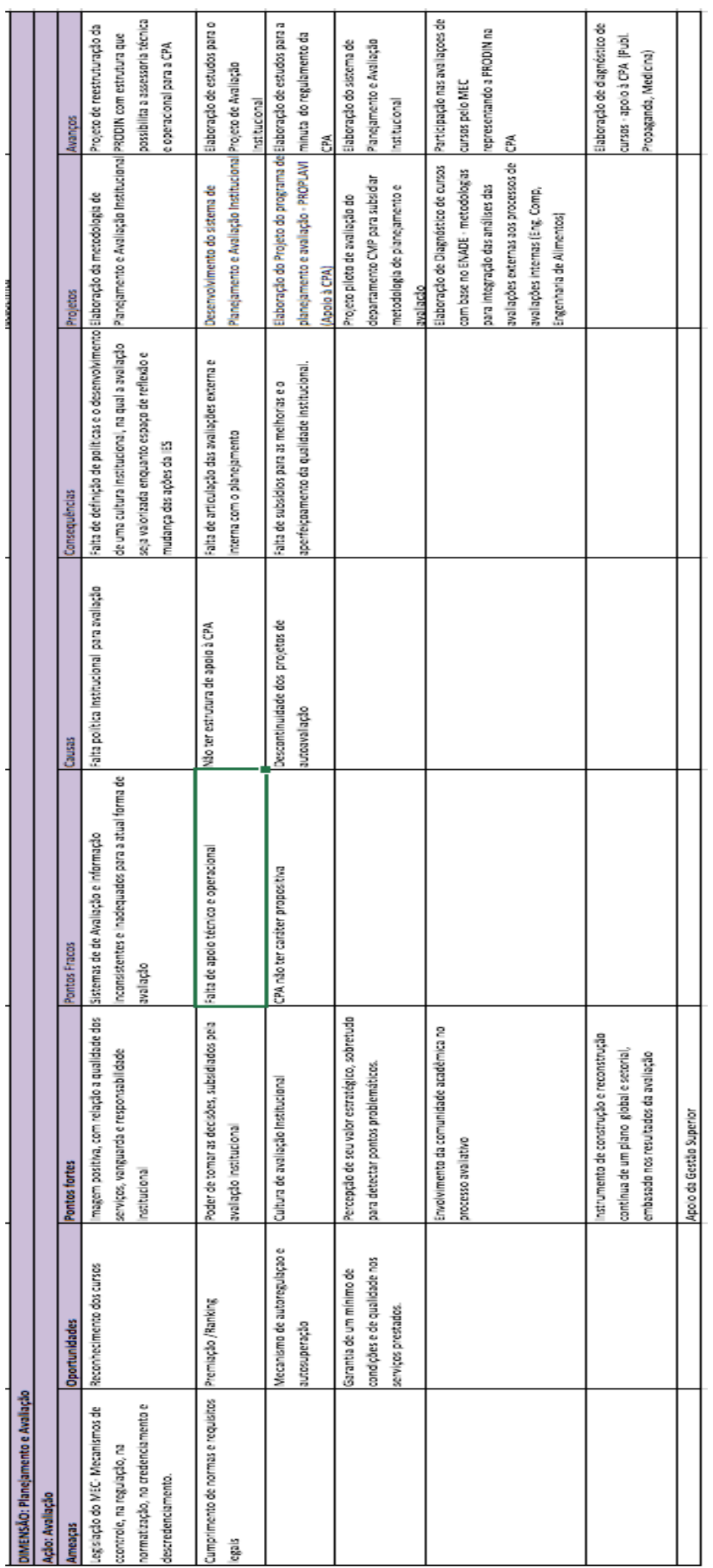




\section{A.3 - DESDOBRAMENTO DA ESTRUTURA DE PLANEJAMENTO À ESTRUTURA DE PROJETO}

A estrutura de planejamento na IES é dimensionada para 5 anos, embora os cursos apresentem tempo próximo da projeção do PDI, seus cronogramas de ajustes são decorrentes de cronograma de planejamentos anterior, ou no mesmo prazo regulamentar apresentam conflitos de interesses entre si. Todos projetos buscam a disponibilidade orçamentária no horizonte de projeção do planejamento.

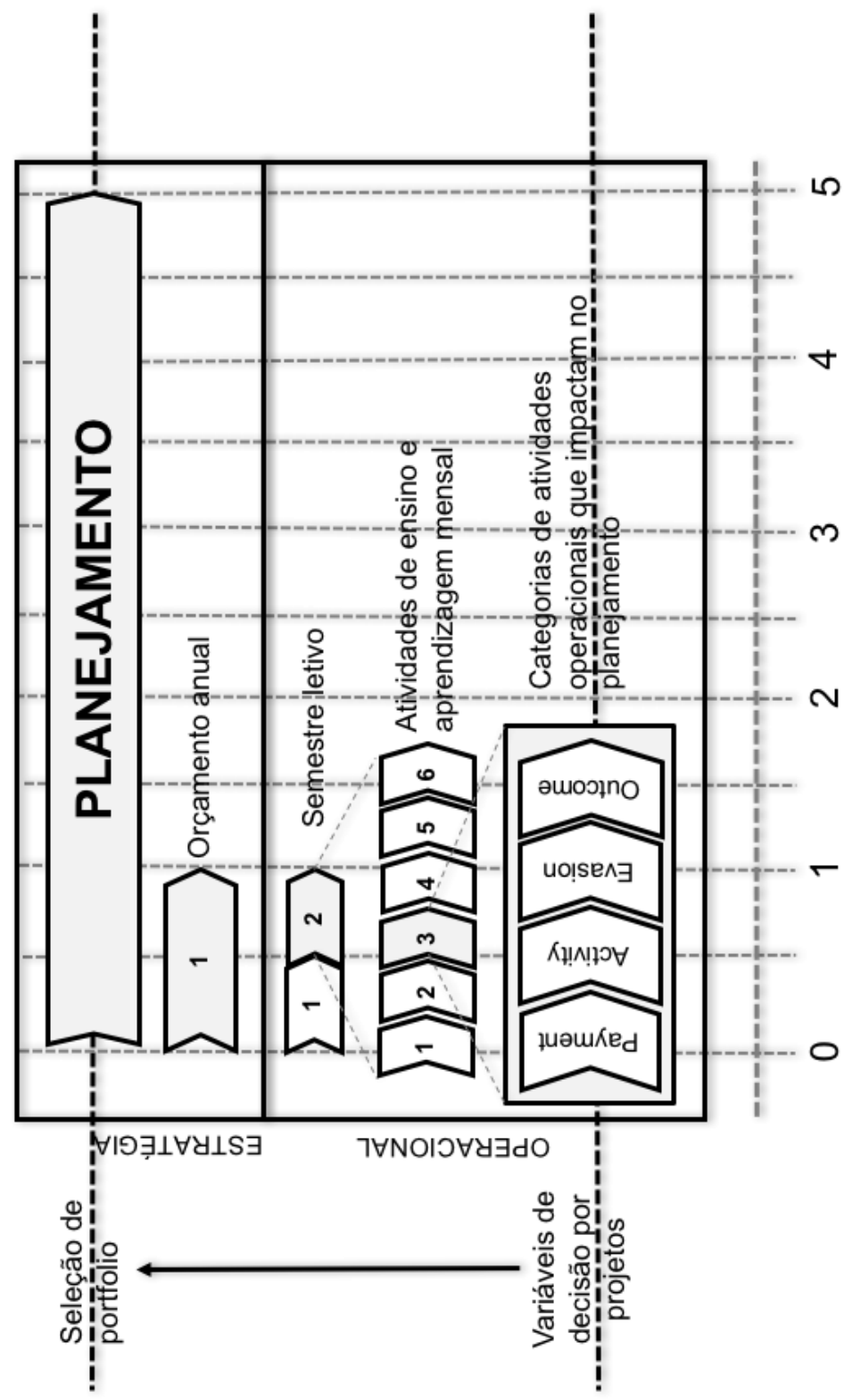

Figura A.3.25: Desdobramento do planejamento da IES. 


\section{A.5 - PONTO DE VERIFICAÇÃO DE RISCO DO MECANIMO DE PROGNÓSTICO DE RISCO.}

Seguem os registros dos resultados obtidos no processo de simulação de portfolios para a identificação do limiar de risco de insustentabilidade para decisão cooperada.
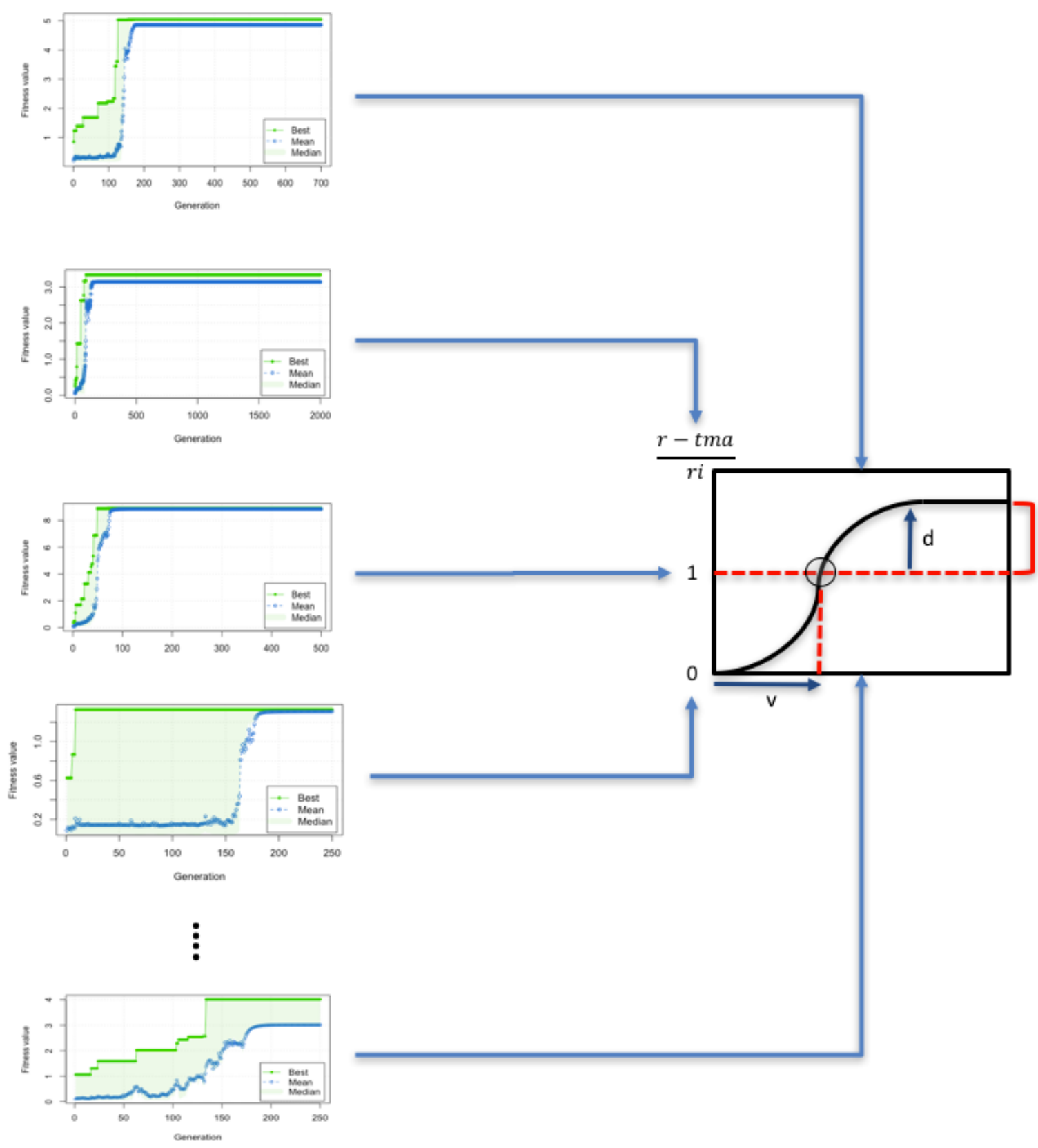

Figura A.4.26: Visão do ponto de minimização de risco de insustentabilidade. 


\section{A.6 - DESEMPENHO DO PLANEJAMENTO PARTICIPATIVO NOS ANOS 2007 A 2010}

Tratar-se de uma IES particular, conforme os índices do diagrama o processo de decisão participativo é sugerido ajustes no processo de projeção e execução. Isso é justificado pela

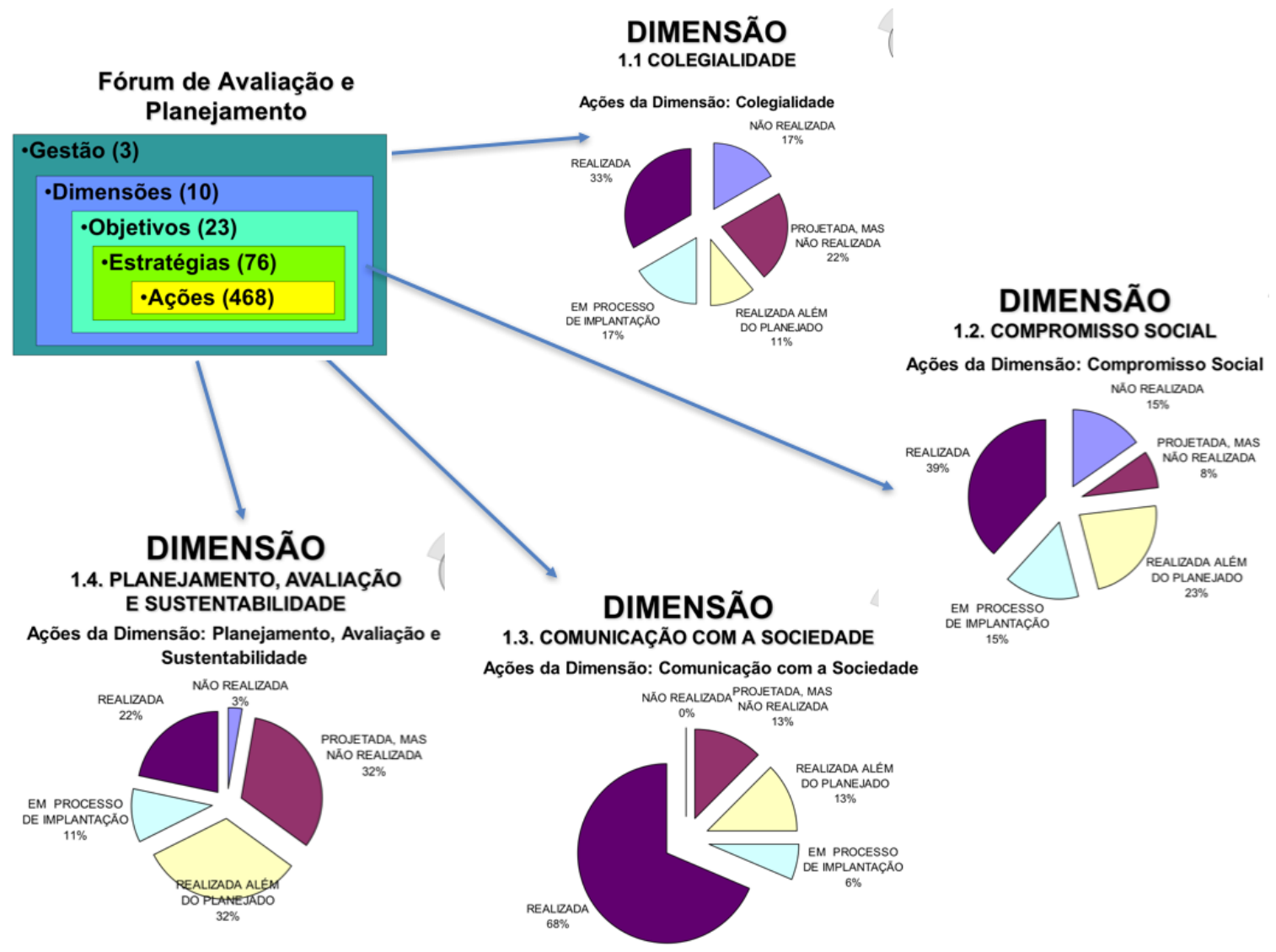

Figura A.5.27: Resultados de ações planejadas na IES. 


\section{A.7 - COMPARAÇÃO ILUSTRADA DA TMP E A PROPOSTA DO MECANISMO QUE CONGREGA A TMP E O AJUSTE POR VARIÁVEIS DE DECISÃO DOS PROJETOS.}

A TMP propõe ajustes nas participações dos ativos financeiros nos portfolios, espera-se assim buscar a melhor composição de ativos para obter melhor eficiência. O mecanismo proposto possibilita realizar ajustes nos desempenhos dos projetos, no lugar dos ativos financeiros, que compõe os portfolios. Assim, ao encontrar o melhor desempenho é possível verificar se o nível de risco da eficiência do portfolio, de forma a buscar novo desempenho de eficiência de portfolio, por meio de reajustes nos projetos. No entanto, ao possibilitar esse procedimento de reajuste é também encontrado um problema adaptativo que obstaculiza a caminhada em direção ao ganho de eficiência. O problema adaptativo gera conflitos de interesses na participação dos projetos no portfolio, isso exigiu a integração do algoritmo genético como estrutura de apoio aos ajustes dos projetos.

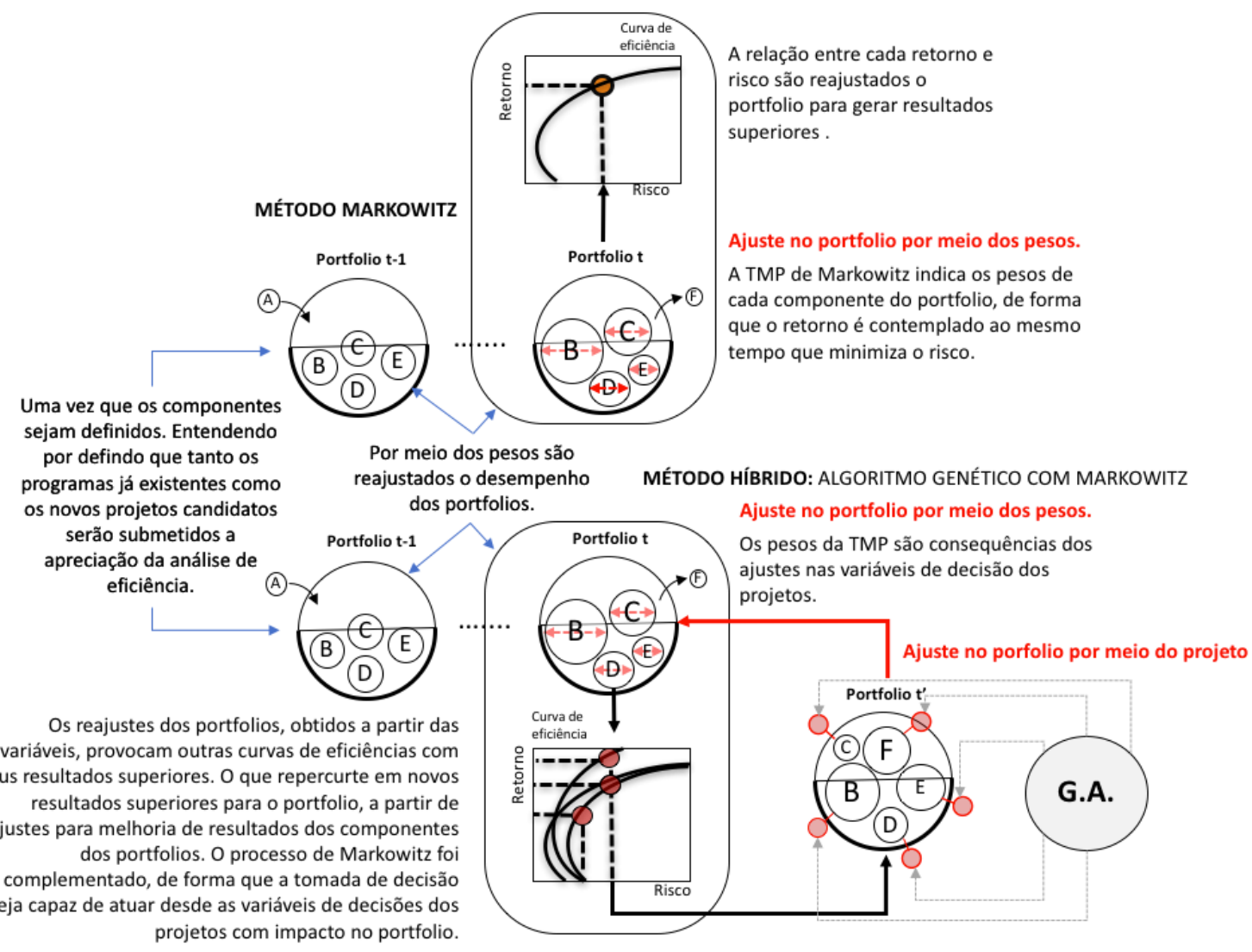

Figura A.6.28: Diagrama da TMP tradicional e com o G.A.. 
